\title{
Perspective
}

PERSPECTIVE Actualité en histoire de l'art

\section{2| 2010}

\section{Antiquité/Moyen Âge}

\section{La décoration monumentale à Rome aux XI ${ }^{\mathrm{e}}$ et $\mathrm{XII}^{\mathrm{e}}$ siècles : révisions chronologiques, stylistiques et thématiques}

Architectural décor in Rome in the eleventh and twelth centuries: a revision of chronology, styles and themes

Der Monumentaldekor in Rom im 11. und 12. Jahrhundert: chronologische, stilistische und thematische Wiederaufarbeitung

La decorazione monumentale a Roma nei secoli XI-XII: revisioni cronologiche, stilistiche e tematiche

La decoración monumental en Roma en los siglos XI y XII: revisiones cronológicas, estilísticas y temáticas

\section{Stefano Riccioni}

\section{OpenEdition}

Journals

\section{Édition électronique}

URL : http://journals.openedition.org/perspective/1145

DOI : 10.4000/perspective. 1145

ISSN : 2269-7721

Éditeur

Institut national d'histoire de l'art

Édition imprimée

Date de publication : 31 décembre 2010

Pagination : 319-360

ISSN : 1777-7852

\section{Référence électronique}

Stefano Riccioni, «La décoration monumentale à Rome aux xle et x\| ${ }^{e}$ siècles : révisions

chronologiques, stylistiques et thématiques », Perspective [En ligne], 2 | 2010, mis en ligne le 13 août 2013, consulté le 01 octobre 2020. URL : http://journals.openedition.org/perspective/1145 ; DOI : https://doi.org/10.4000/perspective.1145 


\section{La décoration monumentale à Rome aux XI ${ }^{\mathrm{e}}$ et XII ${ }^{\mathrm{e}}$ siècles : révisions chronologiques, stylistiques et thématiques}

\section{Stefano Riccioni}

La décoration monumentale de la Rome médiévale a fait l'objet d'un regain d'attention notable de la part de la critique après la publication, il y a quatre ans, des deux premiers volumes de La pittura medievale a Roma, 312-1431: Corpus e Atlante (ANDALORO, ROMANO, 2006). Ces ouvrages marquent un point d'orgue dans un développement important de la recherche depuis les vingt dernières années. L'art de la première période de la réforme, qu'on peut considérer idéalement conclue avec le pontificat d'Innocent II (1130-1143), s'enracine profondément dans son contexte, et par conséquent dans l'histoire de Rome et de l'Église, inévitablement liée à ce qu'il est convenu d'appeler la " réforme grégorienne " ${ }^{1}$, qui joua un rôle de premier plan dans l'histoire de l'Europe entre le $\mathrm{XI}^{\mathrm{e}}$ et le $\mathrm{XII}^{\mathrm{e}}$ siècle. Cette époque de transformations dépasse, en amont et en aval, le pontificat de Grégoire VII (1073-1085), qui lui donna pourtant son nom, et on peut l'étendre jusqu'au début du XIII ${ }^{\mathrm{e}}$ siècle, date à laquelle le pontificat d'Innocent III scella l'accomplissement du renouvellement des institutions ecclésiastiques et de l'autonomie politique que l'Église s'était donnés pour objectif.

Trois thèmes, étroitement liés à l'historiographie, l'expansion urbaine, la liturgie stationale et l'alphabétisation, ont en outre été mis en relation avec les arts. Le premier se rattache au fait que malgré les luttes souvent sanguinaires qui ne cessèrent d'opposer le pape, $\mathrm{l}^{\prime}$ Empire et l'aristocratie citadine, entre les $\mathrm{XI}^{\mathrm{e}}$ et $\mathrm{XII}^{\mathrm{e}}$ siècles, Rome connut une expansion urbaine consistante et fut en grande partie reconstruite et " embellie ", un développement démographique et urbain qui contribua de manière sensible à la proclamation de la république

Stefano Riccioni est chercheur en histoire de I'art médiéval à la Scuola Normale Superiore de Pise et chercheur associé à I'UMR 5594 ARTeHIS "Archéologie-Terre-Histoire-Sociétés » de I'Université de Dijon. II a été boursier de plusieurs institutions, parmi lesquelles l'École française de Rome, le Pontifical Institute of Mediaeval Studies de Toronto et la Getty Foundation de Los Angeles. II mène des recherches sur I'art roman et l'art gothique, ainsi que sur l'épigraphie médiévale, dont il a publié les résultats dans des revues scientifiques et dans les actes de plusieurs congrès internationaux. Il est l'auteur de la monographie II mosaico absidale di S. Clemente a Roma : exemplum della Chiesa riformata, Spolète, 2006. 
romaine (HUBERT, 1990, 2001). Le deuxième élément est lié à la réforme de la liturgie. Comme l'avait suggéré Roger Reynolds lors d'un colloque organisé à la Fordham University en 1998, mais encore inédit (PALAZzo, $2006 ; 2007$, p. 20, note 16), les nombreux recueils de droit canon réalisés à Rome dans la seconde moitié du XI siècle, et en particulier ceux de Deusdedit et d'Anselme de Lucques, contiennent une nouvelle vision de la liturgie définie par la réforme grégorienne (REYNOLDS, sous presse). En particulier, l'usage que l'on faisait à Rome des stations processionnelles et l'habitude, très enracinée, de célébrer certaines festivités religieuses dans des basiliques déterminées en fonction d'un calendrier précis, permettaient au pontife d'affirmer sa présence dans l'habitat urbain et de transférer dans diverses églises la liturgie ailleurs réservée à la seule cathédrale (voir notamment DE BLAUUW, 1994, 2002 ; PARLATO, 2000, 2002 ; Di CARPEGNA FALCONIERI, 2002, p. 235-241, 250-256). Le troisième élément fut la reprise de l'alphabétisation et l'utilisation de l'écriture à des fins de propagande, un phénomène très intéressant, mais encore trop peu étudié pour les $\mathrm{XI}^{\mathrm{e}}$ et XII ${ }^{\mathrm{e}}$ siècles, et qui concerne aussi les arts (PETRUCCI, 1986 ; SUPINO MARTINI, 200la-b), surtout pour le rapport entre épigraphie, histoire et image (KOCH, 1990, 1995 ; FAVREAU, 1997, 1999a-b ; RICCIONI, 2000, 2002, 2007b ; PETRUCCI, 2002 ; GIOVÈ MARCHIOLI, 2006).

Sans prétendre à l'exhaustivité, c'est avec les principales lignes de ce contexte en tête qu'il faut comprendre la décoration monumentale de la Rome des $\mathrm{XI}^{\mathrm{e}}$ et $\mathrm{XII}^{\mathrm{e}}$ siècles. Nous proposons ici un ample panorama des publications sur le sujet.

\section{Les thèmes}

Entre les $\mathrm{XI}^{\mathrm{e}}$ et $\mathrm{XII}^{\mathrm{e}}$ siècles, Rome connut une expansion urbaine notoire et fut en grande partie reconstruite et " embellie " (HUBERT, 1990, 2001). Cette phase de restructuration architectonique intense de la ville, fut suivie, à l'intérieur des édifices ecclésiastiques, par la réalisation de nouveaux aménagements liturgiques et d'appareils décoratifs monumentaux. L'Église de Rome confia aux cycles de peintures et de mosaïques la célébration de sa politique de renouvellement. Plusieurs de ces cycles nous sont hélas parvenus à l'état de fragments ; certains ont été très repeints et d'autres irrémédiablement perdus ; mais on peut identifier, sur certains d'entre eux, les traits communs qui en font les indicateurs d'une renaissance des arts obéissant au point de vue de la réforme ecclésiastique. Parallèlement à cette " renaissance " des arts figuratifs, d'autres secteurs artistiques connurent une augmentation considérable de leur production. En liaison avec la décoration des églises, la réforme aboutit aussi à une nouvelle organisation du texte de la Bible, transcrit sur de luxueux manuscrits de grand format, qu'il est convenu d'appeler « Bibles atlantiques ». La reconstruction des édifices ecclésiastiques (mais aussi laïques) impliqua en outre la réalisation d'ornements liturgiques, pour lesquels on fit appel à des ateliers de marmorarii qui atteignirent un degré de spécialisation et de qualité artistique de plus en plus élevé2 ${ }^{2}$

Les études de ces dix dernières années ont mis en évidence de nombreux thèmes : l'émergence d'une théorie de l'art susceptible d'être définie comme "grégorienne "; le rapport entre l'art monumental et les Bibles atlantiques ; les commanditaires ; l'écriture ; les relations entre l'art et la liturgie ; l'art réformé en dehors de Rome ; la dimension internationale de la réforme et de la production artistique qu'elle inspira. Au sein de ces catégories thématiques principales, les ouvres individuelles - cycles picturaux, tableaux sur bois et mosaïques - ont fait l'objet d'oscillations de datation, et par conséquent d'interprétation, parfois importantes. 
La première étape de ce parcours a été la publication du catalogue de l'exposition sur les Bibles atlantiques (Le Bibbie atlantiche..., 2000) et du volume Arte e iconografia a Roma, placé sous la direction de Maria Andaloro et de Serena Romano (ANDALORO, Romano, [2000] 2002a). L'année 2001 vit la publication en italien des études d'Hélène Toubert, éditées par Lucinia Speciale (TOUBERT, SPECIALE, 2001), tandis qu'en 2002, Robert Suckale publiait son étude sur le panneau du Vatican (SUCKALE, 2002). Les travaux de Romano ont particulièrement marqué la décennie et la bibliographie sur le sujet, à commencer par la réédition de Roma e il Lazio. Il romanico (PARLATO, ROMANO, [1992] 2001); ils se poursuivirent avec la journée d'étude organisée à Lausanne en 2004 (ROMANO, ENCKELL JULLIARD, 2007) et la publication, dans le cadre de l'imposant projet codirigé avec Andolaro (ANDALORO, ROMANO, 2006), du quatrième volume, intitulé Riforma e tradizione: 1050-1198 (ROMANO, 2006a). La même année, paraissaient également le volume consacré à la mosaïque de l'église San Clemente de Rome (RICCIONI, 2006) et l'étude de Simone Piazza sur les peintures rupestres du sud du Latium et de la Sabine (PIAZZA, 2006). En 2008, Julie Enckell Julliard publiait sa thèse de doctorat sur les peintures de l'abbaye de Farfa (ENCKell JulLIARD, 2008) et un congrès sur la Croix de Rosano (Frosinini, MonCIATTI, WOLF, sous presse) reprenait la publication relative à la restauration de l'œuvre (CIATTI, FROSININI, BELLUCCI, 2007) tout en élargissant la thématique à l'impact de la réforme audelà des murs de Rome. Enfin, le colloque organisé à Genève sur les Bibles atlantiques, en février 1010, a permis d'explorer par d'autres biais la diffusion de cette même réforme par-delà les frontières de la Péninsule (TOGNI, sous presse).

Les thèmes abordés par la critique ces dix dernières années sont donc nombreux et ils appréhendent inévitablement l'évaluation des œuvres et leur chronologie ; mais celui du rapport avec l'Antique, sa valeur idéologique et politique, dans le cadre de la réforme grégorienne et des relations avec l'abbaye du mont Cassin, a continué de déterminer le débat critique de ces dernières années et la lecture de l'art médiéval romain des « origines ».

\section{L'Antique et le mont Cassin}

Dès les premières recherches sur l'art romain des XI et XII siècles, la relation entre le mont Cassin et Rome a suscité beaucoup d'intérêt : bien connue dans ses aspects historiques et politiques, elle s'est révélée problématique en ce qui concerne les contacts artistiques. L'hypothèse formulée par Émile Bertaux (BERTAUX, 1904) 3) qui retraçait la diffusion, à partir du mont Cassin, d'un art bénédictin, fit l'objet de sévères critiques de la part de Geza de Francovich (FrANCOVICH, 1955), lequel sembla clore la question en dénonçant les équivoques du concept d'art bénédictin entendu comme élément moteur de tous les faits picturaux survenus à Rome, et plus largement en Italie du centre et du sud, entre le $\mathrm{XI}^{\mathrm{e}}$ et le XII ${ }^{\mathrm{e}}$ siècle.

Cette ligne d'interprétation a cependant retrouvé une certaine actualité, à une époque relativement récente, grâce à une série de contributions ayant pour objet un autre thème lié à l'art de Rome et du mont Cassin : la récupération, dans une perspective de propagande politique, de formes liées à l'Antique. La référence à un répertoire d'images appartenant à l'antiquité paléochrétienne, et plus généralement romaine, est apparue évidente et constante dans de nombreuses peintures présentes à Rome et dans ses environs. Celles de Santa Pudenziana, de la basilique inférieure de San Clemente, de San Benedetto in Piscinula et de San Gregorio Nazianzeno, à Rome même, ainsi que celles, hors de la ville, de Castel Sant'Elia, de Santa Maria Immacolata de Ceri et de San Pietro, à Tuscania, 
pour ne mentionner que les principales, montrent des caractères communs. Il demeurait toutefois très compliqué - et il l'est, encore de nos jours - assez difficile, d'évaluer la présence des courants stylistiques qui sous-tendirent ce programme. Le corpus de Joseph Wilpert (WILPERT, 1916), l'essai de Gerhard Ladner (LADNER, 1931) et les études d'Edward Garrison (GARRISON, 1953-1962) ont ouvert la voie à la compréhension de cette culture figurative et abouti à la première tentative d'offrir un panorama d'ensemble de la peinture romaine, due à Guglielmo Matthiae (MATthiAe, 1965-1966), pour qui le thème de l'Antique restait un élément très indéterminé, considéré comme une des composantes ayant contribué à former la physionomie particulière de l'école locale.

Dans les années 1970, les études de Toubert ont précisé l'importance historique au rapport avec l'Antique présent dans la peinture romaine, entre le $\mathrm{XI}^{\mathrm{e}}$ et le $\mathrm{XII}^{\mathrm{e}}$ siècle. Outre l'élaboration d'une définition du renouveau paléochrétien destinée à se révéler indispensable à propos de certaines créations fondamentales de la peinture romaine du début du XII ${ }^{\mathrm{e}}$ siècle, telle la mosaïque absidale de l'église San Clemente, la chercheuse proposa de voir dans le retour programmatique à l'antiquité, que ces monuments trahissent, les effets d'un choix culturel précis (TOUBERT, 1970). Il ne se serait pas agi d'un classicisme vague, d'une opération archéologique empreinte d'exigences esthétiques, mais d'une volonté délibérée de récupération de modalités formelles paléochrétiennes, visant intentionnellement à exprimer, dans les termes symboliques d'un " art dirigé », la valeur idéologique de ce retour aux origines, qui fut l'un des éléments fondamentaux du programme de la papauté réformatrice lors de la lutte pour les investitures. La position conceptuelle de Toubert fut d'emblée pleinement reprise à son compte par Ernst Kitzinger (KITZINGER, 1972a), qui pensa pouvoir identifier l'abbaye du mont Cassin, tel que renouvelé par l'abbé Didier, comme le foyer culturel à l'origine de cette programmation idéologique consciente des faits figuratifs qui, à une période ultérieure, devait influencer la papauté dans sa récupération du monde paléochrétien, y compris à Rome. Lorsqu'il définit le moment historique précis et le milieu spécifique où situer la naissance du phénomène du renouveau paléochrétien, Kitzinger vit dans les fragments survivants de la décoration en mosaïque de l'arc de triomphe de la cathédrale de Salerne - qu'avait fait reconstruire l'archevêque Alphan I ${ }^{\mathrm{er}}$, inspirateur de la décoration de l'abbaye du mont Cassin à l'époque de Didier - un témoignage concret des résultats que la volonté antiquisante des commanditaires, jointe aux compétences techniques des artisans byzantins appelés de Constantinople, avait atteints à l'abbaye du mont Cassin (KITZINGER, 1972b). En outre, quand il releva les liens formels et décoratifs existant entre ces fragments et la décoration analogue de l'arc de triomphe situé en l'église San Clemente, à Rome, il y trouva la confirmation du rôle d'exemple joué par le modèle campanien dans le contexte papal. Dans une conférence de 1975, organisée à Dumbarton Oaks par Kitzinger et publiée en 1976 (TOUBERT, 1976), Toubert précisa davantage sa ligne d'interprétation reconnaissant une influence du mont Cassin à Rome, et montra les liens iconographiques et stylistiques unissant les fresques romaines à la culture de l'époque de l'abbé Didier. Elle vit en Raniero di Bleda - abbé de l'église clunisienne de San Lorenzo fuori le mura jusqu'en 1078, avant de devenir cardinal de San Clemente, puis pape sous le nom de Pascal II - le personnage qui aurait favorisé ces liens en appelant à travailler aux fresques de San Clemente, et à celles du portique de San Lorenzo fuori le mura, le même groupe d'artisans, liés à la culture et aux nouveautés du mont Cassin, manifestant ainsi, outre un choix esthétique, un choix idéologique précis d'esprit réformateur et antiquisant. Les contributions ultérieures de la chercheuse, rassemblées dans un volume de miscellanées (TOUBERT, 1990), aboutirent à une définition du concept d' « art de la réforme grégorienne ». 
Ces contributions rouvrirent le débat critique sur l'apport du mont Cassin à Rome, que semblait avoir entièrement clos l'article de Francovich. Un symptôme précis de la renaissance de ce contentieux était perceptible dans l'intervention de Carlo Bertelli, qui revendiquait, en opposition justement aux thèses récurrentes sur l'influence du mont Cassin, la continuité, nette et autonome, de l' "école romaine " (BERTELLI, 1982, p. $288 ; 1983$, p. 117-129). Il en reconnaissait les origines entre la fin du $X^{e}$ et la première moitié du $\mathrm{XI}^{\mathrm{e}}$ siècle, dans les peintures de Santa Maria in Pallara, de Sant'Urbano alla Caffarella, et dans les figures de saintes de l'église souterraine de Santa Maria in via Lata, qu'il attribuait à la restauration de Léon IX ${ }^{4}$ (1049 et 1054). Par la suite, Bertelli proposa même d'avancer la datation des fresques de San Clemente autour de 1078, année où se tint en cette église un synode qui condamna le cardinal Ugo Candido (BERTELLI 1994, p. 229). Il percevait dans ces œuvres la trace d'un choix figuratif déjà en accord avec les exigences idéologiques, propres à la réforme, de retour aux origines (Bertelli, GALASSi PALUZZI, 1971, p. 60 ; Bertelli, 1982, p. 288), un choix opéré dans le milieu clunisien avant même de devenir un principe actif de la politique pontificale. Odon de Cluny fut en effet appelé à Rome par Albéric et le complexe monastique de Santa Maria all'Aventino constitua pour les réformateurs français, à partir du milieu du $X^{e}$ siècle, un lieu de référence précis au sein du contexte romain ${ }^{5}$. Car on y trouve l'autel reliquaire qui, restitué au Xe siècle (PERONI, RICCIONI, 2000 ; RICCIONI, 2002), une période légèrement postérieure à la donation d'Albéric, montre des signes évidents d'une orientation culturelle antiquisante reconductible au milieu clunisien. L'orientation critique de Bertelli, qui accordait une pleine autonomie à l'école romaine, lui attribuait, en première instance, la récupération de l'Antique qui caractérisera ensuite non seulement l'histoire de la reconstruction du mont Cassin voulue par Didier, puis celle de Salerne, mais aussi les facteurs d'archéologie décorative présents dans des œuvres comme les fresques de San Clemente, où Bertelli lui-même admit l'existence d'éléments stylistiques provenant du mont Cassin. En d'autres termes, si le style, au sens large, peut accueillir des motifs venus du mont Cassin, l'aspect antiquisant, qui au bout du compte est celui qui fixe l'intonation idéologique, est le propre d'une tradition romaine consciente d'elle-même.

Une évaluation des termes du retour à l'Antique fut aussi proposée par Francesco Gandolfo, qui donna une définition des attitudes de la papauté envers l'antiquité entre le $\mathrm{XI}^{\mathrm{e}}$ et le $\mathrm{XII}^{\mathrm{e}}$ siècle, et précisa que même les symboles de l'imperium romain trouvèrent place dans les objets d'art commandés par l'Église (GANDOLFO, 1981, p. 339-366; 1984, p. $5-29 ; 1989$, p. 21-32). La dimension artistique qui en ressortait se caractérisait par l'expression d'une symbologie du pouvoir d'orientation classicisante et impériale, dont le chercheur opposa les traits distinctifs aux aspects antiquisants mais, selon lui, purement décoratifs, du renouveau paléochrétien sur lequel se fondait la peinture de la période, dans sa tentative de saisir les diverses motivations et les voies indépendantes de ce parcours culturel. En 1988, Gandolfo publia l'édition mise à jour de l'œuvre de Matthiae, dont il respectait en substance l'orientation, y compris en ce qui concerne la structure rigoureuse de l'analyse stylistique et formelle. Tout en laissant ouverte la question du rapport avec le mont Cassin, le chercheur invitait à réfléchir sur l'idée de renovatio, en tant que constante de l'histoire de la Rome médiévale, mais suggérait d'éviter les interprétations univoques et soulignait la présence de courants qui, bien que contemporains, apparaissaient très diversifiés (MATTHIAE, GANDOLFO, 1988, p. 250). 
Preuve du succès et de l'actualité persistante des études de Toubert, même au cours de la dernière décennie, la traduction de ses textes en italien par Lucinia Speciale a été l'occasion de réaffirmer l'importance de ses recherches (TOUBERT, SPECIALE, 2001). Toutefois, le débat critique de ces dernières années a permis de préciser certains aspects de ses hypothèses, au moins en ce qui concerne, à en croire Romano, " le degré de conscience du contenu idéologique que peintres et commanditaires mettaient dans ces reprises" (ROMANO, 2002a, p. 107). Selon la chercheuse, en effet, les choix résultant du "goût " antiquisant ne relèvent pas seulement d'un choix programmatique et ne renvoient pas de manière univoque à des modèles paléochrétiens, mais semblent plutôt appartenir à une tradition qui marque de façon reconnaissable tout l'art médiéval romain ; Romano a réaffirmé cette thèse lors du congrès organisé à Cuxa en 2007 (RomANo, 2008a).

Pour des raisons différentes, nous avons aussi reconnu dans la reprise de motifs inspirés de l'antiquité, à l'exemple des motifs décoratifs de la mosaïque de San Clemente, un trait spécifique et caractéristique de la culture réformée, et ce, non pas en termes de renouveau paléochrétien, mais en termes de narration et de méditation (RICCIONI, 2006).

\section{La narration}

Également en partie lié au thème de l'Antique, le problème des sources iconographiques des cycles christologiques a été examiné en profondeur par Herbert Kessler, qui a focalisé son attention sur la narration de ces épisodes et sur son déploiement aux murs des églises. Comme l'a souligné Daniel Russo, "Kessler renouvela l'étude des rapports entre les arts et la réforme de l'Église en s'intéressant à la question du narratif en peinture, aux modes de composition et aux emplacements dans les églises, à l'intérieur d'un espace territorialisé autour de Rome et dans Rome même, entre le XI ${ }^{e}$ et le XIV siècle " (Russo et al., 2008 , p. 2). Kessler a en effet indiqué dans les peintures qui décoraient les anciennes basiliques Saint-Pierre et Saint-Paul-hors-les-murs la source iconographique paléochrétienne des cycles figuratifs à thème biblique largement répandus, aux XI ${ }^{e}$ et XII siècles, à Rome et dans le Latium (KESSLER, 1989a, 1989b) ; et il a suggéré, dans ce cas aussi, la valeur idéologique liée aux principes de la réforme et la valeur narrative des histoires peintes, comme on peut également le déduire d'un travail récent sur les fresques de l'église San Pietro in Valle, à Ferentillo (KeSSLER, 2003). En outre, ces cycles paléochrétiens influencèrent aussi la production des exemplaires les plus anciens des Bibles atlantiques (KESSLER, 1989a, p. 45-64; 1989b, p. 119-146), sans doute à travers la circulation de livres de modèles, mais cette dernière hypothèse reste à confirmer (OROFINO, 2008). Les recherches de Kessler sur la décoration des églises italiennes ont été, compte tenu de leur actualité, republiées par le Centro italiano di Studi sull'alto medioevo de Spolète (KESSLER, 2002a). Serena Romano, de son côté, a précisé les rapports avec les prototypes dans les peintures perdues de Saint-Paul-hors-les-murs; les copies réalisées au cours le $\mathrm{XVII}^{\mathrm{e}}$ siècle ne peuvent pas être retenues comme sources fiables, notamment en raison des restaurations de 1200 (ROMANO, 2002b). Ces dernières années, Kessler s'est à nouveau occupé de l'église Saint-Paul-hors-les-murs, précisant certains aspects de la narration picturale du $\mathrm{V}^{\mathrm{e}}$ siècle et le rôle de Pietro Cavallini dans la nouvelle décoration de l'église (KeSSLER, 2004); il a en outre publié, dans le volume placé sous la direction de Paolo Piva, L'arte medievale nel contesto (PIVA, 2006), un essai ambitieux sur la peinture narrative entre le $\mathrm{IV}^{\mathrm{e}}$ et le $\mathrm{XII}^{\mathrm{e}}$ siècle, où sont analysées les auvres romaines et les découvertes récentes, telle l'église de l'Immacolata, à Ceri (KeSSLER, 2006a). 


\section{Les Bibles atlantiques}

L'iconographie liant un groupe de cycles picturaux aux Bibles atlantiques reste un thème très débattu (fig. 1). Le premier à comprendre l'importance du phénomène fut Pietro Toesca (TOESCA, 1929). Par la suite, Garrison reconnut dans les illustrations d'un groupe d'environ quatre-vingt Bibles atlantiques, qu'il définit "umbro-roman", de strictes identités iconographiques avec les cycles picturaux à thème biblique de l'oratoire Saint Thomas Beckett d'Anagni, de San Giovanni a porta Latina, et de San Pietro a Ferentillo, ainsi que des affinités avec les caractéristiques stylistiques de certaines peintures, par exemple celles de Castel Sant'Elia (GARRISON, 1953-1962, I, p. 18-32, 37-68, 83-114, 159-176 ; II, p. 47-69, 97-112, 151-158, 217-227 ; III, p. 33-81, 119-169, 281-300 ; IV, p. 277-375). La découverte, en l'église de l'Immacolata de Ceri, d'un cycle représentant des épisodes de l'Ancien Testament, a offert une possibilité supplémentaire d'enquête sur ce sujet.

L'instrument privilégié des réforma-

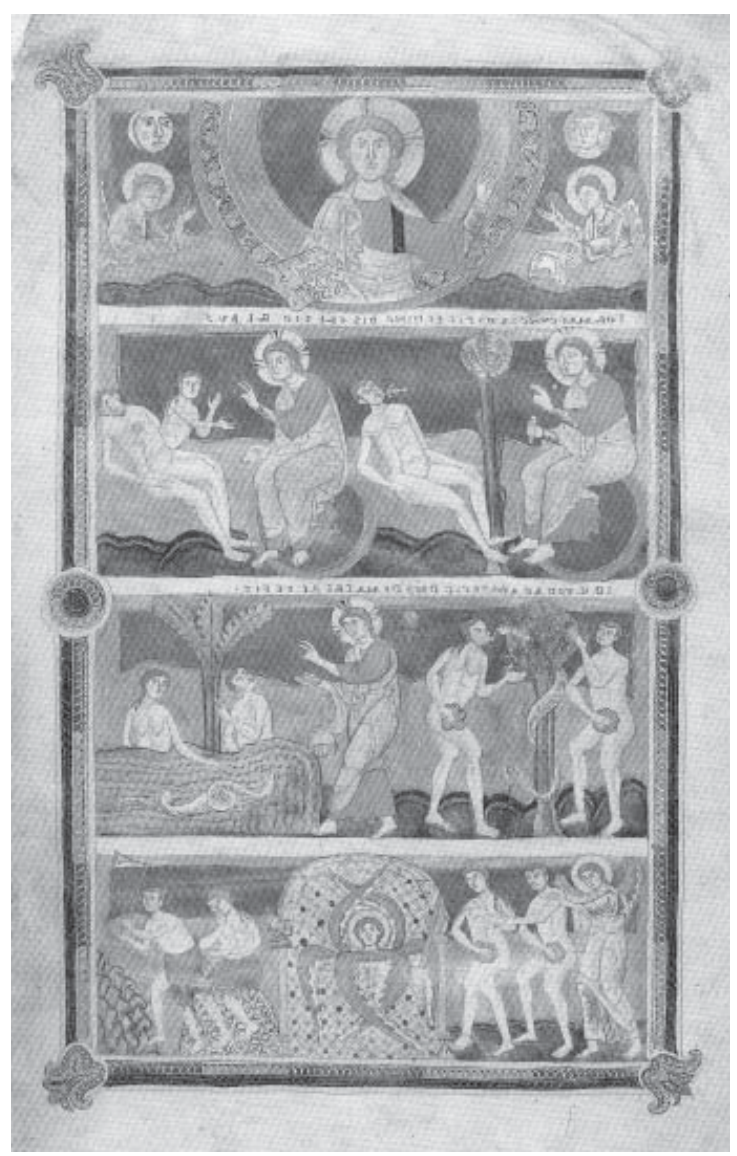

1. Bible du Panthéon, début du XI ${ }^{\mathrm{e}}$ siècle, Cité du Vatican, Biblioteca Apostolica Vaticana, Vat. lat. 12958, f. $4 \mathrm{v}$.

teurs était le livre, et le livre par excellence, la Bible, fit l'objet d'une nouvelle édition dite " atlantique " en raison de son grand format ou, comme on l'a aussi suggéré, " grégorienne " (BARTOLI LANGELI, 1994, p. 954). Le projet de production des Bibles atlantiques vit l'Église $\mathrm{s}^{\prime}$ engager dans la correction du texte ${ }^{6}$, sans doute avec l'aide de Pierre Damien (QUENTIN, 1922, p. 360 et suiv.), et dans sa diffusion, confiée à un modèle de livre dont les caractéristiques graphiques, le format, les schémas décoratifs et les modèles iconographiques étaient rigoureusement codifiés. En particulier, la principale caractéristique des Bibles atlantiques fut la reprise du modèle de l'écriture caroline qui, pour reprendre les termes de Paola Supino Martini, avais la valeur d' " un étendard symbolique de l'Église de Rome dans sa bataille doctrinale et disciplinaire pour le renouvellement et l'unité " (SUPINO MARTINI, 1988, p. 118). L'altérité de l'écriture de ces Bibles par rapport à celle utilisée dans la région de Rome, la "romaine ", une minuscule bien caractérisée, constituait justement une sorte d'épreuve paléographique. L'hypothèse suggérée par la chercheuse, et consistant à voir dans le scriptorium du Latran le lieu de production de ces Bibles ${ }^{7}, n^{\prime}$ a certes reçu le soutien d'aucune preuve documentaire, mais elle a offert une référence réaliste et suggestive, utile pour comprendre la fonction et l'importance de ces codex produits conformément à un modèle qui fut pour le moins " approuvé et diffusé par Rome " ${ }^{8}$ (SUPINO MARTINI, 1988, p. 106-107). Toutefois, plus récemment, Gorman a suggéré que les premières Bibles atlantiques auraient été réalisées à l'abbaye du mont Amiata, non seulement à cause de l'existence du Codex Amiatino, mais aussi de la spécialisation de ce scriptorium dans la production de manuscrits de grand format (GORMAN, 2002, p. 243-278 ; MAGIONAMI, 2006, p. 13-14 ; YAWN, sous presse, p. 171). 


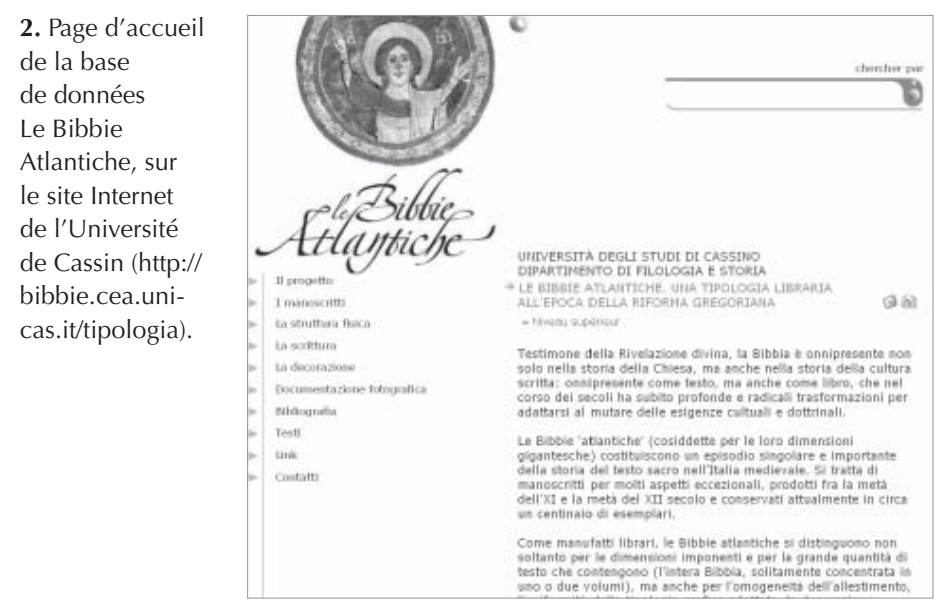
comme le montre l'exemple précoce de celle donnée au chapitre de la cathédrale de Genève par Frédéric, qui en fut l'évêque de 1031 à $1073^{9}$ (TOGNI, 2003).

Pour ce qui concerne les projets en cours, l'Université de Cassin a consacré à l'étude des Bibles atlantiques, à partir de l'exposition de 2000 (Le Bibbie Atlantiche..., 2000), un projet spécifique de recherche (fig. 2) ; le catalogue a permis d'en présenter environ soixante exemplaires parmi les plus significatifs ${ }^{10}$. Les premiers résultats de cette recherche ont été présentés par Giulia Orofino à l'occasion de deux congrès respectivement organisés à Parme (OROFINO, 2003) et à Urbin (OROFINO, 2001-2002) et, plus récemment, dans le volume de miscellanées Les fonts de la pintura romànica, sous la direction de Milagros Guardia et Carles Mancho (OROFINO, 2008).

La collaboration entre l'Université de Cassin (Marilena Maniaci et Giulia Orofino) et celle de Genève (Michel Grandjean et Maurizio Perugi) a abouti à l'élaboration d'un projet de recherche sur les Bibles atlantiques conservées en Suisse. Le volume, placé sous la direction de Nadia Togni, a pour objet l'étude de la Bible de Genève et de celle de Sion (TOGNI, 2003). Cette collaboration s'est en outre poursuivie sous la forme d'un congrès organisé à la bibliothèque de Genève, en février 2010, dont la publication, dirigée par Nadia Togni, est prévue en 2011 (TOGNI, sous presse). Dans le cadre du colloque, Maria Alessandra Bilotta a proposé de mettre en relation les Bibles atlantiques avec les peintures fragmentaires conservées sur les murs des souterrains du Sancta Sanctorum, récemment datées de la deuxième ou de la troisième décennie du XII siècle (CROISIER, 2006a), en suggérant que le Latran aurait pu favoriser les liens et la transmission de modèles iconographiques entre la peinture murale et la décoration des manuscrits (BILOTTA, sous presse).

Enfin, on signale le chapitre de Lila Yawn sur les Bibles atlantiques, non encore publié, pour The Practice of the Bible in the Western Middle Ages, un ouvrage placé sous la direction de Susan Boynton et Diane Reilly et destiné aux étudiants universitaires (YAWN, sous presse).

\section{Écriture et image}

Un autre thème apparu ces dernières années est celui qui concerne l'interaction entre l'image et la parole écrite - gravée sur les ouvres sculptées et sur les édifices publics, peinte sur les cycles picturaux ou exécutée en mosaïque - conçue comme instrument de communication et de propagande de l'Église. Au Moyen Âge, les images sont des transpositions visuelles, souvent soigneusement choisies, des textes, tandis que la parole écrite et exposée sur les monuments (même si elle n'est pas lue), renvoie à l'auctoritas et peut devenir le véhicule de l'invisible (sur ces thèmes, voir NIE, MORRISON, MOSTERT, 2005), bien qu'il ne soit pas avéré que les images aient pu être « lues " plus aisément que les mots (GOMBRICH, 1969, 1982 ; DUGGAN, 1989). 
Concernant le domaine des études dont nous nous occupons ici, les travaux de Kessler ont permis de mieux comprendre la valeur de la parole " exposée " en tant que "mémoire " et image mentale. Dans l'art médiéval, l'association de mots et d'images engendre, selon Kessler, une sorte de "vision spirituelle " semblable à la prédication qui, s'adressant aussi bien aux lettrés qu'aux analphabètes, unifie le public (KESSLER, 1985, 2000). La parole écrite fonctionne donc de manière iconique, renforçant le récit en images à travers l'identification et la caractérisation des figures, à destination d'un public connaissant déjà les histoires grâce à la tradition orale (KESSLER, 1989c). Partant de l'examen du rapport entre écriture exposée et image, entre épigraphie et iconographie, et s'appuyant, entre autres, sur les recherches d'Augusto Campana (CAmPana, 1967, 1976, 1984), d'Armando Petrucci (PetrucCI, 1986) et de Robert Favreau (FAVREAU, 1989, 1996), nous avons pu identifier dans les œuvres des XI et XII ${ }^{e}$ siècles une stratégie de communication précise, qui met en évidence la parole écrite, et sa " mise en page " dans les représentations, en tant que guide à la lecture, avertissement adressé au public et contrôle des images effectué de manière programmatique par le concepteur des décorations monumentales, pour surveiller la transmission correcte des idéaux de la renovatio Ecclesix. Les exigences propagandistes de l'Église réformée se fondaient en effet sur la transformation en spectacle des événements liturgiques, sur la maîtrise de l'interprétation exacte du message doctrinal et sur la séparation qui en résulte entre idiotae et letterati. Ces recherches, présentées à l'occasion des congrès de l'Associazione Italiana degli Storici dell'Arte Medievale (AISAME) en 2004 (RICCIONI, 2007a) et de Lausanne, en 2005 (RICCIONI, 2007b), ont abouti à la monographie sur la mosaïque de San Clemente (RICCIONI, 2006) et aux transcriptions des inscriptions présentes sur les cycles picturaux et les mosaïques, publiées dans le Corpus. Il s'agit d'un travail qui, pour la première fois dans le cadre d'un répertoire relevant clairement de l'histoire de l'art, a examiné et mis en évidence les inscriptions en tant que partie intégrante de l'appareil figuratif. Sur la base de telles prémisses, une approche méthodologique baptisée " épiconographie " a été proposée et présentée lors du congrès de l'AISAME organisé à Parme en 2007 (RICCIONI, 2008). L'application de cette méthode aux cycles picturaux de la Rome réformée, aux mosaïques de San Clemente et de Santa Maria in Trastevere, a permis de révéler leur structure rhétorique, constituée à partir du lien étroit entre texte et image, qui se reflète aussi dans une iconographie fonctionnant par le biais de la sélection des parcours d'interprétation de l'œuvre (RICCIONI, sous presse a-b). Kessler, de son côté, a accueilli cette proposition dans son ouvrage Neither God nor Men (KESSLER, 2007b), qui se concentre sur l'étude de l'inscription peinte au pied de la scène du Buisson-ardent de l'Immacolata de Ceri et reconductible à la production de Baldéric de Bourgueil ${ }^{11}$. Il s'agit d'un travail qui reprend et développe une intuition qu'aussi bien Kessler (KeSSLER, 2002b) que Nino Zchomelidse (ZCHOMELIDSE, 2003) avaient déjà exposée auparavant. Russo a lui aussi reconnu l'importance de la prise en considération de l'organisation des inscriptions au sein de l'espace figuratif, car elles fonctionnent d'une manière très particulière durant la réforme, en tant qu'instrument didactique d'une grande efficacité (RUSSO, 2007, p. 65). Enfin, Speciale - déjà auteur d'une étude sur l'exultet vat. Barb. lat. 592 où elle avait mis en évidence l'importance de l'analyse de l'interaction entre le texte et l'image dans les rapports unissant l'exultet, l'abbaye du mont Cassin de l'époque de Didier et la réforme (SPECIALE, 1991) - a accepté la validité de la nouvelle méthode en s'occupant à nouveau d'écritures et d'images et en abordant les tituli d'Alfan à l'abbaye du mont Cassin, à Salerne et à Sant'Angelo in formis, ainsi que la production des rouleaux d'exultet, lieu par excellence d'expression de la parole lue, récitée et regardée, par le biais des scènes enluminées exposées au public (SPECIALE, 2009a-b). 


\section{Théorie de l'art " réformé "}

L'étude des textes liés à la production artistique de la réforme a aussi mis en évidence un autre aspect de l'art des $\mathrm{XI}^{\mathrm{e}}$ et $\mathrm{XII}^{\mathrm{e}}$ siècles, à savoir sa relation étroite avec les œuvres de Pierre Damien et de Bruno de Segni, remarquée aussi bien par Kessler que par Zchomelidse dans les études citées plus haut. Kessler a ensuite continué dans cette voie lorsqu'il a abordé le thème des peintures de Ceri, et sondé les sources littéraires et doctrinales sous-jacentes aux cycles de peintures et de mosaïques de l'art de la réforme, et qu'il en est venu à formuler l'hypothèse de l'existence d'une théorie de l'art (KesSLER, 2005) dans le cadre d'un mouvement de grande ampleur tirant son origine des écrits de Grégoire le Grand (KESSLER, 2006b). Chez ces auteurs, protagonistes de la réforme et, en un certain sens, inspirateurs de l'idéologie du mouvement, l'image devient l'occasion d'un parcours de méditation conduisant à l'ascèse, d'un cheminement anagogique de prise de distance progressive envers la corporéité (KESSLER, 2007a). Il s'agit là d'un thème abordé également, selon divers points de vue, à l'égard du programme iconographique des mosaïques de San Clemente, un parcours visuel inspiré des textes de Pierre Damien et de Bruno de Segni, organisé sur la base des principes de la mnémotechnie dérivés de l'enseignement de la rhétorique tel qu'on le pratiquait dans les monastères, et adapté à la méditation des chanoines réformés (RICCIONI, 2006). La personnalité de Bruno de Segni et son rapport avec l'Église réformée ont en particulier, ces dix dernières années, fait l'objet d'une attention croissante (CIPOLLINI, 2001). Bruno d'Asti, nommé évêque de Segni par Grégoire VII, fut proche des principes de la réforme dès ses premiers écrits (GRÉGOIRE, 1965 ; HOFFMANN, 1972 ; NAVARRA, 1980). Il participa au violent débat contre Bérenger de Tours et sa doctrine eucharistique (CAPITANI, 1959-1961, p. 127-130), fut chancelier et bibliothécaire de l'Église sous Victor III et électeur d'Urbain II. Il participa aux côtés de ce dernier au concile de Clermont, où fut décidée la première croisade en Terre sainte. En 1105, il se retira au monastère du mont Cassin, dont il fut élu abbé en 1107. Après la polémique avec Pascal II et l'abandon de sa charge d'abbé, il se retira à Segni, où il mourut en 1123. Ses nombreuses œuvres furent largement diffusées au Moyen Âge, surtout dans les milieux ecclésiastiques; elles traitaient avec une extrême rigueur les thèmes les plus chers à la réforme : mours du clergé, interprétations de la Bible et symbologie des mystères de la liturgie.

En accord parfait avec les principes de la réforme grégorienne, dont il fut l'un des plus grands théoriciens, Bruno définit, dans son De Sacramentis ecclesix et ses Sententix, une correspondance attentive et détaillée entre architecture, décorations liturgiques, éléments ornementaux et univers symbolique de la Bible, obtenue en recourant aux figures de rhétorique ${ }^{12}$. Le sermon de dédicace de l'église de Pierre Damien et le De Sacramentis ecclesix de Bruno de Segni ont été abordés par Louis Hamilton (HAmiLton, 2005) dans une perspective historique qui reste cependant attentive aux manifestations figuratives, et plus généralement visuelles, en raison des liens étroits qu'elles entretiennent avec les pratiques théâtralisées de la liturgie réformée. Hamilton a récemment développé et approfondi ses études sur Bruno de Segni et le De Sacramentis ecclesix (HAMilton, 2010), et offert une vision plus claire des écrits du réformateur et de leur impact sur les milieux ecclésiastiques.

La présence d'une théorie de l'art à l'époque de la réforme ecclésiastique du XI siècle et l'analyse fouillée des écrits de Bruno de Segni, qui attendent encore une édition complète et mise à jour, sont donc autant de voies ouvertes aux futures recherches. 


\section{Les commanditaires}

Un autre thème qui, ces dernières années, a suscité l'intérêt de la critique, est celui de l'étude des milieux et des personnalités individuelles responsables ou bailleurs de fonds des décorations réalisées. Gandolfo a étudié les images des commanditaires romains, identifié leurs principaux schémas de représentation et distingué les portraits de commande (où un personnage aux mains voilées tient le modèle architectural réduit de l'église) des portraits de dévotion (où les personnages offrent des dons tels que de la cire à l'état brut ou des chandelles). Il en est ressorti, dans les représentations figurées des mosaïques et des peintures romaines, un parcours de la figure du commanditaire remontant aux modèles de l'antiquité tardive, telle l'image de l'évêque Ecclésius en la basilique San Vitale de Ravenne, et lié à des motivations politiques (GANDOLFO, 2002, 2004). Elisa Tagliaferri a traité de ce phénomène à travers ses apparitions dans des cycles picturaux de la campagne romaine, reprenant certaines conclusions de Gandolfo et suggérant que le portrait de commande pourrait avoir des origines laïques (TAGLIAFERRI, 2008). L'hypothèse de la chercheuse se fonde sur l'observation du fait que la mosaïque de l'arc de triomphe de Saint-Pierre (IV siècle) contenait l'image de l'empereur Constantin offrant le modèle réduit de l'église, comme l'ont montré les études de Paolo Liverani (LIVERANI, 2006). Tagliaferri a ensuite examiné la présence de donateurs laïques, sans doute de riches cultivateurs, qui laissèrent leur nom ou leur effigie sur les peintures qu'ils avaient fait réaliser, et examiné plus en détail les cas de la Grotta degli Angeli à Magliano Romano, de San Biagio à Nepi et de l'ermitage de San Cataldo. Pour revenir à Rome, Patrizia Carmassi y a identifié les familles des commanditaires des peintures de San Clemente et mis en évidence le rôle de Maria Macellaria, qu'elle a mise en relation avec une famille mentionnée à partir de 1123 dans les documents du cartulaire de Santa Maria Nova, où le terme macellarius est souvent répété, ce qui suggère un rapprochement avec la famille des Frangipane, alliés de la papauté réformatrice (CARMASSI, 2001). Romano, de son côté, a défini un panorama historique et culturel de donateurs et de commanditaires qui, au XI ${ }^{\mathrm{e}}$ siècle, apparaît varié et composé de structures ecclésiastiques, monastiques et cardinalices, mais aussi laïques, et qui, à partir du XII siècle, se montre plus organique et lié au contrôle pontifical, dans sa volonté de célébrer le triomphe de l'Église (ROMANO, 2006a, p. 16-21 et 169-179). Dans un essai intégré au catalogue de l'exposition consacrée à Mathilde de Canossa, organisée à Reggio Emilia en 2008-2009, la chercheuse a en outre indiqué un nouveau champ d'investigation en s'attardant sur le rôle des commandes passées par des femmes et de leurs images, et en partant de l'examen d'une série d'œuvres romaines comme le panneau du Vatican, les peintures de l'église inférieure de San Clemente - à propos desquelles Romano a approfondi le rôle de Maria Macellaria - et la fresque fragmentaire de Santa Balbina (ROMANO, 2008b). À l'occasion d'une intervention récente, elle est revenue sur le thème des commanditaires laïques, en particulier ceux de San Clemente, et soutenu l'hypothèse " très aventurée " d'un lien entre le Beno de Rapiza de San Clemente et les Rapizones, les comtes de Todi et de Spolète, dont la présence est attestée en haute Sabine, près de l'établissement religieux de Farfa, et qui soutinrent dans un premier temps l'antipape Cadalus. Le passé de Beno, qui provenait d'une famille désormais en disgrâce, aurait donc été racheté par Maria Macellaria, qui provenait au contraire d'une lignée définie comme "familière " par Grégoire VII, et donc très liée au parti des vainqueurs. Il en ressort un panorama du monde des commanditaires extrêmement complexe, et de plus en plus étroitement lié à la chronologie de la réforme et aux papes qui la soutinrent, y compris avec l'aide de personnages féminins (ROMANO, 2009). 


\section{Corpus d'œeuvres du XI ${ }^{\mathrm{e}}$ siècle}

Les thèmes évoqués jusqu'ici sont largement présents dans le corpus de la peinture médiévale romaine, projet dirigé par Maria Andaloro et Serena Romano, qui a rouvert certains débats et proposé de nombreux ajustements chronologiques, stylistiques et thématiques. Le projet a fourni un regard historico-chronologique et diachronique sur les œuvres comme l'ont souligné les comptes rendus publiés (voir ANDALORO, 2006, et Romano, 2006a). Pour ce qui concerne l'Atlante (Atlas) publié par Andaloro et coordonné par Manuela Viscontini (ANDALORO, 2006). Il s'agit d'un instrument très utile à la compréhension de la disposition des peintures et des mosaïques dans leurs cadres architecturaux d'origine, reconstitués précisément et accompagnés de planimétries claires, qui facilitent la remise en contexte des cycles (fig. 3), efficace surtout pour les ouvres fragmentaires ou conservées dans des sites altérés par les stratifications temporelles. Une autre nouveauté importante de ce projet est l'insertion des ouvres perdues dans le même catalogue que celui des ouvres encore existantes, donnant ainsi une pleine visibilité à des témoignages restés à l'arrière-plan du panorama de la peinture romaine. Concernant le $\mathrm{XI}^{\mathrm{e}}$ siècle, on peut par exemple consulter les notices de Romano relatives aux Épisodes de la vie de saint Laurent, sainte Cyrille, saint Irénée, saint Abbondio et d'autres saints, situés sur le portique méridional de San Lorenzo fuori le mura (ROMANO, 2006f). Une approche novatrice de l'étude des documents figuratifs - mentionnée aussi par les comptes rendus de John Osborne, de Xavier Barral i Altet et de Beat Brenk, pour le premier volume, et de Kessler, pour le quatrième (voir ANDALORO, ROMANO, 2006) apparaît aussi dans l'insertion de courtes notices épigraphiques donnant la transcription et la description graphique des textes inscrits dans les contextes visuels.

Tous ces éléments témoignent d'une démarche mise à jour sur les méthodologies de recherches qui ajoutent à l'examen stylistique traditionnel la prise en compte de facteurs historiques et documentaires, ainsi qu'une attention " archéologique " accordée au contexte qui, associée à l'emploi de la technologie informatique - pour ce qui concerne l'Atlante - a permis de faire apparaître de nouveaux éléments de réflexion et de modifier le panorama de la peinture romaine, rouvrant la question des " origines", en ce qui concerne le milieu du XI ${ }^{e}$ siècle, et suggérant quelques déplacements chronologiques des plus importants.

3. Reconstitution 3D du mur nord de l'église Saint-Pierre de Rome [La pittura medievale a Roma, 312-1431, Atlante. Percorsi visivi, vol. 1, p. 33, n. V].

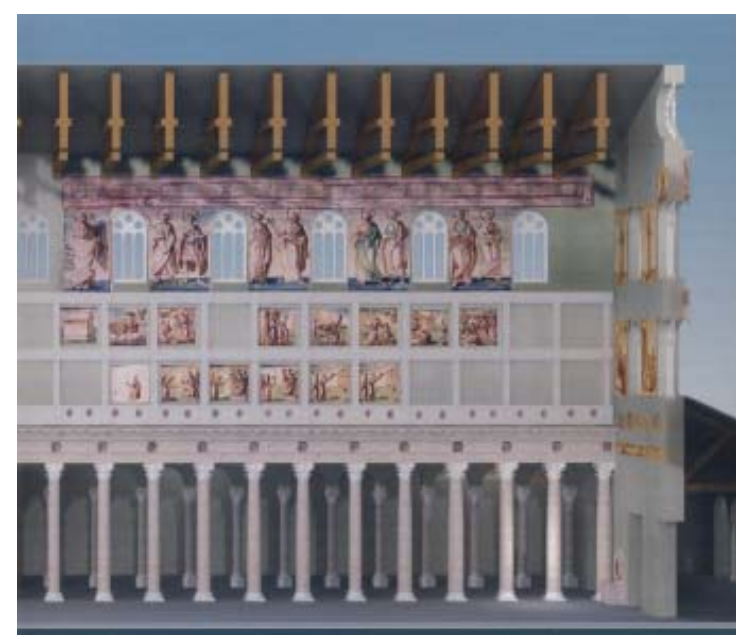

Les travaux de Giulia Bordi ont abouti à l'identification d'un groupe cohérent d'œuvres datables vers le milieu du $\mathrm{XI}^{\mathrm{e}}$ siècle, qu'il faut mettre en relation avec le panneau du Vatican, les peintures de San Clemente et les saintes autrefois présentes sur le portique de l'église Sant'Agnese fuori le mura. Il faut aussi rapprocher toutes ces œuvres de la Bible de Sainte Cécile, de même que les figures de saintes de l'église souterraine de Santa Maria in Via Lata, datées par la chercheuse des environs de 1049 (BORDI, 2006a, p. 37-39) ${ }^{13}$. Bordi examine aussi 
les peintures de la chapelle H9 de San Lorenzo fuori le mura représentant une Vierge en trône avec l'Enfant, l'Archange et des figures de saints (fig. 4), qu'elle propose de situer aux alentours de $1049^{14}$. En l'occurrence, une donnée non négligeable est l'attention accordée par la chercheuse aux inscriptions, qui se sont révélées être un élément important de soutien à l'hypothèse d'une nouvelle datation; en outre, ces peintures contiennent une des premières "signatures" d'artiste de la Rome médiévale : "Iohannes infelix pictor " 15 (BORDI, 2006b, p. 40-44; 2007, p. $213-$ 222). Un autre cycle découvert grâce aux recherches de Bordi est l'Institution de l'eucharistie, avec des donateurs (fig. 5), située dans la sixième niche du mur gauche de l'église Santa Balbina et datée du troisième

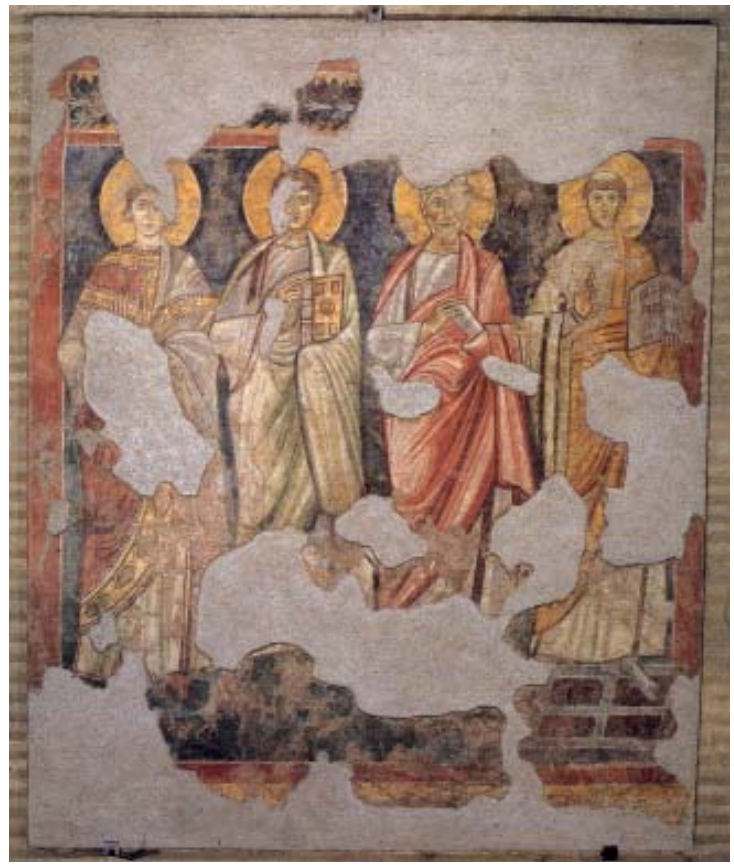
quart du XI ${ }^{\mathrm{e}}$ siècle (BORDI, 2006c) qu'il faut mettre en relation non seulement avec la Bible de Sainte Cécile, mais aussi avec les peintures de l'église inférieure de San Crisogono (BORDI, 2006d), dont nous reparlerons plus loin. Au pied de la Crucifixion, sur le registre inférieur, on trouve une famille de donateurs, Leo peccator et son épouse, coniux peccatrix, dont les noms sont désormais perdus ; il y avait sans doute, à côté de la mère, le portrait de sa fille. Les donateurs, dont l'auréole carrée qui les entoure indique qu'ils étaient vivants, ont été mis en relation avec Beno de Rapiza et Maria Macellaria, tels qu'ils apparaissent sur les fresques de l'église inférieure de SanClemente, en raison de leur iconographie et du contexte " eucharistique "; ils constituent un élément supplémentaire utile à la compréhension du monde des commanditaires romains (ROMANO, 2008b, p. 194).

Sont venues s'ajouter à ces œuvres la Vierge avec une donatrice découverte au baptistère de San Clemente durant les fouilles menées entre 1993 et 1995, que Romano date du troisième quart $\mathrm{du} \mathrm{XI}^{\mathrm{e}}$ siècle (ROMANO, 2006c), précisant ainsi la datation proposée par Guidobaldi, qui penchait pour la fin du siècle (GUIDOBALDI, 1997, p. 475), et la découverte, par Alessandra Acconci, des Quatre archanges peints dans la galerie de la basilique pélagienne de San Lorenzo, datables du deuxième quart

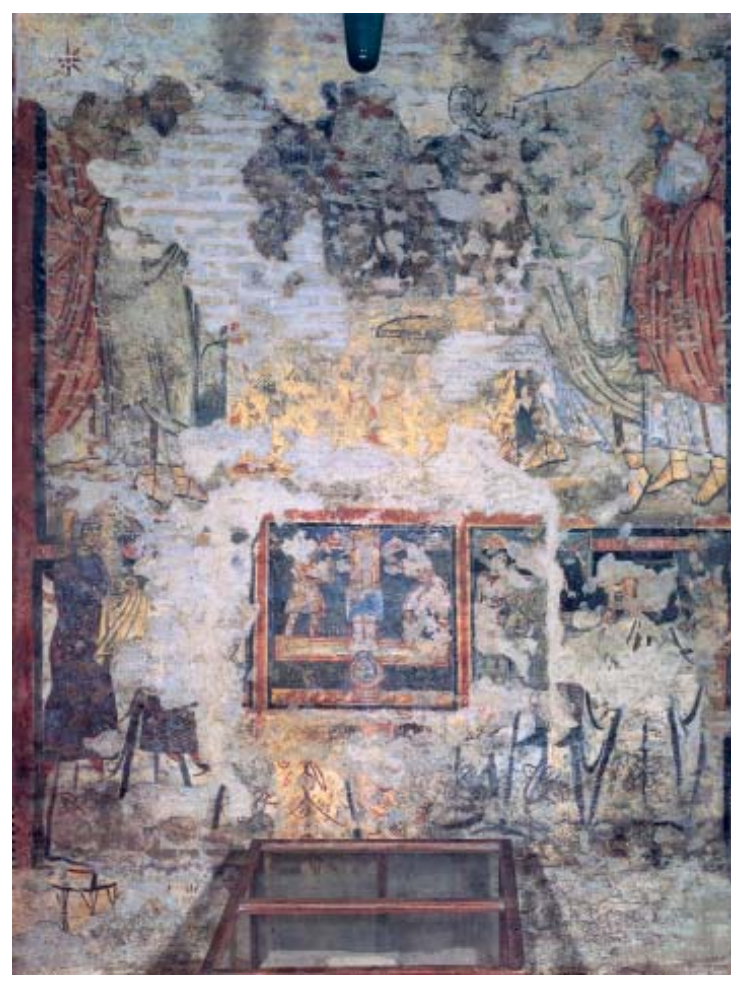

5. Institution de l'Eucharistie et panneau avec les donateurs, troisième quart du $\mathrm{XI}^{\mathrm{e}}$ siècle, Rome, Santa Balbina. 
du XI ${ }^{e}$ siècle. Ces peintures n'étaient connues que par des copies et elles témoignent, selon la chercheuse, d'une culture picturale précoce, à mettre en relation avec les peintures perdues du portique méridional (ACCONCI, 2007).

Les peintures de Sant'Urbano alla Caffarella, récemment étudiées par Kirstin Noreen, qui a suggéré que les scènes narratives doivent être datées du pontificat d'Urbain II (10881099 ; NOREEN, 2001, 2002), n’ont pas été incluses dans le volume relatif aux ouvres réalisées à partir de 1050. On consultera aussi, à ce propos, les comptes rendus du Corpus rédigés par Osborne et Kessler (voir ANDALORO, ROMANO, 2006), qui avait accepté de les dater de la fin du XI ${ }^{\mathrm{e}}$ siècle (KeSSLER, 2003, p. 81). L'étude de Stefania Pennesi sur les tableaux de la tour de l'église Santi Nereo e Achilleo (PEnNESI, 2007, p. 113-140) semblerait avoir des conséquences sur les cycles de la Caffarella et de Santa Maria in Pallara, dont il faudrait avancer la datation entre la fin du $\mathrm{X}^{\mathrm{e}}$ et le début du XI $\mathrm{XI}^{\mathrm{e}}$ siècle. Dans la notice signée par Pennesi et publiée dans l'Atlante, en effet, l'auteur suggère l'idée d'une réalisation unitaire du cycle mais, sceptique quant à une datation vers la fin du $\mathrm{XI}^{\mathrm{e}}$ siècle, penche plutôt pour accepter la date de 1011, suggérée par Wilpert, ou " quelques décennies plus tard, vers le milieu du $\mathrm{XI}^{\mathrm{e}}$ siècle " (PENNESI, 2006, p. 139). Il semble en tout cas évident que ces peintures seront traitées dans le troisième volume du Corpus, qui rassemblera les œuvres réalisées autour de l'an 1000, comme le déduit aussi Kessler (voir ANDALORO, ROMANO, 2006).

Ne pouvant aborder dans le cadre de cet article tous les cas individuels catalogués, nous nous attarderons sur trois œuvres charnière du $\mathrm{XI}^{\mathrm{e}}$ siècle, qui ont rouvert le débat sur l'art romain : le panneau du Vatican, les peintures de San Crisogono et celles de l'église inférieure de San Clemente.

\section{Le panneau du Vatican}

Un des arguments qui ont ravivé le débat critique de ces dernières années concerne le déplacement chronologique du tableau sur bois représentant le Jugement dernier et conservé aux Musei Vaticani (fig. 6), déplacement proposé par une étude de Suckale (SUCKALE, 2002) et repris par Romano et Felipe Dos Santos (ROMANO, DOS SANTOS, 2006), à la suite de la restauration effectuée en 1997 par le Laboratorio di Restauro dei Musei Vaticani (DE LUCA, 2006). On a proposé pour cette œuvre des datations oscillant entre le $\mathrm{XI}^{\mathrm{e}}$ et le XIII ${ }^{e}$ siècle ${ }^{16}$, mais il faut, selon Suckale, la situer entre 1060 et 1071 ; parmi les divers arguments avancés pour étayer cette thèse, un rôle décisif est joué par la présence dans l'œuvre de la Constantia figurant aussi dans des documents rédigés au cours des mêmes années et liés à la cénobie religieuse de Santa Maria in Campo Marzio, lieu de conservation originel du panneau (SUCKALE, 2002, p. 19). Avant 1140, ce monastère n'était pas bénédictin et il abritait une communauté de chanoinesses régulières; les appellatifs domina ou ancilla Dei s'adaptent en effet mieux aux chanoinesses, puisque les bénédictines utilisaient le terme de moniales. Suckale perçoit sur le panneau des éléments ottoniens et saliques qui le rattachent au monde nordique et germanique, entré en contact avec Rome et le mont Cassin, avant l'avènement de Didier, par l'intermédiaire des personnages engagés dans la réforme et de la circulation d'objets artisanaux représentatifs de la culture transalpine. Les hypothèses de Suckale ont été en substance acceptées par Romano et Felipe Dos Santos, qui ont précisé le rôle d'incunable joué par le tableau envers la peinture romaine du $\mathrm{XI}^{e}$ siècle et indiqué comme ses " héritiers les plus naturels " les peintures de l'église inférieure de San Clemente, lesquelles perdent cependant " la composante nordique, remplacée par une influence du mont Cassin bien plus radicale ", le contact ayant peut-être été établi par le biais 
de deux manuscrits provenant du mont Cassin $(99 \mathrm{H}$ et $98 \mathrm{H})$, dont le premier date de 1072 (ROMANO, Dos SANTOS, 2006, p. 53). La critique s'est montrée dans l'ensemble plutôt favorable à ces hypothèses ; Kessler souligne le lien étroit unissant le panneau du Vatican à la lunette de San Gregorio Nazianzeno quant au style, aux motifs et à la provenance (voir ANDALORO, ROMANO, 2006) ; la précision chronologique est aussi acceptée sans réserves par Julie Enckell Julliard et par Arturo Carlo Quintavalle (ENCKELL JULLIARD, 2007, p. 30 ; QuinTAVALLE, 2010, p. 148). En marge de nos travaux sur la mosaïque de San Clemente et, plus récemment, sur les inscriptions de la croix de Rosano, nous avons pu vérifier la pertinence des observations de Redig de Campos, parfaitement compatibles avec une datation située dans la seconde moitié du XI ${ }^{\mathrm{e}}$ siècle (RICCIONI, 2006, p. 27, note 79 ; sous presse c). Miklos Boskovits, en revanche, a avancé des critiques circonstanciées envers l'anticipation chronologique, en raison des incertitudes pesant sur les commanditaires - puisque Benedetta, et non pas Costantia, se trouve à droite de la Vierge - et de l'anomalie du support, un bois de châtaigner utilisé pour le mobilier et non pas pour les tableaux, et par conséquent mieux adapté à un trône " avec cimaise ronde de forme semblable à ceux en marbre " (BoskoviTs, 2010, p. 7). Mais c'est surtout pour des raisons stylistiques qu'il faut, selon Boskovits, éloigner le tableau de la datation suggérée et le rapprocher d'autres œuvres romaines, comme le cycle pictural conservé à l'oratoire marial de Santa Pudenziana et celui de l'abside de Santa Maria in Pallara - tous deux datés aujourd'hui des vingt premières années du XII siècle $^{17}$ ou encore la mosaïque de San Clemente, pour laquelle l'auteur accepte une datation située vers 1118 (CROISIER, 2006b; RICCIONI, 2006). L'œuvre serait donc reconductible au renouvellement culturel coïncidant avec le pontificat de Pascal II (Boskovits, 2010, p. 9). La rétrodatation du devant d'autel du Vatican obligerait donc à réviser la chronologie d'autres œuvres romaines attribuables à la période grégorienne examinées dans le volume en question mais, selon Boskovits, on courrait dans certains cas le risque de situer leur exécution beaucoup trop tôt. Romano est récemment revenue sur le panneau du Vatican à propos de ses commanditaires, dont elle a souligné le goût marqué pour l'antiquité ; elle a aussi réaffirmé l'appartenance de l'œuvre au contexte romain - en liaison avec les peintures murales du monastère de la

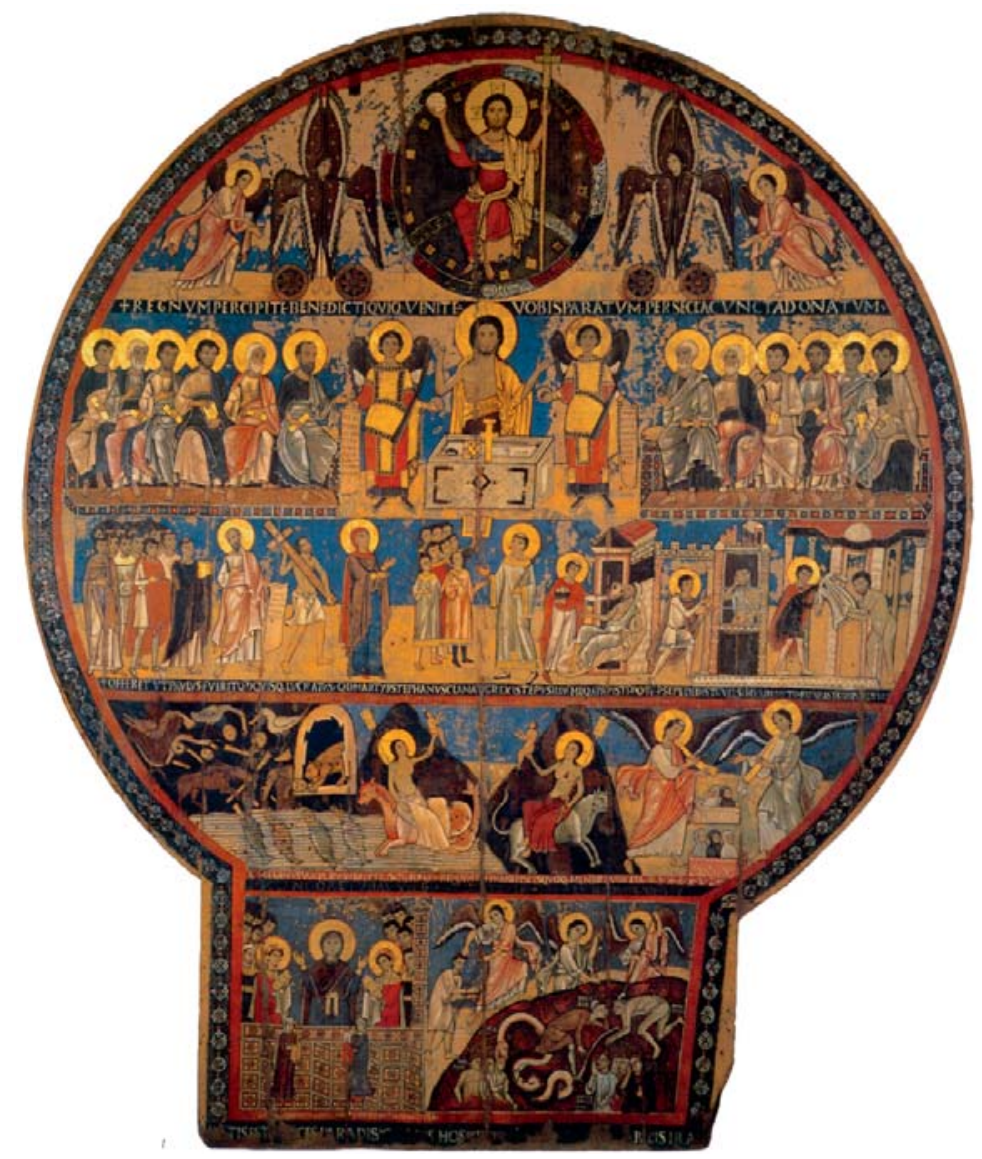

6. Jugement universel, 1061 1071, Cité du Vatican, Musei Vaticani. 
Via Lata et avec les deux figures de Sant'Agnese (BORDI, 2006a, 2006e) - et ses rapports avec la première phase de la réforme, tout en signalant ce qu'elle doit aux milieux aristocratiques ottoniens. C'est précisément la reconnaissance de la variété du panorama romain, composé de présences impériales et pontificales porteuses de commandes et de clientèles diversifiées, qui, selon la chercheuse, justifierait la diversification des modalités et des manières picturales, ainsi que des orientations du style et du goût (ROMANO, 2008b, p. 190-193).

\section{Les peintures de San Crisogono}

Dans les années 1980, Brenk a fourni une importante contribution à la connaissance des rapports entre Rome et le mont Cassin. En étudiant les fresques à sujets bénédictins de la paroi septentrionale de la basilique inférieure de San Crisogono (fig. 7), et celles de la façade opposée de la même église, Brenk y reconnut la présence de systèmes originaires du mont Cassin, comparables aux miniatures du Vat. lat. 1202 (BRENK, 1984, p. 57-65; 1985, p. 227-234; voir aussi SPECIALE, 2002). En conséquence de ces observations, Brenk avait été amené à dater les fresques, contrairement à l'opinion courante selon laquelle elles remontaient au $\mathrm{X}^{\mathrm{e}}$ siècle, des années 1057-1058, lorsque l'abbé du mont Cassin, Frédéric de Lorraine, était aussi cardinal de San Crisogono, avant de devenir pape sous le nom d'Étienne IX ; la critique accueillit favorablement cette hypothèse jusqu'à il y a quelques années. Les fresques de San Crisogono auraient donc été en pratique le témoignage d'une influence du mont Cassin à Rome (et du renouveau paléochrétien), avant même l'époque de Didier. Ces peintures restaient fortement indicatives d'un échange culturel entre le monastère et Rome, même si, d'un point de vue artistique, on ne pouvait plus les considérer comme une importation passive de motifs provenant du mont Cassin, mais au contraire comme le point d'arrivée d'une tradition qui s'était formée à Rome dès le X $X^{e}$ siècle (MATTHIAE, GANDOLFO, 1988, p. 254-255 ; ROMANO, 2002a, p. 108-112 ; PARLATO, ROMANO, [1992] 2001, p. 55-57). Eleonora Mazzocchi a, quant à elle, déplacé la datation du cycle à une période légèrement postérieure (1060-1070) et mis en évidence la présence d'épisodes tirés de la vie d'autres saints, en particulier sainte Catherine, dont l'intervention modifierait la perspective du cycle narratif (MAZZOCCHI, 2001, p. 51-52). Les aspects " bénédictins " du récit en ressortiraient donc limités. Mazzocchi a précisé davantage ces hypothèses, en ce qui concerne les aspects iconographiques, à l'occasion d'un congrès organisé à Lausanne (MAZzOCCHI, 2007). Il s'agit là d'observations que Romano a discutées de manière critique, précisant à son tour l'importance de l'élément bénédictin, en

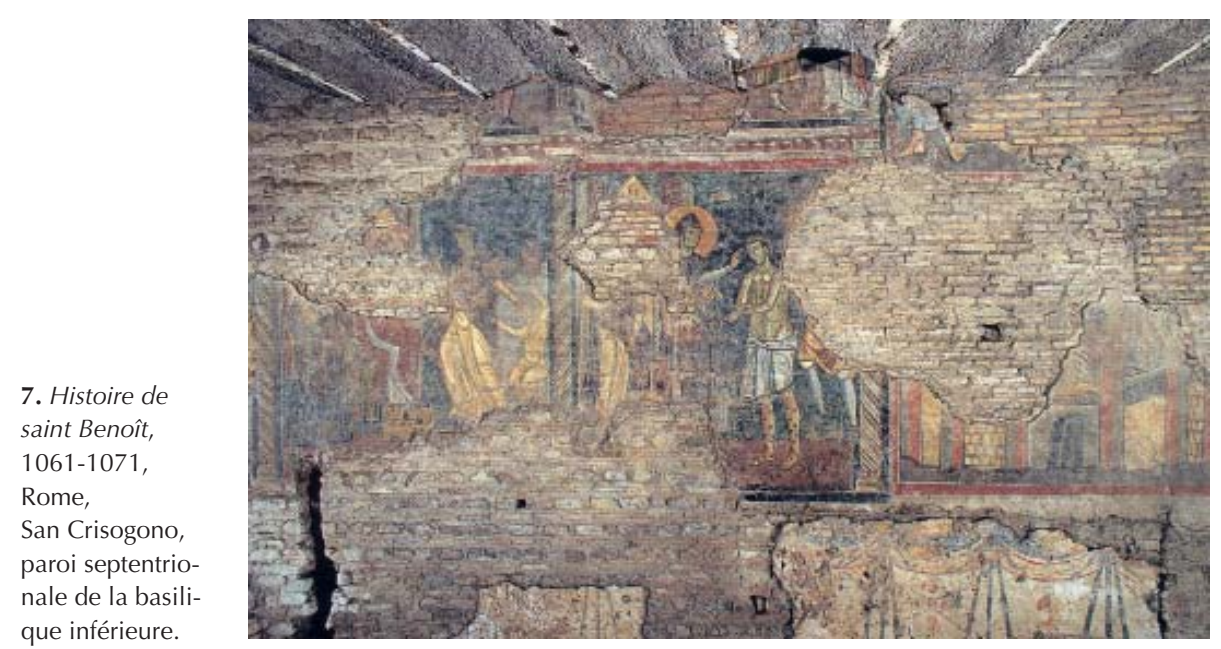
particulier dans les épisodes de la vie de saint Maur et de saint Benoît, et réaffirmant l'existence de contacts avec le Lectionnaire 1202 (ROMANO, 2006g, p. 79-87 ; 2007, p. 11). En outre, la datation des peintures devrait, selon Romano, coïncider avec le cardinalat d'Étienne (1057-1069), un homme de la réforme qui fut aussi abbé de San Gregorio al Celio. 
Les affinités suggérées par la chercheuse avec les peintures de Sant'Andrea al Celio viendraient confirmer cette thèse (ROMANO, 2006g, p. 87). Toujours à propos de l'église inférieure de San Crisogono, les recherches de Bordi, exposées dans le Corpus, permettent désormais de resituer aussi dans le contexte du troisième quart du $\mathrm{XI}^{\mathrm{e}}$ siècle les panneaux à fausses marqueteries de marbre situés dans l'abside, les figures de saints de la crypte, le cycle d'épisode de la vie de saints, sur le mur droit, et les figures fragmentaires de la façade opposée. Il s'agit d'une découverte importante, qui modifie sensiblement la perception de ce chantier pictural, qui comprenait des personnalités diverses, et de l'ensemble de l'entreprise décorative, qui n'en apparaît que plus complexe (BORDI, 2006d ; 2007, p. 222-230).

\section{Les peintures de San Clemente}

Les peintures de l'église inférieure de San Clemente constituent l'élément central autour duquel la critique s'est efforcée de reconstituer la production artistique de l'Église réformée, notamment en raison de leur lien étroit avec l'histoire de la ville et les événements rattachés à la lutte pour les investitures. À ce propos, la tenue à Rome, en 1078, d'un synode au cours duquel Ugo, cardinal de San Clemente, fut condamné pour avoir soutenu Cadalus contre Grégoire VII, revêt une importance significative. Les documents nous apprennent toutefois qu'en 1080, Ugo Candido cosigna le décret du synode de Brescia en qualité de cardinal de San Clemente. Il s'agissait donc selon toute probabilité de la même personne que celle qui, encore à cette date, était titulaire de l'église (BARCLAY LLOYD, 1989, p. 53-79 ; CARMASSI, 2001, p. 1-6 et 38-61; CLAUSSEN, 2002, p. 299-347). En outre, la même année, Ugo Candido figure parmi les électeurs de l'antipape Clément III. Pour résoudre cette situation conflictuelle, Grégoire VII nomma cardinal le moine clunisien Raniero de Bleda ou de Galeata, qui avait été abbé de San Lorenzo fuori le mura et sera élu pape sous le nom de Pascal II.

Ce choix s'intégrait à la politique de renouvellement de l'Église qui occupa la totalité du pontificat de Grégoire VII. Traditionnellement liée à l'incursion de Robert Guiscard, en 1084 (MULlooly, 1866, p. 184 ; WILPERT, 1906 ; KRAUTHEIMER et al., 1937, p. 120-131), et aux événements qui culminèrent avec un incendie qui endommagea sérieusement la colline du Celio, cette hypothèse ne semble plus défendable aujourd'hui, puisque, outre l'absence de traces patentes de combustion dans l'église inférieure ${ }^{18}$, les travaux d'Hamilton ont montré que le complexe architectural de San Clemente ne faisait pas partie des édifices ayant une position militairement stratégique, et il n'existait donc aucune raison de l'attaquer (HAMILTON, 2003, p. 393-394). Toutefois, l'église subit, selon toute probabilité, des dommages, puisque les structures murales érigées dans la nef centrale de la basilique inférieure sembleraient témoigner de travaux de consolidation. En outre, Rome fut frappée en 1091 par un tremblement de terre qui endommagea, entre autres, les églises Santa Maria in Trastevere et San Crisogono ; on ne peut exclure que les secousses aient aussi touché San Clemente (BARCLAY LLOYD, 1989, p. 57). La critique a élaboré ses raisonnements à partir de ces données historiques.

Selon les thèses de Toubert, le cycle serait la manifestation la plus évidente de l'influence culturelle exercée sur Rome par l'abbaye du mont Cassin à l'époque de l'abbé Didier. La chercheuse expliquait ainsi un choix non seulement esthétique, mais aussi idéologique, d'esprit réformé et antiquisant. Reprenant en partie les argumentations de Toubert, Cristiana Filippini a soutenu que la coïncidence entre le nom du saint auquel est consacrée la basilique et celui de l'antipape Clément III, choisi par Guibert au moment de son accession au trône pontifical, pourrait permettre d'expliquer les peintures aussi bien dans le sens d'une 
interprétation réformée (qui a la préférence de la chercheuse) - si on voit dans la scène représentant Saint Clément en trône parmi des saints une forme d'opposition à l'antipape - que dans le sens contraire, si l'on suppose que les peintures ont été commandées non par Raniero mais par Ugo Candido, qui aurait ainsi voulu glorifier le pape qu'il avait soutenu (FILIPPINI, 1999). Cette seconde hypothèse pourrait expliquer la reconstruction intégrale de la basilique à l'époque de Pascal II, qui aurait voulu effacer toutes les traces d'un cardinal schismatique (FILIPPINI, 1999, p. 281-287). La datation de la réalisation des peintures sous le pontificat d'Urbain II a aussi trouvé confirmation dans les études de Zchomelidse (ZCHOMELIDSE, 1996, p. 97-98), qui vit dans la présence de saint Nicolas un lien avec le pape français et qui identifia, toujours à propos de ce même lien, un contact avec la décoration de l'église Santa Maria Immacolata, à Ceri. S'appuyant sur une recherche historique et documentaire, Carmassi a fourni elle aussi une interprétation intéressante de la scène de la Translation des reliques, et précisé les liens avec les commanditaires appartenant aux élites nobiliaires romaines, par exemple les Frangipane, alliés d'Urbain II lors de la lutte pour les investitures (CARMASSI, 2001). La situation chronologique des peintures sous le pontificat d'Urbain II (1088-1099), selon une hypothèse qui voyait dans l'église San Clemente un lieu d'orthodoxie de la papauté réformatrice, et qu'acceptèrent aussi Osborne et Romano (OSBORNE, 1997 ; ROMANO, 2002a), semblait donc acquise. Sur le fondement des intuitions de Zchomelidse, Tagliaferri a suggéré l'existence d'affinités iconographiques et thématiques entre les saints représentés sur les piliers et la production artistique française, en particulier pour ce qui concerne le personnage principal de Daniel dans la fosse aux lions (sur le pilier de la Messe de saint Clément), et surtout la figure de saint Nicolas, présente sur la portion supérieure du pilier où se situent les scènes de la vie de saint Alexis (TAGLIAFERRI, 2003). Filippini s'est à nouveau occupée des scènes de la vie de saint Clément, qu'elle a interprétées comme une sorte de calendrier liturgique des fêtes qui lui sont consacrées; elle a par ailleurs suggéré que les fresques du Miracle de Chersonèse et de la Translation des reliques auraient été réalisées en fonction de la destination funéraire de l'espace du portique (GuidobaLDI, 1992, p. 223-227) et de la glorification des reliques du saint (FILIPPINI, 2002, 2004) ; cette dernière hypothèse a aussi été acceptée par Osborne (OSBORNE, 1997). Valentino Pace a récemment contesté la valeur funéraire de la Messe de saint Clément et attribué aux peintures une valeur d'ex-voto en remerciement de la guérison du fils des donateurs, ce puerulus Clemens représenté sur la plinthe (PACE, 2007, p. 55-56). En outre, Pace a réaffirmé l'importance qu'il y a à ne pas négliger la présence des Épisodes de la vie de saint Alexis, qui sont situés entre les trois panneaux relatant l'histoire de saint Clément et qui sont les seules peintures à ne pas avoir été commandées (jusqu'à preuve du contraire) par Beno de Rapiza et Maria Macellaria. Le chercheur a en outre repris à son compte la remarque de Filippini, qu'il oriente résolument dans le sens d'une réalisation hostile au pape (PACE, 2007, p. 56-57), acceptant ainsi en partie la théorie d'un art guibertien, que Claussen avait formulée à propos de la sculpture (CLAUSSEN, 2006, 2007, 2008). D'autres publications de Filippini ont analysé l'image de saint Clément et la fonction narrative revêtue par sa légende hagiographique au sein de l'espace liturgique (FILIPPINI, 2004, 2006), ainsi que les Épisodes de la vie de saint Alexis. Concernant ce dernier cycle, la chercheuse a fait siennes les observations de Pace - qui voit dans la figure d'Alexis un saint exemplaire aux yeux du mouvement réformateur, en raison de la charité et de la chasteté qui caractérisèrent son parcours existentiel (PACE, 1993-1994) - et elle resitue les peintures sur l'arrière-plan de la lutte pour les investitures. Le choix de représenter la légende de saint Alexis confirmerait le lien entre la réalisation des peintures de San Clemente et la réforme (FILIPPINI, 2007). 
Dans son récent travail pour le Corpus, Romano a pris ses distances envers la datation établissant un lien entre les peintures et l'incursion de Robert Guiscard (1084), mais aussi avec celle qui les situait sous le pontificat d'Urbain II ; revenant sur l'hypothèse de Bertelli, elle a avancé la datation des ouvres, proposé une relation avec le synode de 1078, et réaffirmé le caractère obligatoire de la célébration des évêques et des papes sanctifiés, dans les basiliques qui leur sont consacrées. Le lien proposé par la chercheuse prend naturellement en considération aussi bien l'action de Raniero de Bleda, à l'époque titulaire de l'église, que l'option d'un terme ante quem fourni par l'année 1084, date à laquelle la position d'Ugo Candido était renforcée par la présence à Rome de l'antipape. Tout en reconnaissant la légitimité historique de l'alternative, Romano n'accepte donc pas l'hypothèse " antipapiste" (ROMANO, 2006a, p. 26-31, 129-150;2007, p. 10). Assez critique sur une

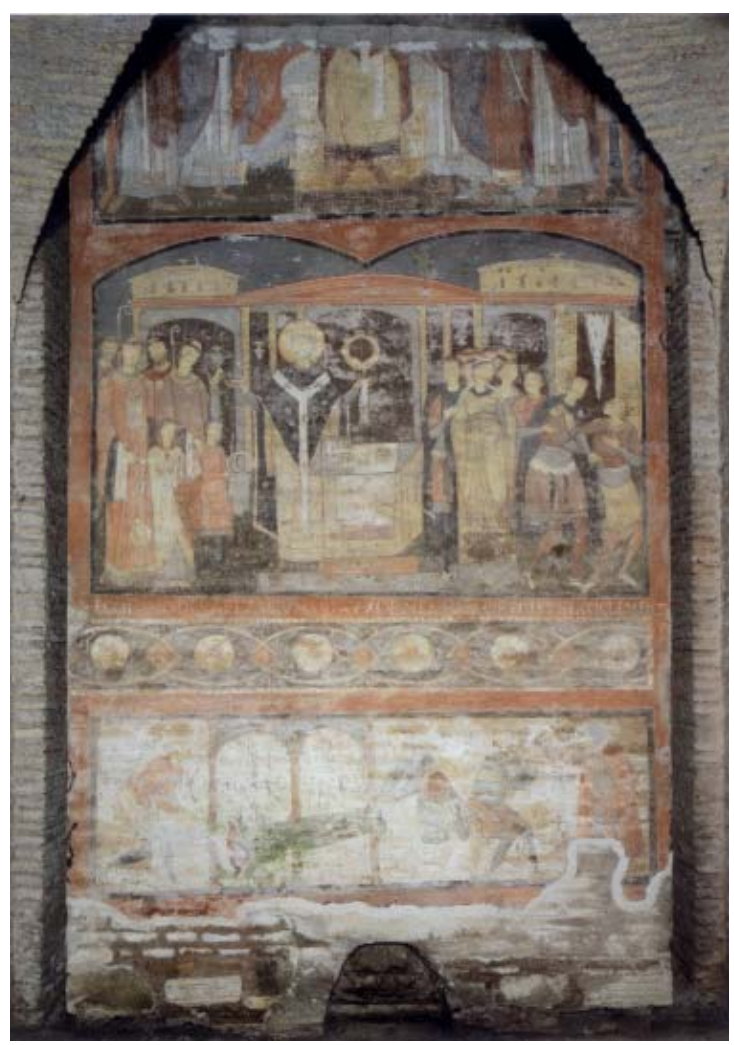
datation de peintures située en 1078, ou en tout cas antérieure à 1084, Boskovits considère, sur le fondement d'un examen stylistique, " plus probable une exécution avant la dernière décennie du XI ${ }^{\mathrm{e}}$ siècle " (BOSKOVITS, 2010, p. 8).

Les points essentiels des thèses de Romano portent sur les aspects du programme liés à l'ecclésiologie et à la martyrologie, tout en attirant l'attention sur les Épisodes de la vie de saint Alexis, dont le culte était lié au passé ottonien de Rome et, par ce biais, également au panneau du Vatican (ROMANO, 2008b). La chercheuse est par la suite revenue sur le sujet pour aborder le schéma narratif des peintures, et en particulier de celles ayant pour sujets la Messe de saint Clément et la Tentative d'arrestation (fig. 8) ; elle en propose une lecture visuellement unitaire, bien que scandée par les textes écrits situés à côté des personnages, selon une mise en scène dramatisée s'appuyant sur la pratique scénique, et plus précisément sur les systèmes illustratifs des comédies de Térence. Leur large diffusion au cours du Moyen Âge, en particulier à la cour ottonienne mais aussi au mont Cassin, formerait ainsi le contexte de la Passion de saint Clément et de sa représentation (ROMANO, 2009, p. 63-69).

\section{Corpus d'œuvres du XII ${ }^{\mathrm{e}}$ siècle}

Concernant le $\mathrm{XII}^{\mathrm{e}}$ siècle aussi, le Corpus a pris en considération une série d'œuvres perdues, et en particulier : la décoration du narthex de la basilique pélagienne de San Lorenzo fuori le mura, orné d'Épisodes de l'enfance du Christ (dernier quart du $\mathrm{XI}^{\mathrm{e}}$ siècle-début du XII ${ }^{\mathrm{e}}$ siècle [?]) et de la Pentecôte (premier quart du XII ${ }^{\mathrm{e}}$ siècle ; ACCONCI, 2006) ; les fresques de San Salvatore in Thermis, connues à travers des documents photographiques (première moitié du XII ${ }^{\mathrm{e}}$ siècle [?] ; ENCKELL JULLIARD, 2006a) ; la fresque détachée et le cycle, perdu, représentant des épisodes de la vie de saints, qui décoraient autrefois le portique de
8. Messe de saint Clément, 10781084, Rome, San Clemente. 


\section{Vierge \\ trônant entre \\ saint Silvestre et \\ saint Anastase, \\ provenant de \\ Rome, oratoire \\ de San Nicola \\ al Patriarchio \\ Lateranense, \\ œuvre perdue \\ [ROMANO, \\ 2006a, p. 290 \\ n. 1].}

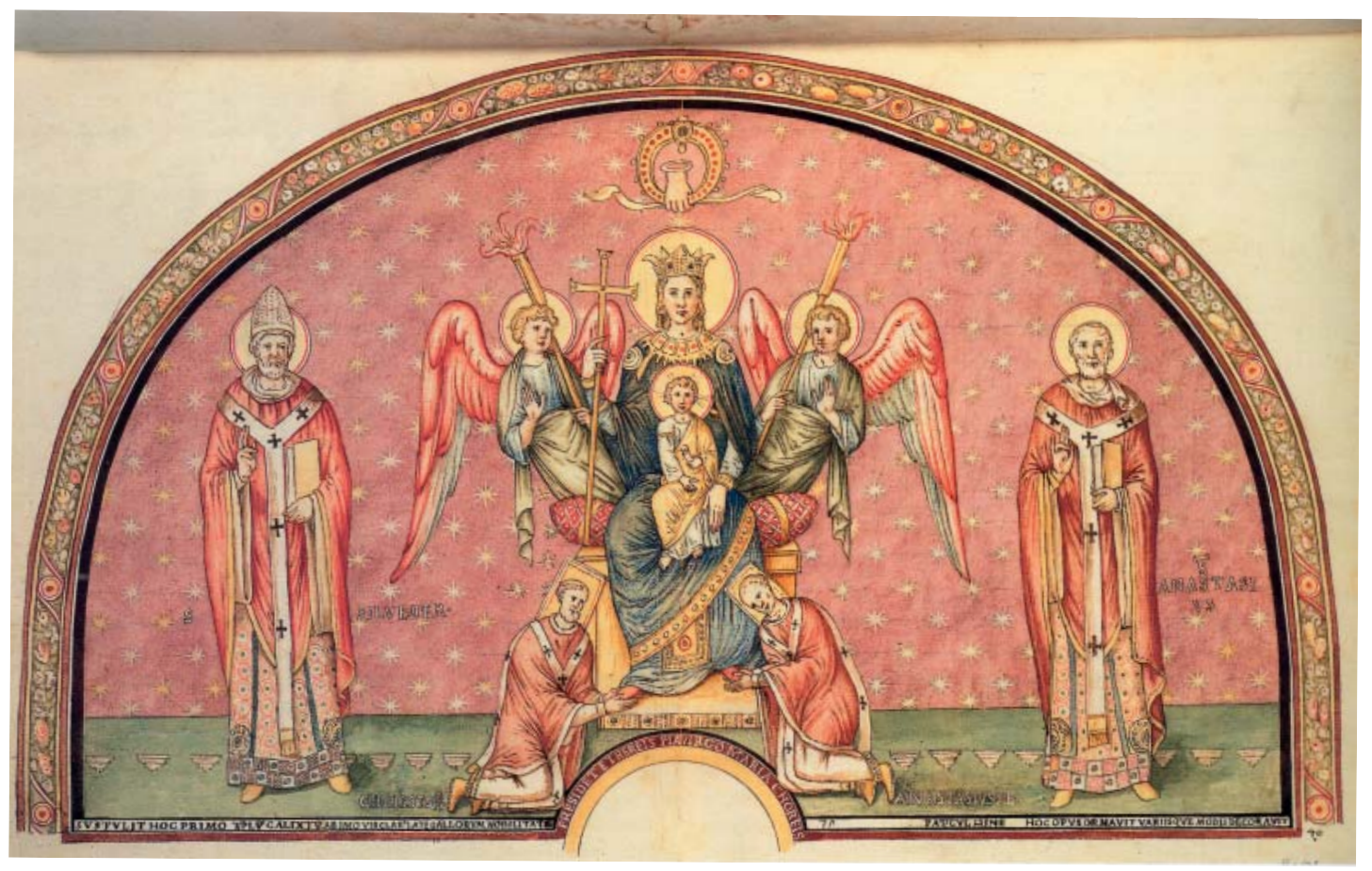

Santa Cecilia in Trastevere et qui datent de 1099-1118 (Dos SANTOS, 2006a) ; la décoration de l'oratoire de San Nicola al Patriarchio Lateranense (fig. 9), qui remonte à 1130-1134 (CROISIER, 2006c) ; la décoration de la cuvette de l'abside de San Lorenzo in Lucina, réalisée en 1130-1138 (ROMANO, 2006h) ; la peinture représentant le Couronnement de Lothaire III, au Patriarchio Lateranense, exécutée en 1133-1149 (CROISIER, 2006d) ; le tableau incluant le prêtre Boninus, à San Salvatore in onda, sans doute datable de la première moitié du XII siècle (CROISIER, 2006e) ; la décoration en mosaïques de la façade de Santa Maria Nova, effectuée en 1165-1167 (ENCKELL JULLIARD, 2006b). Autant d'œuvres qui ont ainsi acquis une parfaite visibilité, grâce aux reproductions accompagnant leurs notices, et qui restituent une vision diachronique plus complète de la peinture romaine des $\mathrm{XI}^{\mathrm{e}}$ et $\mathrm{XII}^{\mathrm{e}}$ siècles. Ces découvertes sont donc venues combler, bien que virtuellement, une importante lacune, tout en favorisant l'organisation thématique et le débat critique, comme on l'a vu par exemple dans le cas des peintures de l'oratoire de San Nicola et du Couronnement de Lothaire III, naguère abordé par Ingo Herklotz dans le cadre de la propagande visuelle du XII siècle (HERKLOTZ, 2000, p. 95-152).

En outre, le Corpus a fourni quelques précisions et sujets de débat, par exemple dans le cas des peintures de l'oratoire de Santa Pudenziana ayant pour sujet la Theotokos et les Épisodes de la vie de saint Pudens, de saint Novatus et de saint Timothée. Dans une étude légèrement antérieure au Corpus, Alessia Trivellone les avait situées sous le pontificat de Grégoire VII, donc durant le troisième quart du $\mathrm{XI}^{\mathrm{e}}$ siècle, et avait lié leur datation à la plaque portant une inscription de commémoration des restaurations réalisées par le cardinal Benedictus. Selon la chercheuse, cette plaque appartenait à un autel reliquaire qui aurait pu être en rapport avec une éventuelle fonction mémorielle de l'oratoire et avec les peintures glorifiant les origines apostoliques de l'Église (TRIVELLONE, 2007). Exprimant une opinion divergente, mais sans pour autant contester la valeur apostolique du cycle, Jérôme Croisier a jugé légitime de donner aux peintures une datation plus tardive, située dans les vingt premières années du XII ${ }^{\mathrm{e}}$ siècle ${ }^{19}$, et il a suggéré certains 
rapprochements stylistiques avec un groupe de peintures comprenant celles des souterrains du Sancta sanctorum, celles de la basilique Sant'Anastasio a Castel Sant'Elia, de l'église paroissiale de Vallerano et de la Grotta degli Angeli, à Magliano Romano (CROISIER, 2006a). Cette hypothèse a été réaffirmée, encore récemment, par Romano (ROMANO, sous presse).

De son côté, Enckell - dans son étude sur le panneau représentant trois figures à mi-corps, peint pour l'abside de Santa Maria in Pallara - a considéré qu'il fallait en déplacer la datation aux vingt premières années du XII ${ }^{e}$ siècle ${ }^{20}$, soit à la fin de la vie de Léon d'Ostie, qui mourut dans l'église entre 1115 et 1117. La chercheuse y a en outre perçu des consonances stylistiques avec les peintures de Santa Pudenziana et de Castel Sant'Elia (ENCKell JulLiARD, 2006c).

Romano est par la suite revenue à la décoration fragmentaire - qui montre des animaux, des sarments végétaux ornés de fleurs, de fruits et de figures de putti, ainsi qu'une scène narrative de sujet difficile à identifier - peinte dans les combles des nefs latérales de l'église supérieure de San Clemente, et elle est revenue sur leur datation vers la fin du XIII ${ }^{e}$ siècle, qu'elle avait elle-même proposée par le passé (ROMANO, 1992, p. 94-98). Une inspection des lieux a en effet permis de retrouver d'autres éléments, telles les têtes et les frises ornementales, que Romano a rattachées à un répertoire ayant évolué des peintures de l'église inférieure de San Clemente à celles de Ceri et Castel Sant'Elia, et dont elle a déplacé la datation dans les années 1120 (Romano, 2006c). Enfin, Dos Santos a pensé pouvoir proposer de nouvelles hypothèses quant à la chronologie des peintures de l'oratoire de San Giuliano, en l'église Saint-Paul-hors-les-murs, dont les parties conservées représentent une Crucifixion, encadrée d'un Saint Pierre et d'un Saint Paul, et une Théorie de saints. Le cycle serait reconductible à l'action d'Anastasius, mentionné en 1099 dans les papiers de l'abbaye, dont il fut l'abbé de 1119 à 1139. Cette hypothèse se fonde sur l'intégration de l'inscription fragmentaire lisible sur le cartouche de l'apôtre Matthieu. En outre, Dos Santos étaye sa théorie en établissant un lien stylistique entre les peintures de Saint-Paul-hors-les-murs et celles des cycles de Ceri et de Castel Sant'Elia (Dos SANTOS, 2006b, 2007). On voit donc à quel point les décorations monumentales encore conservées en dehors de Rome jouent un rôle important dans la compréhension des phénomènes artistiques des $\mathrm{XI}^{\mathrm{e}}$ et $\mathrm{XII}^{\mathrm{e}}$ siècles, que nous décrirons brièvement à la fin de cet article.

Parallèlement aux études publiées dans le Corpus, un texte de Claudia Viggiani a présenté la découverte d'une peinture murale conservée en la basilique Santi Bonifacio e Alessio all'Aventino, dans un petit espace situé au fond de la nef latérale droite, au-delà du clocher, qui faisait sans doute partie de la façade postérieure (VIGGIANI, 2006). Cette peinture se subdivise en deux parties décoratives qui représentent respectivement, en haut, un saint (à gauche) et un ange (à droite), et, en bas, une architecture face à laquelle on aperçoit, sur la gauche, un autre ange, peut-être agenouillé. Le saint est selon toute probabilité Alexis "le pèlerin ", une figure chère aux réformateurs du XI ${ }^{\mathrm{e}}$ siècle, comme on l'a vu à propos des peintures de l'église inférieure de San Clemente. Viggiani y reconnaît en effet des points de contact avec l'église clémentine, mais aussi avec l'Immacolata de Ceri et l'église Sant'Anastasio de Castel Sant'Elia, ainsi qu'avec les prophètes du grand arc absidal de l'église Santa Maria in Trastevere, et plus précisément la figure d'Isaïe. Se fondant sur ces rapprochements, la chercheuse a avancé l'hypothèse d'une datation de peu postérieure à 1143, année du probable achèvement de la mosaïque du Trastevere (VIGGIANI, 2006, p. 138 et 139). Toutefois, pour des raisons thématiques et stylistiques, une datation située vers la fin du XI siècle, et pas au-delà du tout début du XII ${ }^{e}$, nous semble plus plausible. Romano partage pleinement cette opinion et rapproche les peintures récemment découvertes du 
contexte et des exigences de la politique figurative de l'Église réformée, et en particulier des peintures de l'église inférieure de San Clemente représentant la Légende de saint Alexis, pour des raisons de style pictural, de thématique hagiographique et de système compositionnel des murs ; elle précise par ailleurs : "Stylistiquement, le fragment de l'Aventin n'est compréhensible que comme la stricte continuation de la manière de San Clemente : elle se situe entre cette dernière, le panneau du Latran [représentant l'histoire d'Ananie et Saphira] et Ceri » (ROMANO, sous presse).

\section{Mosaïques}

$\mathrm{Au} \mathrm{XII}^{\mathrm{e}}$ siècle, l'événement le plus significatif intervenu dans le domaine de la décoration monumentale romaine fut la renaissance de l'art de la mosaïque, que certains mettent en relation avec la reconstruction de l'abbaye du mont Cassin (comme on l'a vu plus haut), et qui se rattache en substance à la phase finale de la réforme, en tant que manifestation de son triomphe présumé sur l'Empire et sur les incertitudes politiques qui avaient déchiré la ville pendant presque un siècle.

\section{San Bartolomeo all'Isola}

À la suite des travaux du Corpus, il semblerait que la première manifestation, à Rome, d'une renaissance de l'art de la mosaïque, doive être reconnue dans celle de San Bartolomeo all'Isola, que Simone Piazza date du XII siècle, sous le pontificat de Pascal II. Il s'agit de l'image d'un Christ à mi-corps (fig. 10) appartenant à une plus vaste décoration située sur la façade de l'église, remplacée par une façade baroque en 1625. Se fondant sur les Considerazioni sulla pittura de Giulio Mancini ${ }^{21}$, érudit ayant vécu entre le $\mathrm{XV}^{\mathrm{e}}$ et le XVI ${ }^{\mathrm{e}}$ siècle, où la datation de la mosaïque est située sous le pontificat de Pascal II - dont le nom figure aussi sur l'inscription gravée sur l'architrave du portail d'entrée - et compte tenu du fait que Pascal II avait choisi, en 1105, d'établir sa résidence sur l'île tibérine, le chercheur a pensé qu'il fallait avancer la datation de l'œuvre en 1113, s'opposant ainsi à l'hypothèse selon laquelle elle daterait du milieu du XII ${ }^{\mathrm{e}}$ siècle, ou d'une période légèrement postérieure (MATTHIAE, GANDOLFO, 1988, p. 58, 265). L'année 1113 correspond en effet aux travaux effectués dans l'église et mentionnés sur l'inscription du portail. La mosaïque manifeste, selon Piazza, des affinités stylistiques avec les visages des martyrs de l'oratoire marial de Santa Pudenziana, avec les peintures de l'abside de Castel

10. Le Sauveur en buste, vers 1113, Rome, San Tommaso in formis.

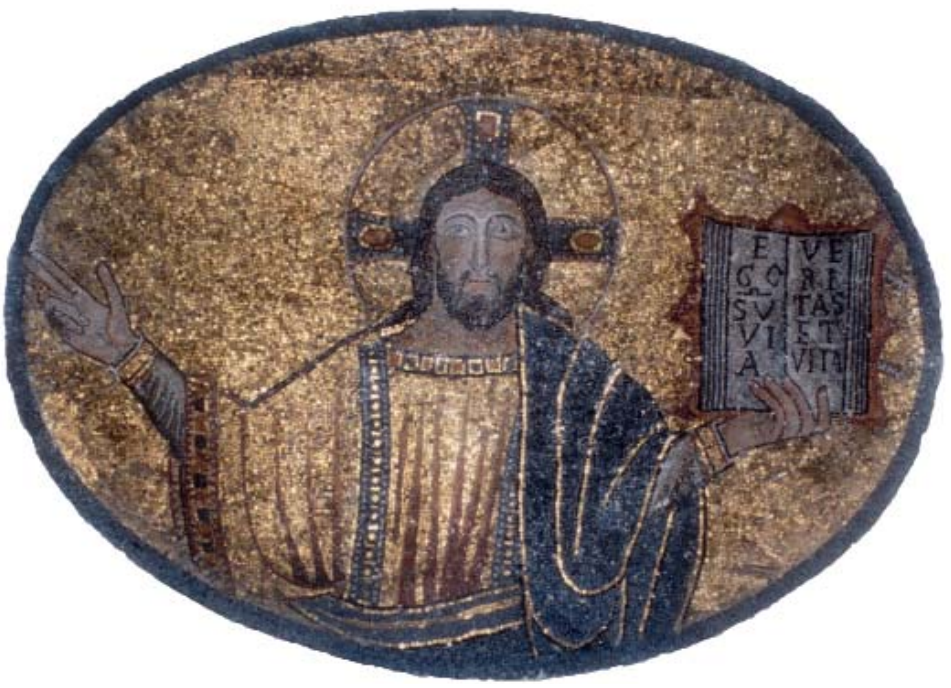

Sant'Elia, et avec celles de la lunette de la Grotta degli Angeli, à Magliano Romano (PIAZZA, 2006, p. 193). Cette nouvelle découverte, acceptée récemment encore par Romano (ROMANO, 2010) confirmerait la réalisation, sous le pontificat de Pascal II, de travaux de reconstruction et d'embellissement qui se seraient poursuivis avec la mosaïque de San Clemente, ou auraient commencé en même temps qu'elle. 


\section{San Clemente}

La mosaïque de San Clemente reste en effet le monument le plus important et le plus significatif de la renaissance de cette technique : il s'agit d'un événement crucial non seulement pour l'art romain de la fin du $\mathrm{XI}^{\mathrm{e}}$ et du début du XII ${ }^{\mathrm{e}}$ siècle, mais aussi pour la compréhension d'un moment historique et culturel complexe de l'évolution de l'Église, qui vécut, sous le pontificat de Pascal II, une première trêve dans la lutte pour les investitures. Nous avons déjà cité plus haut la bibliographie relative aux événements historiques liés à l'église inférieure. Concernant la construction de l'église supérieure et ses vicissitudes, les études de Joan Barclay Lloyd (BARCLAY LLOYD, 1989) n'ont pas seulement mis à la disposition de la critique les sources documentaires, elles ont aussi montré l'importance des édifices conventuels annexés à l'église pour l'accueil des chanoines réformés. Selon la chercheuse, les travaux furent voulus par Pascal II et devaient se conclure en 1118, occupant ainsi une partie significative de son pontificat (BARCLAY LLOYD, 1989).

La mosaïque représente, sur la calotte absidale, un Christ mort sur la croix - que certains ont aussi interprété comme un reliquaire en raison de l'inscription déployée en bas de la calotte - d'où partent des sarments d'acanthe ornés d'animaux, de scènes de la vie quotidienne, de putti et d'oiseaux. L'arc de triomphe abrite la représentation de deux binômes de saints : à droite, Pierre et Clément ; à gauche, Paul et Laurent (fig. 11). Au centre, le Christ bénissant est entouré d'un clipeus surmonté des symboles des évangélistes ; sur les côtés, on aperçoit les prophètes Jérémie (à droite) et Isaïe (à gauche). De nombreuses inscriptions, qui courent le long de l'arc absidal, au pied des binômes de saints, sur les cartouches des prophètes et à la base de la calotte absidale, viennent compléter la décoration.

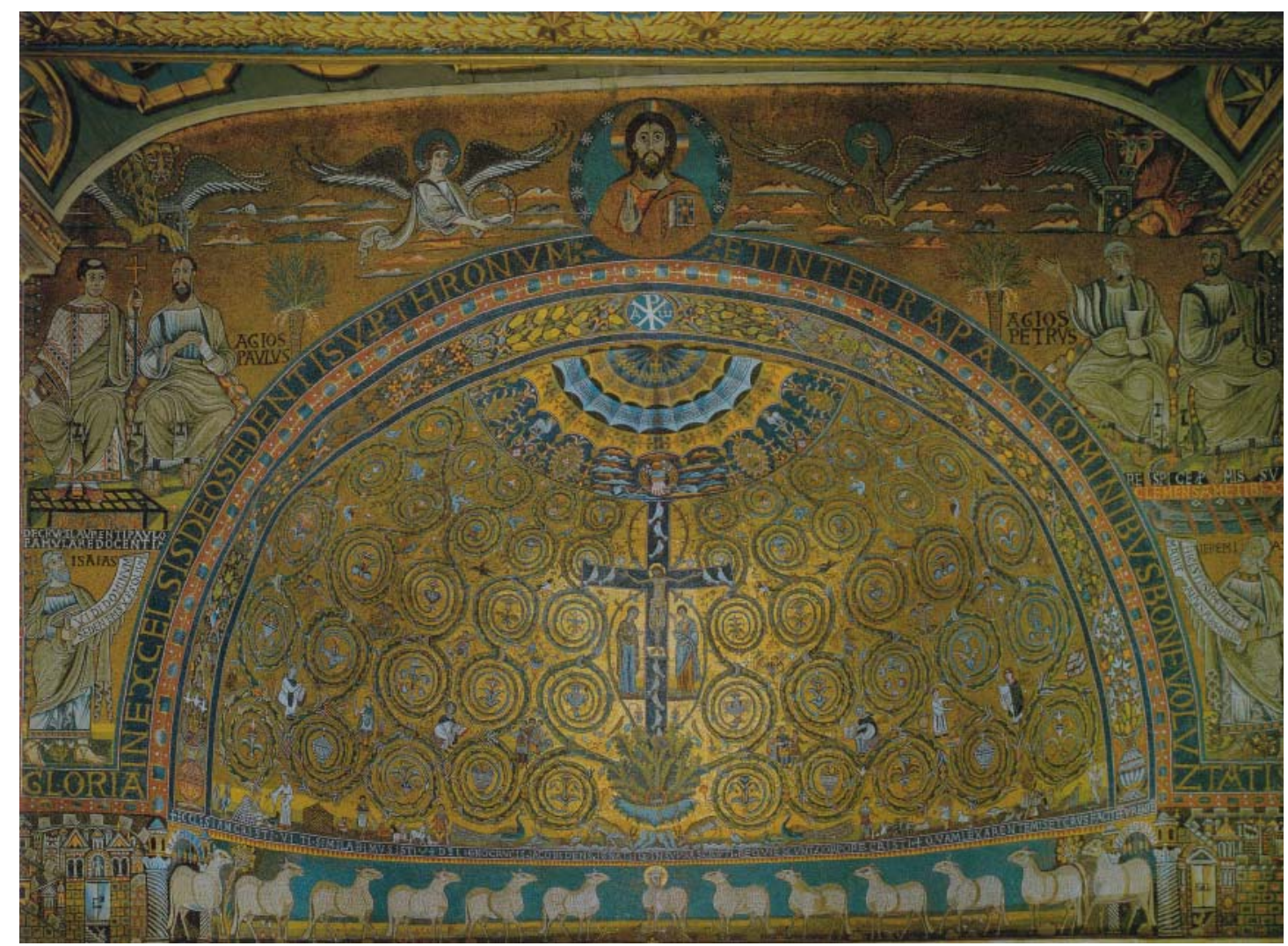


Cette mosaïque a souffert, quant à son interprétation et à sa mise en contexte historique, de l'absence de référence chronologique certaine et de points de comparaison solides sur le plan artistique, absence aujourd'hui atténuée par la découverte de la mosaïque de San Bartolomeo all'Isola, tout en restant annonciatrice d'importants épigones, par exemple à Santa Maria in Trastevere et à Santa Maria Nova. Dans ce cas aussi, l'enquête iconographique de référence reste celle proposée par Toubert, qui mit en évidence la reprise de thèmes antiquisants liés au milieu monastique du mont Cassin et à la réforme de l'Église (TOUBERT, 1970). La mosaïque de San Clemente serait ainsi l'expression d'un retour programmé à l'Antique, et plus précisément aux formes de l'art paléochrétien, de manière à refléter la renovatio ecclesix, qui visait à un retour aux idéaux et aux styles de vie des premiers chrétiens. Cette entreprise était donc mise en relation avec l'action de l'abbé Didier, qui se lança dans l'ambitieux projet consistant à reconstruire l'abbaye du mont Cassin en s'inspirant des modèles de l'antiquité classique et qui, en 1066, fit venir des artistes de Constantinople pour décorer de mosaïques somptueuses la nouvelle abside de la basilique (consacrée en 1071), dont il ne reste hélas plus rien. Comme on l'a vu plus haut, Kitzinger, qui reconnaissait dans la décoration en mosaïque de San Clemente l'expression des principes de la réforme, replaça la renaissance de cette technique à Rome dans le contexte de la culture du mont Cassin et indiqua la cathédrale de Salerne, consacrée par Grégoire VII en l'an 1085, comme un archétype possible des innovations introduites ensuite dans le milieu romain ; Pace (PACE, 1997) le suivit sur cette voie. Gandolfo exprima une opinion divergente, à l'occasion de sa mise à jour de l'œuvre de Matthiae, lorsqu'il traita de la renaissance de la technique de la mosaïque dans les absides des églises romaines. Établissant une distinction entre la référence à l'Antique d'esprit impérial et celle d'esprit paléochrétien, il voyait en effet dans la mosaïque de San Clemente " une correspondance précise avec les exigences de propagande politique de l'antipape Anaclet II ", dont il suggérait une intervention postérieure à 1130 (MATthiAe, GANDOlFO, 1988, p. 267). Dans un ouvrage paru avant la publication du Corpus et de notre monographie, Antonio Iacobini accepta lui aussi cette hypothèse, tout en remarquant que la reprise de thèmes et de modèles empruntés à l'antiquité avait abouti à une création complètement nouvelle (IACOBINI, 2006, p. 466-467).

Comme on l'a vu plus haut, les thèses de Toubert ont récemment été remises en cause. Romano a réduit à sa juste valeur la portée idéologique du renouveau paléochrétien, et expliqué l'emploi de modèles et de spolia provenant de l'antiquité par la familiarité que les artistes romains avaient avec eux (ROMANO, 2002a ; 2006e, p. 167-168, 174-178). Mais on a surtout remis en question l'hypothèse de Kitzinger. Antonio Braca et Antonio Iacobini ont, de deux points de vue différents, proposé à nouveau de déplacer la datation de la mosaïque de Salerne, et mis en évidence la distance stylistique et chronologique qui la sépare de celle de San Clemente. Selon les thèses de Braca, il faudrait replacer ces mosaïques dans le contexte du byzantinisme des années 1140-1150 (BRACA, 2003). Iacobini pense en revanche que la mosaïque avait été programmée dès le début par Alfan, mais que sa mort et celle de Robert Guiscard, survenues la même année (1085), imposèrent un changement qui conduisit à " traduire le projet d'origine en termes d'économie accrue ", c'est-à-dire en peinture. Les travaux auraient été confiés au chantier sicilien de Monreale, qui réalisa les décorations en utilisant les fresques comme dessins préparatoires, dans les années précédant 1190 (IACOBINI, 2005). Toutefois, selon les conclusions de Iacobini, même si la mosaïque de Salerne n'avait pas été réalisée par des artisans du mont Cassin, elle reflèterait une conception imprégnée des schémas antiquisants des réformateurs, car elle en calquait le programme peint. Le lien entre le mont Cassin et Rome tiendrait donc encore, au moins en ce qui concerne l'élaboration 
des thèmes iconographiques, mais aussi en raison de certains signes évidents de la présence d'un scriptor de culture grecque ou originaire du mont Cassin, qui traça d'une écriture «à la grecque " les inscriptions de l'arc et de la calotte (RICCIONI, 2007a).

Pour passer à d'autres thèmes, Werner Telesko a mis en évidence la confluence, dans la mosaïque de San Clemente, de nombreuses traditions différentes, à commencer par l'influence de Pierre Damien, sur le fondement d'une idée centrale : la transposition en formes monumentales des croix reliquaires ottoniennes (TELESKO, 1994). L'analyse proposée par JeanClaude Bonne a quant à elle précisé le thème de l'ornementation, entendue comme " mode " de traitement esthétique des images, qui fait évoluer dans un sens fonctionnel ses « modalités esthétiques " (BONNE, 1997). Les travaux de Thümmel avaient reposé la question de la diversité stylistique de la décoration, bien que la justification adoptée par le chercheur, qui suggérait l'insertion de parties d'une mosaïque plus ancienne, réutilisées comme spolia dans la décoration actuelle (THÜMMEL, 2002), ne soit plus acceptable à la lumière des examens techniques effectués par l'Istituto Centrale del Restauro à l'occasion des restaurations ; ces examens ont en effet relevé la présence de deux groupes de mosaïstes, qui travaillèrent de manière unitaire en partant du sommet de l'arc et en descendant vers le bas, le travail étant séparé entre la droite et la gauche, aussi bien sur l'arc que sur la calotte absidale (BASILE, 2000 ; RICCIONI, 2006).

Enfin, nous avons consacré à la mosaïque une monographie qui part des thèses de Toubert, mais qui propose une approche interprétative différente. L'examen conjoint des textes et des images a révélé la présence d'un schéma narratif inspiré des techniques de la rhétorique, telle qu'on l'enseignait dans les écoles monastiques, qu'on la synthétisait dans la mnémotechnique et qu'on l'appliquait à l'écriture des livres. Les images et les textes, fondés sur les écrits de Pierre Damien et de Bruno de Segni, furent organisés selon une série de procédés visuels et graphiques qui guidaient la lecture des images et des sujets qui leur étaient liés, séparés en fonction d'une sorte de hiérarchie thématique entre l'arc absidal et la calotte. Les thèses de Toubert, bien qu'en partie toujours valables, ont été précisées dans le sens de la valeur idéologique et narrative du choix des thèmes iconographiques, non plus reconductibles à une vague reprise formelle d'images empruntées à l'antiquité, mais sélectionnées et organisées de manière originale. Le programme iconographique glorifie en effet l'Église des origines, sous la direction de l'Église romaine réformée, telle que représentée sur l'arc absidal, et confère aux chanoines réformés un rôle de conduite des fidèles, évident sur les images de la calotte. Les différents registres d'organisation de la composition, que nous jugeons comparables au fonctionnement d'une machina cognitiva se prévalant aussi d'un usage savant de la couleur (RICCIONI, sous presse a-b), y sont interprétés comme une invitation à l'ascèse, à la lutte entre le bien et le mal, et au refus de la mondanité ; tous ces thèmes s'adressaient aux chanoines réformés, à travers un mécanisme rhétorique sélectionnant les idiotze et les litterati. Le rôle assigné aux inscriptions et son examen ont été considérés comme la partie la plus stimulante de l'ouvrage, mais ils ont aussi fait l'objet de débats (voir RICCIONI, 2006). Il s'agit d'un projet sophistiqué, élaboré sous le pontificat de Pascal II, qui impliqua des artistes et des intellectuels - par exemple Léon d'Ostie provenant du milieu campanien du mont Cassin ou romains ; il eut aussi des conséquences sur l'ensemble de la reconstruction de l'église, y compris les bâtiments édifiés pour accueillir les chanoines réformés, dont la datation devrait se situer avant 1118, comme l'avait suggéré Barclay Lloyd, suivie par Claussen, à propos de la consécration de l'église (BARCLAY LLOYD, 1989, 2005, p. 43-51 ; CLAUSSEN, 2002, p. 303). Ces positions ont également été reprises par Croisier, dans sa notice du Corpus (CROISIER, 2006b), et par Kessler (KESSLER, 2007a). En ce qui concerne la datation de la mosaïque, et son appartenance à la culture de Pascal II, des opinions 
favorables ont été exprimées par Alessio Monciatti (MONCIATTI, 2007, p. 56), Quintavalle, qui est même favorable à une date encore plus ancienne, autour de 1110 (QUINTAVALLE, 2008, p. 149 ; 2009, p. 409, 437, note 41) et Boskovits (BosKOvITS, 2010, p. 9).

\section{Santa Maria in Trastevere}

La mosaïque de Santa Maria in Trastevere constitue l'apogée de la "poétique " grégorienne, mais aussi son chant du cygne (fig. 12). Les changements intervenus dans la situation politique et les premières affirmations de l'Église modifièrent en effet les stratégies artistiques de la papauté, qui prenait ses distances envers les idéaux des premiers réformateurs.

En 1130, à la mort d'Honorius II (1124-1130), Gregorio Papareschi fut élu pape sous le nom d'Innocent II (1130-1143), tandis que son opposant, Pietro Pierleoni, était élu antipape sous le nom d'Innocent II. Ce dernier contraignit le pape légitime à s'enfuir et il gouverna Rome jusqu'en 1138, l'année de sa mort. Le lien étroit unissant la famille Pierleoni au quartier du Trastevere ainsi que le passé de Pietro Pierleoni, qui y avait été cardinal de l'église Santa Maria, ont conduit des chercheurs, parmi lesquels Krautheimer, à lui attribuer les premiers travaux de restructuration de l'édifice (KRAUTHEIMER, 1980, p. 163). Les études de Kinney ont cependant fait apparaître des sources documentaires indiquant qu'Innocent II fut l'initiateur de la reconstruction de l'église (Liber pontificalis et Liber politicus de Benedetto Canonico), achevée en 1148 (KINNEY, 1975, p. 215-216). Lorsque, en 1139, Innocent II - membre de la famille des Papareschi, c'est-à-dire de l'autre puissante famille romaine elle aussi établie dans le Trastevere - reprit possession de la ville, il voulut faire établir par le deuxième concile du Latran la damnatio memorix de l'antipape, et rendre nuls tous les actes promulgués par ce dernier.

12. Mosaïque de la calotte absidiale et arc de triomphe, vers 1143, Rome, Santa Maria in Trastevere.

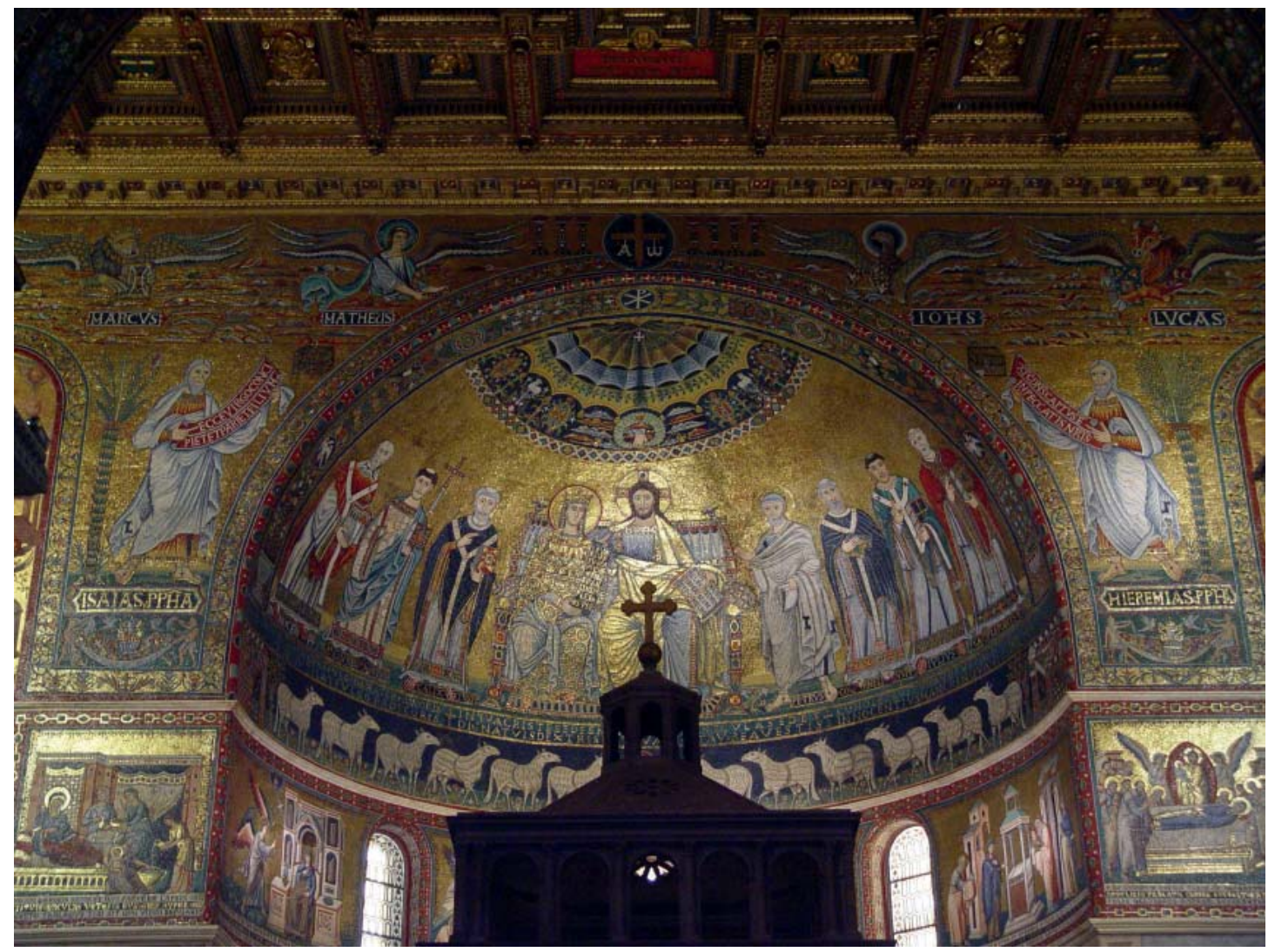


On ne peut donc pas exclure l'hypothèse selon laquelle Anaclet II aurait été le promoteur et l'initiateur des premiers travaux de restauration, mais en l'absence de sources allant dans ce sens, la critique a préféré s'en tenir à ce que l'évidence des documents - dont toute mention d'Anaclet est absente - et des persistances architectoniques et artistiques nous indique (PARLATO, ROMANO, [1992] 2001, p. 60-75). On n'a publié ces derniers temps aucune étude spécifiquement consacrée à la mosaïque de Santa Maria in Trastevere, dont l'interprétation gravite en substance autour de la bibliographie des trente dernières années, mentionnée dans les notices de Romano (PARlato, Romano, [1992] 2001, p. 69-74) et de Croisier (CROISIER, 2006f).

Cette mosaïque montre une iconographie inédite du Christ et de la Vierge Marie, assis sur le synthronum et tenant respectivement à la main un codex et un rouleau tous deux recouverts d'écriture. Sur les deux côtés, on voit une théorie de saints et Innocent II offrant le modèle réduit de l'église. La calotte absidale a pour thème Marie sponsa du Christ, et donc l'union de Jésus et de l'Église. L'hypothèse d'Émile Mâle (MÂLE, 1953, p. 182 et suiv.), confirmée par Matthiae (MATTHIAE, 1965-1966, p. 305-314), selon laquelle l'iconographie aurait des origines françaises, en particulier dans le vitrail perdu offert à Notre-Dame de Paris par Suger, avec qui Innocent II fut souvent en contact, ne peut plus être retenue depuis les études de Verdier (VERDIER, 1976, p. $227-236 ; 1980$, p. 40 et suiv.). Car il est désormais acquis que sur ce vitrail, le triomphe de Marie prenait simplement la forme du couronnement de la Vierge, et non pas de son intronisation.

Kinney a mis en évidence la principale signification de la mosaïque, conçue comme une glorification de l'Église romaine, à travers l'identification de la sponsa du Cantique des cantiques avec la Vierge et l'Ecclesia, comme l'attestent les textes exégétiques. L'assimilation de l'Église romaine et de la basilique Santa Maria in Trastevere est réaffirmée par la présence, sur la calotte, de saints qui sont tous, d'une manière ou d'une autre, liés à l'église et au quartier du Trastevere (KINNEY, 1975). Par la suite, Ursula Nilgen a fait ressortir la forte valeur politique de la composition (NILGEN, 1981). Selon la chercheuse, les travaux furent commencés par Anaclet II, qui aurait prévu de faire représenter la Madone de Miséricorde, au centre de la cuvette de l'abside, sous l'aspect de la reine des cieux ; ces hypothèses furent acceptées par Gandolfo et Herklotz (MATTHIAE, GANDOLFO, 1988, p. 267 ; HERKLOTZ, 2000, p. 151). Anaclet II avait en effet beaucoup de dévotion pour cette icône, au point de l'utiliser comme une sorte de manifeste politique dans la décoration de la chapelle San Nicola, au palais du Latran. Selon Nilgen, l'avènement d'Innocent II conduisit à la mise à l'écart de ce culte et à son remplacement, y compris d'un point de vue iconographique, par le thème de l'intronisation. On aurait ainsi voulu souligner le parallélisme entre l'image du Christ et celle du pape, qui, pendant les cérémonies liturgiques, était assis au centre de l'abside (NILGEN, 1981, p. 1-33; 1996, p. 162-163).

De son côté, Kitzinger a suggéré que l'étreinte des deux personnages sur le trône serait le reflet de la liturgie du 15 août, et plus précisément de la station durant laquelle l'Acheropita-l'icône du Christ conservée dans le Sancta sanctorum - faisait face à l'église Santa Maria Nova en même temps que l'Hodighitria conservée dans cette même église. Durant cette rencontre, les fidèles entonnaient le chant Maria quid est?, tiré du Cantique des cantiques, et qui se trouve inscrit, sous forme de dialogue, sur le rouleau et le codex respectivement tenus à la main par la Vierge et le Christ. Kitzinger pensait, en outre, que le visage de ce dernier était une copie de l'Acheropita du Latran, et que celui de Marie reproduisait l'icône de Santa Maria Nova : autant de reprises témoignant d'un goût antiquisant que le chercheur baptisa du nom d' " antiquarianism ». En ce qui concerne le Christ, l'hypothèse selon laquelle il constituerait une citation déclarée de l'icône du Sauveur conservée dans le Sancta sanctorum (KITZINGER, 1980 ; BELTING, [1991] 2001, p. 387-403 ; ANDALORO, ROMANO, [2000] 2002b, p. 93 ; PARLATO, 2002, p. 65) apparaît de plus en plus convaincante. 
La question que pose le visage de Marie reste en revanche plus controversée ; Boskovits a suggéré qu'il s'agirait d'un remaniement effectué par Cavallini, mais cette hypothèse ne semble plus acceptable depuis la restauration de la mosaïque, en 1991-1992 (TIBERIA, 1999, p. 209-212 ; VERITÀ, 2000, p. 56). Tout en acceptant les thèses de Kitzinger, Tronzo considère cependant que le visage de la Vierge est celui de la Madone Tempuli, qui, de même que celle de la mosaïque, est une advocata (TRONZO, 1989, p. 173) ; cette hypothèse a récemment été acceptée, en raison du geste d'intercession de Marie, par Enrico Parlato et par Romano ${ }^{22}$ (ANDALORO, ROMANO, [2000] 2002b, p. 92 ; PARLATO, 2000, p. 61-64). Gerhard Wolf en revanche a suggéré qu'elle aurait pour modèle la Madone de Miséricorde et observé la volonté de la présenter sous l'aspect d'une reine (WOLF, 1990, p. 184, 298, note 445) ; nous avons repris cette hypothèse lors d'un récent examen de la mosaïque (RICCIONI, 2009 ; sous presse b). Il semble en revanche qu'on doive exclure que l'icône de Santa Maria Maggiore, qui attendait l'image du Christ en l'église de l'Aventin (BELTiNG, [1991] 2001, p. 401) ait participé à la procession. Cependant, une opinion assez répandue veut qu'au cours de la procession, l'Acheropita ait rencontré diverses icônes mariales (PARLATO, 2002, p. 66). Plus récemment, Romano a rappelé que la pratique consistant à utiliser les icônes de la ville pour attribuer à la Vierge une physionomie familière était courante (ROMANO, sous presse).

Kinney est par la suite revenu sur la mosaïque dans le cadre d'un livre de miscellanées offert à Ilene H. Forsyth, où elle a abordé la manière de "voir " et de "lire " l'œuvre en distinguant deux axes d'interprétation, l'un vertical et l'autre horizontal, à l'intérieur desquels s'articulent les thèmes figuratifs, les gestes et les inscriptions (KINNEY, 2002). Dans son ensemble, l'examen de l'œuvre offre des intuitions et des images que nous avons en partie acceptées dans un travail d'analyse de la mosaïque, qui fait jouer aux modalités de composition liées à la disposition et au texte des inscriptions, ainsi qu'à l'utilisation de la couleur, le rôle de guide de l'interprétation et de la symbolique des images (RICCIONI, 2009, sous presse a-b). Cette recherche a fait apparaître, outre l'importance des thèses de Bernard de Clairvaux, le rôle des écrits ecclésiologiques de Bruno de Segni. L'œuvre se prête donc à de multiples lectures, organisées selon un schéma semblable à celui de la mosaïque de San Clemente, mais adapté aux nouvelles exigences de l'Église " triomphante ».

\section{La peinture romaine aux portes de Rome}

Pour conclure, il faut signaler quelques travaux récents traitant de la décoration monumentale hors de la ville de Rome, car elle lui est liée pour des raisons historiques, et d'affinités stylistiques et programmatiques. Sur les monuments du Latium, l'ouvrage de Romano, Roma e il Lazio. Il Romanico, dont il existe une nouvelle édition mise à jour, reste un guide fondamental (PARLATO, ROMANO, [1992] 2001). Les documents picturaux conservés à Rome et dans sa région y sont subdivisés en notices importantes ou courtes, accompagnées d'une bibliographie toujours d'actualité. Signalons en particulier le cas de l'église de l'Immacolata de Ceri (fig. 13) dont les peintures furent découvertes en 1973 (PREMOLI, 1975-1976) et publiées par Antonio Cadei, qui les datait de 1160-1170 (CADEI, 1982), suivi en cela par Toubert (TOUBERT, 1990, p. 450). Par la suite, Zchomelidse (ZCHOMELIDSE, 1996) a étudié le cycle et précisé sa datation, qu'il situait à l'époque du cardinalat de Pietro, évêque de Porto (1102-1133/34) ; Romano a quant à elle accepté la suggestion de Gandolfo (MATTHIAE, GANDOLFO, 1988, p. 256) consistant à considérer les peintures comme une déclinaison des fresques de San Clemente, au sein d'une tradition dont le parcours commence avec cette église romaine pour se poursuivre, hors de la ville, avec les églises San Pietro, à Tuscania, San Biagio, à Nepi, et Sant'Anastasio, à Castel Sant'Elia (PARLATO, ROMANO, [1992] 2001, p. 159-165). Le cycle, qui dérive clairement du prototype de la basilique Saint-Pierre du Vatican, 
doit être replacé dans le contexte de la réforme et revêt beaucoup d'importance pour la compréhension de la diffusion des thèmes et des styles liés à Rome. Kessler a mentionné à plusieurs reprises ces peintures : il a suggéré d'en avancer la datation et de les rapprocher de celles de San Clemente, datées, avant le Corpus, des environs de 1090, et en tout cas aux alentours du passage au XII ${ }^{\mathrm{e}}$ siècle (KESSLER, 2002 a, p. 56 ; 2007a, p. 29 , note 28$)$; nous avons signalé certains éléments graphiques

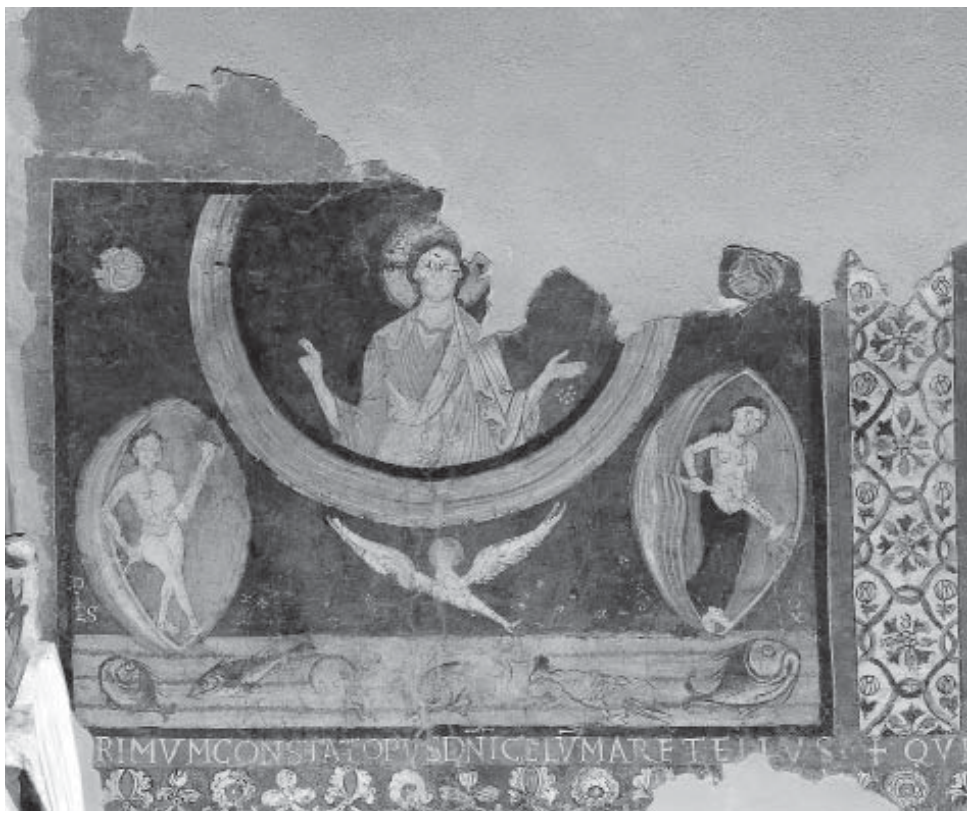
des inscriptions à mettre en relation avec les manuscrits produits au mont Cassin au cours du $\mathrm{XI}^{\mathrm{e}}$ siècle. Enfin, à la suite des recherches exposées dans le Corpus, Romano a précisé leurs liens avec l'église San Pietro de Tuscania et surtout avec les peintures de l'église inférieure de San Clemente ; elle a aussi suggéré une datation située au moment de la conclusion de la crise ouverte par l'antipape Guibert et de la réorganisation de la Curie opérée par Pascal II (ROMANO, 2006b, p. 31), par conséquent durant les vingt premières années du XII siècle, voire un peu avant (ROMANO, sous presse).

Concernant l'église San Pietro de Tuscania, la suggestion de Gandolfo (MATTHIAE, GANDOLFO, 1988, p. 256-258), qui consiste à mettre en rapport les peintures de l'abside et de la nef droite représentant des épisodes de la vie des apôtres avec la date inscrite sur le ciboire (1093), a été reprise par Romano (PARLATO, ROMANO, [1992] 2001, p. 187 ; ROMANO, 2006b, p. 31) et récemment réaffirmée par Boskovits (BOSKOVITS, 2010, p. 12) ; signalons en outre, toujours à propos de ces mêmes peintures, la thèse de doctorat de Tagliaferri (TAGLIAFERRI, 2004-2005). Le cycle de l'église Sant'Anastasio, à Castel Sant'Elia, qu'il faut lui aussi replacer dans le contexte de la peinture romaine, doit être daté, selon Peter Hoegger, auteur d'une monographie sur le sujet, du premier quart du XII ${ }^{e}$ siècle (HOEGGER, 1975). Les thèses du chercheur ont été confirmées par Romano, qui a précisé la datation des œuvres (première ou seconde décennie du XII ${ }^{e}$ siècle) et pris aussi en considération les inscriptions, en particulier celles, nombreuses, qui mentionnent l'abbé Bovone (PARLATO, ROMANO, [1992] 2001, p. 167-178). À propos de ces mêmes inscriptions, y compris celles peintes sur la calotte, on peut en outre se référer aux notices de Luisa Miglio (MIGLIO, 2002) publiées dans le premier volume des Inscriptiones Medii Aevi Italix, publié par le Centro Italiano di Studi sull'Alto Medioevo de Spolète ; sur la base d'une analyse paléographique, la chercheuse situe elle aussi la datation des peintures avant les années 1130 (MIGLIO, 2002, p. 32). Enfin, Suckale, lui aussi sur le fondement de l'examen des tituli, considère qu'on ne peut pas situer la datation des peintures avant 1100 (SUCKALE, 2002, p. 27). Lors du congrès de Lausanne, Delia Kottmann, tout en tenant compte des études précédentes, y compris celles relatives à l'architecture et aux inscriptions, s'est attardée sur l'examen de l'iconographie du cycle
13. Création du ciel et de la terre, vers 1100 , Ceri, église de I'Immacolata. 
apocalyptique, suivant le schéma de classification suggéré par Peter Klein (KLEIN, 1992 ; KLein, LAUfNeR, FrANZ, 2001). Ce cycle, qui constitue un unicum dans le panorama de la peinture romaine et latiale, du moins si l'on s'en tient aux ouvres conservées, montre selon la chercheuse des analogies avec certaines miniatures, en particulier les illustrations de la Bible de Roda, et on peut l'insérer dans le troisième groupe du schéma de Klein (KotTMAnN, 2007). Il faut enfin mentionner la thèse de doctorat soutenue par Alison Locke-Perchuk consacrée à l'ensemble du complexe architectural de Castel Sant'Elia (LOCKE-PERCHUK, 2009). Au même congrès de Lausanne, Piazza a présenté quelques exemples de peintures rupestres conservées à Bolsena, Vallepietra, Magliano Romano et Alatri, renconductibles, selon le chercheur, aux orientations idéologiques et thématiques qui marquèrent l'art des réformateurs romains (PIAZZA, 2007) ; sa recherche s'insère dans le cadre plus vaste d'un travail qui traite des phénomènes religieux ayant influencé les décorations de sites rupestres réalisées, entre le $\mathrm{VI}^{\mathrm{e}}$ et le XIII ${ }^{\mathrm{e}}$ siècle, en Italie centrale (PIAZZA, 2006). À ce sujet, du moins pour la partie consacrée à la réforme, Russo est lui aussi intervenu pour faire remarquer la façon dont le phénomène des peintures rupestres s'intègre à une conjoncture artistique marquée par une forte demande ecclésiastique, durant le mouvement de réforme de l'Église, et par la médiation des Bénédictins. Il s'agit, selon Russo, d'une " communication orientée " qui, prenant en compte la définition d' « art dirigé " offerte par Toubert, investit toute la culture figurative, selon un processus de plus vaste portée que le chercheur définit comme " l'ecclésiologie déployée " par la papauté romaine, à travers des entreprises d'ordre monumental, visuel et scriptural (RUsso, 2007, p. 64). Concernant Magliano Romano, signalons l'Appendice de Romano, dans le volume Roma e il Lazio (PARLATO, ROMANO, [1992] 2001, p. 322-323), et l'article de Simona Moretti (MORETTI, 2003-2004), qui situent la datation des peintures dans la première moitié du XII ${ }^{e}$ siècle, en relation avec le cycle de l'oratoire de Santa Pudenziana et avec les peintures de Ceri.

Les travaux d'Enckell Julliard sur l'église abbatiale de Farfa, et en particulier sur les peintures de la "tour-clocher " représentant le Cycle de Job, l'Ascension, jointe à l'épisode de la Traditio legis, et l'Adoration du phénix, a permis d'intégrer ces témoignages aux premiers développements artistiques liés à la réforme de l'Église et à l'influence des mœurs monastiques, d'inspiration clunisienne, adoptés par l'abbaye. Ces peintures, que Enckell date des alentours de 1060 et qu'elle rapproche des cycles de San Crisogono et de Sant'Andrea al Celio, furent conditionnées par le renouvellement des pratiques liturgiques dictées par Cluny, et donc orientées, conformément aux exigences monastiques, vers une évocation visuelle de la vie claustrale et de la rédemption finale après la mort. Dans l'histoire de la réforme et des mouvements artistiques qui lui sont liés, Farfa se présente donc comme une sorte de croisée des chemins, car, bien que placée sous le protectorat de l'Empire germanique, elle joua un rôle important pour la réforme ecclésiastique en raison de ses liens avec la Toscane de la dynastie de Lorraine et avec l'abbaye du mont Cassin de l'époque de Didier (ROMANO, ENCKELl JULLIARD, 2007 ; ENCKELL JULLIARD, 2008).

Un autre cycle souvent cité comme expression de l'art lié à la réforme est celui de Sant'Angelo in formis, traditionnellement considéré comme la réplique du modèle perdu des décorations de l'abbaye du mont Cassin. Speciale est revenue sur le sujet dans plusieurs publications récentes; elle y a traité des restaurations (SPECIALE, 2003, 2006) et mis en lumière l'anthologie épigraphique composée pour l'abbaye du mont Cassin, qui permet de reconstituer l'iconographie perdue des mosaïques et des peintures, lesquelles se trouvaient, selon la chercheuse, à l'intérieur de l'église et non pas du vestibule (SPECIALE, 2009a). 
Il s'agit de vers qui, toujours selon la chercheuse, ne furent pas créés par le seul Alfan de Salerne, mais par plusieurs auteurs de "prestige spirituel reconnu " (SPECIALE, 2009a, p. 148), comme le montre aussi le distique demandé à Pierre Damien pour les peintures du premier réfectoire du mont Cassin, que Speciale a tiré de l'oubli. On retrouve également cette attention et cette méthode, telles que définies par la chercheuse, dans les nombreuses inscriptions de Sant'Angelo in formis, qui refléteraient donc une programmation bien vivante au mont Cassin, sollicitée aussi par le renouvellement de la liturgie chantée, laquelle servait de médiatrice au message écrit et qu'on retrouve mise en œuvre dans les rouleaux d'exultet. Quintavalle aussi est revenu aux peintures de Sant'Angelo in formis, et il a formulé quelques observations relatives à la Crucifixion, qui montre un Christ triumphans entouré des Marie, de la Madone et de Saint Jean, où apparaissent plusieurs points de contact avec la Croix de Rosano "aussi bien dans les choix d'écriture picturale que dans la structure générale " (QuintAVALLE, 2008, p. 150). Surtout, Quintavalle a réaffirmé l'hypothèse de l'existence, même au mont Cassin, d'un cycle peint dont on trouve l'écho dans l'exultet et qui fut repris à Sant'Angelo in formis.

Signalons enfin que Boskovits a indiqué une autre voie de diffusion possible des caractéristiques de la peinture romaine et perçu, dans les bustes des personnages masculins de la petite nef sud de la Cappella Palatina de Palerme, un lien de parenté étroit avec la production picturale romaine du XII siècle (BosKoviTs, 2008, p. 408).

Le thème de la présence d'un art "réformé " en dehors du territoire de l'Église de Rome est désormais souvent abordé par la critique : il est donc impossible de prétendre à l'exhaustivité dans le cadre de cet article. Outre les publications déjà mentionnées à propos de Bibles atlantiques, il suffira de citer ici les expositions sur Mathilde de Canossa (Canossa 1077..., 2006 ; Matilde di Canossa..., 2008 ; Matilde e il tesoro..., 2008) celles de Lucques (Lucca e l'Europa..., 2010) et du Vatican/Compostelle (Compostela e l'Europa..., 2010) et les travaux récents de Quintavalle (QuinTAVALLE, 2003b, 2008, 2010), de Russo (Russo, 2005), de Speciale (SPECIALE, 2007a) et de Dorothy Glass (GLASS, 2008).

Dans ce contexte, et plus près du sujet de la peinture romaine, la publication des résultats de la restauration de la croix de Rosano (CiATti, Frosinini, Bellucci, 2007 ; fig. 14) et le congrès organisé au Kunsthistorisches Institut de Florence en 2009, sur le thème La pittura su tavola del XII secolo (Frosinini, MONCIATTI, WOLF, sous presse), dont on peut lire le compte rendu publié par Tagliaferri (TAGLIAFERRI, 2009), ont permis d'ajouter une nouvelle œuvre au Corpus de la peinture romaine, et en outre de réfléchir aux liens entre l'art de Rome et le contexte " européen". S'opposant à l'hypothèse rattachant l'auteur de la croix de Rosano au milieu toscan (Boskovits, 1993, p. 206-217), Monciatti, pour ce qui concerne la culture figurative (MONCIATTI, 2007), Tommaso Gramigni et

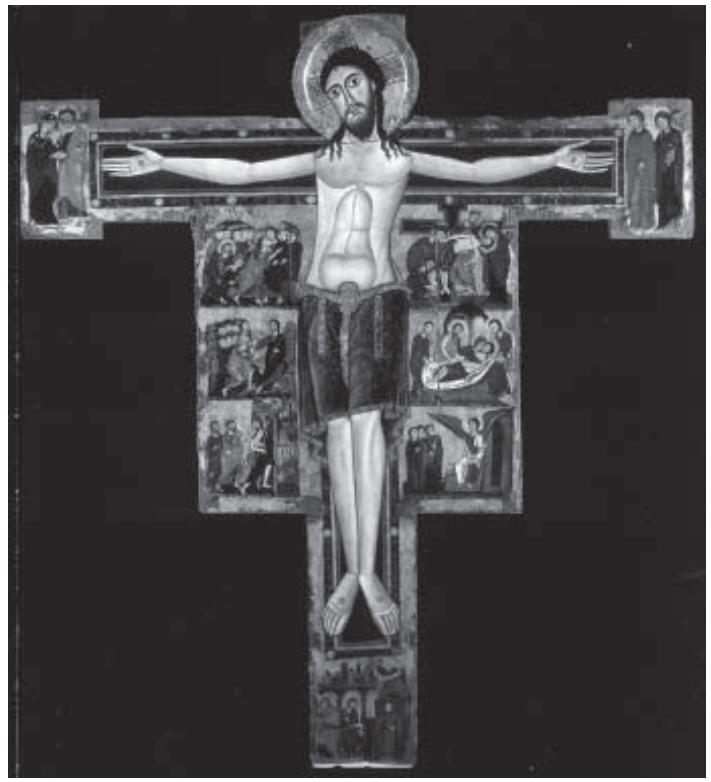

14. Crucifixion vers 1129 , Rosano, abbaye Santa Maria Assunta. 
Stefano Zampogni, pour les aspects paléographiques (GRAMIGNI, ZAMPONI, 2007), et dans un ample panorama de mises en relation graphiques et culturels (RICCIONI, sous presse a), ont jugé l'œuvre reconductible au territoire " romain "; sa datation reste en revanche fixée en 1129, année de la consécration de l'église Santa Maria Assunta de Rosano, placée sous le patronage des comtes Guidi.

Les aspects les plus importants mis en relief par ces études sont l'appartenance de la croix au mouvement culturel de la réforme de l'Église, aux XI ${ }^{\mathrm{e}}$ et XII ${ }^{\mathrm{e}}$ siècles, et les points de contact avec le milieu des réformateurs romains. Ces hypothèses ont ouvert un intéressant débat, qui met aussi en jeu les méthodes de l'histoire de l'art. Elles ont été contestées par Angelo Tartuferi (TARTUFERI, 2009), qui, pour des raisons stylistiques, rattache la croix à un milieu arétin des origines et la date du dernier quart du XII siècle, et, au cours du congrès, par Miklos Boskovits (Boskovits, sous presse), qui, pour les mêmes motifs, a rejeté l'idée d'une appartenance de la croix au milieu romain ; elles ont en revanche été accueillies favorablement par Quintavalle, qui perçoit " une identité de modèles culturels " ayant imprégné les mosaïques et les fresques du mont Cassin, puis les peintures de Sant'Angelo in formis, et enfin la croix de Rosano (QUiNTAVALLE, 2008, p. 152). Un élément particulièrement intéressant concerne aussi l'insertion du panneau dans une perspective de recherche embrassant le contexte plus large de l'art européen de la réforme. Le panneau semble en effet être le produit d'une convergence culturelle d'esprit clairement "réformé ", conformément aux principes partagés aussi hors de Rome (KESSLER, sous presse ; RICCIONI, sous presse c) ; car les vers inscrits sur la croix sont tirés d'œuvres d'auteurs comme Baldéric de Bourgueil. Cet écrivain, qui appartenait au cercle de la Loire, fut aussi l'auteur des tituli accompagnant la crucifixion représentée sur le manuscrit de Verdun, que Kessler a suggéré de mettre en relation avec la croix de Rosano, en soulignant l'influence de la culture française sur la réforme grégorienne (KESSLER, sous presse). Il s'agit d'un parcours qui trouve dans les études sur la réforme en France une correspondance déjà remarquée à propos de peintures de Berzéla-ville, dont l'iconographie avait été caractérisée par Éric Palazzo comme fortement liée à l'Église réformée de Rome, à travers le choix des saints représentés - les reliques de certains d'entre eux se trouvaient en effet à Cluny - (PALAzzo, 1998), et dont Russo a précisé les aspects ecclésiologiques (RUSSO, 2000). Enfin, plus récemment, Romano a attiré l'attention sur certains liens unissant le mont Cassin, Rome et la France, par le biais des événements liés aux reliques de saint Benoît et de saint Maur. Les vicissitudes biographiques de ce dernier, représentées dans des cycles peints et enluminés entre Rome et le mont Cassin, pour la partie " italienne " de son existence, continuèrent avec une « vie " en France racontée par Odon de Glanfeil. Les reliques de saint Maur furent en effet envoyées au mont Cassin par Odilon de Cluny en 1034 ; en outre, le Lectionnaire 1202, préparé pour la consécration du mont Cassin de l'année 1071, intègre la partie française de la biographie de saint Maur. Selon la chercheuse, il faut donc établir un rapport entre la reprise de son culte et le déroulement de la réforme ecclésiastique, en étroite relation avec les milieux clunisiens (ROMANO, 2007).

Enfin pour terminer sur un point de vue européen, on ne peut taire les liens unissant le mouvement des réformateurs romains à Cluny, évoqués à plusieurs reprises dans les études passées et aujourd'hui au centre de l'attention de la critique (CONSTABLE, 2010), grâce au cycle de congrès organisés pour la célébration des mille cent ans de la fondation de la célèbre abbaye. À propos de ces initiatives, on peut consulter le projet publié dans le Bulletin du Centre d'études médiévales d'Auxerre (BUCEMA, 2009) ; s'agissant de travaux en cours, on renverra à leur conclusion et à la publication des actes. 


\section{Notes}

Je voudrais remercier tous ceux, amis et collègues, qui, à des titres divers, m'ont fourni des articles, des informations, des indications de travaux parfois non encore publiés, des conseils et des précisions : autant de témoignages de l'esprit de collaboration d'un milieu scientifique passionné, parfois polémique, mais tendant au fond toutes ses forces vers l'objectif commun de la compréhension des phénomènes culturels. Ma plus sincère reconnaissance, également, à Maria Ferroni, pour son soutien fondamental.

1. Par l'expression " réforme grégorienne ", l'historiographie désigne le processus complexe de changements institutionnels, religieux et politiques, qui marqua l'histoire de l'Église d'Occident à partir de la seconde moitié du XI ${ }^{\mathrm{e}}$ siècle. On dispose d'une vaste bibliographie sur la réforme de l'Église. Bien que dépassée par les orientations récentes de l'historiographie, l'étude de FLICHE, 1977 reste très utile. Il faut y ajouter au moins TELLENBACH, 1936 ; VIOLANTE, 1965 ; MICCOLI, 1966 ; LADNER, 1967 ; COWDREY, 1970, 1983, 1998, 2000 ; STICKLER éd., 19701991 ; MORGHEN, 1974 ; LADNER, 1983 ; CAPITANI, 1986-1988, 1990 ; STROLL, 1987, 1991, 1997, 2004 ; FORNASARI, 1996 ; GOEZ, 2000 ; TABACCO, 2004 ; CANTARELLA 2005 ; SCHIEFFER 2008. Pour les études antérieures à 1970, on peut se référer à la bibliographie raisonnée de GHIRARDINI, 1970. Sur l'histoire de Rome, les ouvrages de référence indispensables sont les travaux classiques de GREGOROVIUS, (1886) 1973 ; HOMO, 1934 ; BREZZI, 1947 ; KRAUTHEIMER, 1981, et, plus récemment, HUBERT, 1990 ; DELOGU, 1998 ; VAUCHEZ, 2001 ; DI CARPEGNA FALCONIERI, 2002 ; CAROCCI, 2006.

2. Sur ces thèmes, voir, parmi les publications des dix dernières années, ClAUSSEN, 2002, 2006, 2007, 2008. Pour une opinion différente sur des thèmes analogues, GANDOLFO, 2007. En ce qui concerne l'Italie du nord, voir QUINTAVALLE, 2003b ; sur le thème des croix envisagé dans un contexte tenant compte de l'Europe, voir QuINTAVALLE, 2008, 2009. Pour une perspective plus exclusivement européenne, voir GLASS, 2008.

3. Pour une version mise à jour de l'ouvrage de Bertaux, voir Adriano Prandi, Aggiornamento dell'opera di Émile Bertaux sotto la direzione di Adriano Prandi, IV-VII, Rome, 1978.

4. Gandolfo, qui ne connaissait pas la totalité de la décoration, a exprimé sa perplexité quant à une datation en 1049, et suggéré une affinité stylistique avec les fresques provenant de San Nicola in Carcere, da- tables des environs de 1128 ; voir MATTHIAE, GANDOLFO, 1988, p. 253.

5. Sur la production artistique des clunisiens et ses rapports avec la réforme grégorienne, voir, entre autres, COWDREY, 1970 et TOUBERT, 1994.

6. BERGER, 1893, p. 141-142. À propos du texte des Bibles atlantiques, le chercheur fut le premier à y reconnaître une " véritable édition " ; il pensait en particulier au groupe de volumes italiens. Sur le texte de la Vulgate, voir aussi VERCELLONE, 18601864. Plus récemment, LOBRICHON, 2000.

7. Cette hypothèse avait déjà été émise par le passé, notamment TOESCA, 1929, p. 71 ; GARRISON, 1953-1962. Toutefois, FICHTENAU, 1950, et BRIEGER, 1965, s'y opposèrent.

8. L'hypothèse fut acceptée, entre autres, par AYRES, 1994, p. 127, et par BARTOLI LANGELI, 1994, p. 954, qui jugeait " très convaincante l'idée selon laquelle ce centre avait son siège à Rome ".

9. Genève, Bibliothèque publique et universitaire, ms. lat. I.

10. La documentation photographique, réalisée à l'époque et toujours en cours, est en ligne sur le site Internet http://bibbie.cea.unicas.it, qui met à la disposition des chercheurs un large ensemble de matériaux d'étude : la liste des reproductions consultables auprès de l'Université de Cassin, une base de données bibliographiques progressivement mise à jour, ainsi que les recherches (contributions sur l'écriture et la décoration des Bibles, essais et monographies sur les volumes isolés) réalisées dans les années postérieures à l'exposition.

11. Baldericus Burgulianus, De visitatione infirmorum, PL 40, c. 1154. Ce traité a circulé aussi sous le nom d'Augustin et la patrologie latine le mentionne comme une œuvre d'auteur incertain ; pour l'attribution à Baldéric de Bourgueil, voir, entre autres, ARNULF, 1997, p. 276, 279-285 et 298.

12. Bruno Signinus Episcopus, De sacramentis Ecclesix, mysteriis atque ecclesiasticis ritibus, PL, 165, cc. 1089B - 1110A ; Sentantix, I, De figuris ecclesix, PL, 165, cc. 875A - 902B, et Sententix, II, De ornamentis ecclesix, in PL, 165, cc. 901B - 942D.

13. Les œuvres ont été mises en relation en particulier avec le panneau du Vatican, les peintures de San Clemente et le panneau provenant de la chapelle H9 de San Lorenzo fuori le mura.

14. Ces tableaux, réapparus dans les années 1940, et détachés en 1977, ont été datés du VIII ${ }^{\mathrm{e}}$ siècle (MATTHIAE, 1965-1966 ; BER-
TELLI, 1983 ; ANDALORO, 1987) ; seule fait exception une note de John Osborne, qui suggérait une datation située au $\mathrm{XI}^{\mathrm{e}}$ ou au XII ${ }^{\mathrm{e}}$ siècle (OSBORNE, 2004, p. 148).

15. Deux autres signatures antérieures sont visibles à Rome : celle de Saturninus monachus, à Sant'Andrea ad Clivum Scauri (IX ${ }^{\mathrm{e}}$ siècle), et celle de Sergius pictor, à San Saba (X $X^{\mathrm{e}}$ siècle) ; voir BORDI, 2009.

16. REDIG DE CAMPOS, 1935, p. 149-151. Le chercheur situait la datation du panneau, notamment sur la base de l'examen paléographique des inscriptions, dans les années 1080. Pour une datation à la fin du $\mathrm{XI}^{\mathrm{e}}$ siècle : BATARD, 1958. Pour une datation au cœeur du XII ${ }^{\mathrm{e}}$ siècle : AVRIL, 1983 ; MATTHIAE, GANDOLFO, 1988 ; PARLATO-ROMANO, (1992) 2001. Pour une datation au XIII ${ }^{\mathrm{e}}$ siècle : PAESELER, 1938 ; IACOBINI, 1991.

17. Concernant Santa Pudenziana, Croisier situe ses peintures dans les années 11201140 (CROISIER, 2006a), tandis que Trivellone pense qu'il faut les dater du pontificat de Grégoire VII (TRIVELlONE, 2007).

18. Les fouilles les plus récentes effectuées dans l'édifice inférieur n'ont pas non plus fait apparaître de traces de combustion : voir GUIDOBALDI, 1992, p. 227 ; 1997 ; GUIDOBALDI et al., 2004, p. 390-415.

19. Concernant l'inscription de la plaque, l'emploi du terme ecclesiam a poussé Croisier à suivre les indications de Panvinius et Ugonius, qui virent l'inscription dans l'ambon de l'oratoire de San Pastore, autrefois communiquant avec l'espace principal de la basilique et remplacé, au XVI ${ }^{e}$ siècle, par la chapelle Caetani. San Pastore servait de baptistère à l'église et pouvait être considéré comme un édifice autonome (CROISIER, 2006a, p. 203). La question n'est cependant pas résolue : l'auteur de ces lignes juge plausible l'appartenance de la plaque à un autel reliquaire, bien qu'on ne dispose d'aucune preuve qu'il ait été exécuté pour l'oratoire marial, et pense qu'il faut approfondir l'analyse des rapports entre la plaque et l'architrave du portail d'entrée (RICCIONI, 2008, sous presse c).

20. On tendait autrefois à dater le panneau de la période immédiatement postérieure à 1061, année où Alexandre II concéda le monastère à l'abbaye du mont Cassin ; parmi les publications les plus récentes, voir BERTELLI, 1982, p. 293 ; MATTHIAE, GANDOLFO, 1988, p. 251.

21. MARUCCHI, 1956-1957, I, p. 271 ; II, p. 20,178

22. Sur ce sujet, voir aussi WIRTH, 1999, p. 435-441 ; BELTING, (1990) 2001, p. 402. 


\section{Bibliographie}

- ACCONCI, 2006 : Alessandra Acconci, " La decorazione del nartece della basilica pelagiana di San Lorenzo fuori le mura ", dans ROMANO, 2006a, p. 183-187.

- ACCONCI, 2007 : Alessandra Acconci, "Un perduto affresco a S. Lorenzo fuori le Mura. Appunti per la storia della basilica pelagiana nell'XI secolo ", dans ROMANO, ENCKELL JULLIARD, 2007, p. 85-111. - ANDALORO, 2006 : Maria Andaloro éd., La pittura medievale a Roma, 312-1431: Corpus e Atlante, I, L'orizzonte tardoantico e le nuove immagini, 312-468, Milan, 2006.

- ANDALORO, ROMANO, (2000) 2002a : Maria Andaloro, Serena Romano éd., Arte e iconografia a Roma: da Costantino a Cola di Rienzo, (Di fronte e attraverso, 537), Milan, (2000) 2000.

- ANDAlORO, Romano, (2000) 2002b : Maria Andaloro, Serena Romano, "L'immagine nell'abside", dans ANDALORO, ROMANO, (2000) 2002, p. 73-102.

-ANDALORO, ROMANO, 2006 : Maria Andaloro, Serena Romano éd., La pittura medievale a Roma, 312-1431: Corpus e Atlante, 6 vol., Milan, 2006 [CR par John Osborne, dans The Burlington Magazine, 150/1267, 2008, p. 687-688 ; par Xavier Barral i Altet dans Zeitschrift für Kunstgeschichte, 72, 3, 2009, p. 437-442 ; par Beat Brenk, Herbert Leon Kessler, dans Arte medievale, sous presse].

- ARNulf, 1997 : Arwed Arnulf, Versus ad picturas: Studien zur Titulusdichtung als Quellengattung der Kunstgeschichte von der Antike bis zum Hochmittelalter, (Kunstwissenschaftliche Studien, 72), Munich, 1997. - AVRIL, 1983 : François Avril, "Le arti del colore ", dans François Avril, Xavier Barral I Altet, Danielle Gaborit-Chopin éd, Il tempo delle crociate, Milan, 1983, p. 131-224.

- AYREs, 1991 : Larry M. Ayres, "Gregorian Reform and Artistic Renewal in Manuscript Illumination: The 'Biblia Atlantica' as an International Artistic Denomination ", dans Studi Gregoriani, 14, 1991, p. 145-152.

- AYRES, 1994 : Larry M. Ayres, "The Italian Bibles Giant Bibles: aspects of their Touronian ancestry and early history ", dans Richard Gameson éd., The early medieval Bible, (Cambridge Studies in Palaeography and Codicology, 2), Cambridge, 1994, p. 125-154.

- AYRES, 2000 : Larry M. Ayres, «Le Bibbie Atlantiche. Dalla Riforma alla diffusione in Europa ", dans Le Bibbie atlantiche..., 2000, p. 27-37.
-BARCLAY LLOYD, 1989 : Joan Barclay Lloyd, San Clemente miscellany, III, The medieval Church and Canonry of S. Clemente in Rome, Rome, 1989.

-BARCLAY LLOYD, 2005 : Joan Barclay Lloyd, "A New Look at the Mosaic of San Clemente ", dans Anne J. Duggan, Joan Greatrex, Brenda Bolton éd., "Omnia disce ": Medieval Studies in Memory of Leonard Boyle, O.P., Aldershot, 2005, p. 9-27.

- BARTOLI LANGELI, 1994 : Attilio Bartoli Langeli, "Scritture e libri da Alcuino a Gutenberg ", dans Gherardo Ortalli éd., Storia d'Europa, III, Il Medioevo, Turin, 1994, p. 935-983.

- BAsILE, 2000 : Giuseppe Basile, « Il mosaico absidale di S. Clemente a Roma ", dans BORSOOK, GIOFFREDI SUPERBI, PAGLIARULO, 2000, p. 149-155.

-BATARD, 1958 : Yvonne Batard, "Les fresques de Castel S. Elia et le 'Jugement dernier' de la Pinacotèque Vaticane ", dans Cahiers de civilisation médiévale, 1 , 1958, p. 171-178.

- BAXANDALL, 1971 : M. Baxandall, Giotto and the Orators: Humanist Observers of Painting in Italy and the Discovery of Pictorial Composition, 1350-1450, Oxford, 1971.

- Belting, (1990) 2001 : Hans Belting, Il culto delle immagini. Storia dell'icona dall'età imperiale al tardo medioevo, Rome, 2001 [éd. orig. : Bild und Kult: eine Geschichte des Bildes vor dem Zeitalter der Kunst, Munich, 1990 ; trad. fr. : Image et culte : une histoire de l'image avant l'époque de l'art, Paris, 1998].

-BERG, 1965 : Knut Berg, "Notes on some early Giant Bibles ", dans Acta ad archaeologiam et artium historiam pertinentia, 2, 1965, p. 167-176.

-BERG, 1968 : Knut Berg, Studies in Tuscan Twelfth-Century Illumination, Oslo, 1968.

- BERGER, 1893 : Samuel Berger, Histoire de la Vulgate pendant les premiers siècles du Moyen Âge, Paris, 1893.

- BertAuX, 1904 : Émile Bertaux, L'art dans l'Italie méridionale, I, De la fin de l'Empire Romain à la Conquête de Charles d'Anjou, 3 vol., Paris, 1904.

- Bertelli, 1982 : Carlo Bertelli, "San Benedetto e le arti in Roma: Pittura ", dans Atti del VII Congresso internazionale di studi sull'Alto Medioevo, (colloque, Norcia/ Subiaco/Cassino/Montecassino, 1980), I, Spolète, 1982, p. 271-302.

- Bertelli, 1983 : Carlo Bertelli, «Fondazioni medievali dell'arte italiana ", dans Fredericio Zeri éd., Storia dell'arte italiana, II, Dal Medioevo al Quattrocento, Turin, 1983, p. 117-129.
- Bertelli, 1994 : Carlo Bertelli, « La pittura medievale a Roma e nel Lazio ", dans Carlo Bertelli éd., La pittura in Italia: l'Altomedioevo, Milan, 1994, p. 206-242. - Bertelli, GALASsi PALUzzI, 1971 : Carlo Bertelli, Carlo Galassi Paluzzi, Santa Maria in Via Lata: la chiesa inferiore e il problema paolino, (Le chiese di Roma illustrate, 114), Rome, 1971.

- Le Bibbie atlantiche..., 2000 : Le Bibbie atlantiche: il Libro delle Scritture tra monumentalità e rappresentazione, Marilena Maniaci, Giulia Orofino éd., (cat. expo., Cassino, Abbazia di Montecassino/Florence, Biblioteca Medicea Laurenziana, 2000-2001), Milan, 2000.

- BilotTA, sous presse : Maria Alessandra Bilotta, " La Réforme Grégorienne et ses programmes iconographiques : le cas des peintures murales de l'ancien Palais des Papes du Latran à Rome et leur rapport avec l'illustration des Bibles Atlantiques ", dans TOGNI, sous presse.

-BISCHOFF, 1992 : Bernhard Bischoff, Paleografia latina, Padoue, 1992.

-BOECKLER, 1930 : Albert Boeckler, Abendländische Miniaturen bis zum Ausgang der romanischen Zeit, Berlin/Leipzig, 1930. -Bonne, 1997 : Jean-Claude Bonne, «De l'ornement à l'ornementalité. La mosaïque absidale de $\mathrm{S}$. Clemente à Rome ", dans Le rôle de l'ornement dans la peinture murale du Moyen Âge, (colloque, Saint-Lizier, 1995), (Civilisation médiévale, 4), Poitiers, 1997, p. 103-118.

- BORDI, 2006a: Giulia Bordi, « Le figure di sante nella chiesa di Santa Maria in Via Lata ", dans ROMANO, 2006a, p. 37-39.

- BORDI, 2006b : Giulia Bordi, « La vergine in trono con bambino, l'arcangelo e le figure di santi dalla cappella H9 di San Lorenzo fuori le mura ", dans ROMANO, 2006a, p. 40-44.

- BORDI, 2006c : Giulia Bordi, "La decorazione pittorica di due nicchie in Santa Balbina ", dans ROMANO, 2006a, p. 8994.

- BORDI, 2006d : « La decorazione pittorica della basilica inferiore di San Crisogono ", dans ROMANO, 2006a, p. 68-76.

- BORDI, 2006e : Giulia Bordi, "I pannelli staccati con due figure di sante già in Sant'Agnese fuori le mura (Pinacoteca Vaticana) ", dans ROMANO, 2006a, p. 63-65. - BORDI, 2007 : Giulia Bordi, "Crescentius, un infelix pictor dell'VIII secolo? Nuove proposte di datazione per un gruppo di dipinti romani ", dans ROMANO, ENCKELL JULLIARD, 2007, p. 213-246. - BORDI, 2009 : Giulia Bordi, "Un pictor, un magister e un'iscrizione 'enigmatica' 
nella chiesa inferiore di San Saba a Roma nella prima metà del X secolo ", dans Opera Nomina Historiae, Giornale di Cultura artistica, 1, 2009, p. 51-76, revue électronique (http://onh.giornale.sns.it/ numero_1_2009.php).

- BORSOOK, GIOFFREDI SUPERBI, PAGLIARULO, 2000 : Eve Borsook, Fiorella Gioffredi Superbi, Giovanni Pagliarulo éd., Medieval Mosaics: Light, color, materials, (Villa i Tatti, 17), Milan, 2000, p. 149-155. - Boskovits, 1993 : Miklòs Boskovits, A critical and historical corpus of Florentine painting, I, The Origins of Florentine Painting, 1100-1270, Florence, 1993.

- Boskovits, 2008 : Miklòs Boskovits, "A proposito del soffitto della Cappella Palatina di Palermo ", dans Arte Cristiana, 849, 2008, p. 401-412.

- Boskovits, 2010 : Miklòs Boskovits, " Pittura su tavola a Roma nel XII secolo: problemi aperti ", dans Arte cristiana, 856, 2010, p. 5-20.

- Boskovits, sous presse : Miklòs Boskovits, "Pittura su tavola a Roma nel XII secolo ", dans FrosinINI, MONCIATTI, WOLF, sous presse.

- BRACA, 2003 : Antonio Braca, Il Duomo di Salerno: architettura e culture artistiche del Medioevo e dell'età moderna, (Collana di studi storici salernitani, 19) Salerne, 2003.

- BRENK, 1984 : Beat Brenk, "Die Benediktszenen in S.Crisogono und Montecassino ", dans Arte Medievale, 2, 1984, p. 57-65.

- BRENK, 1985 : Beat Brenk, "Roma e Montecassino: gli affreschi della chiesa inferiore di S.Crisogono", dans RACAR, 12/2, 1985, p. 227-234.

- BREZZI, 1947 : Paolo Brezzi, Roma e l'impero medievale, Bologne, 1947.

- BRIEGER, 1965 : Peter H. Brieger, "Bible illustration and Gregorian Reform ", dans Geoffrey John Cuming éd., Studies in Church History, II, Londres/Édimbourg, 1965, p. 154-164.

- BUCEMA, 2009 : "Cluny, 2010. Rencontres internationales", dans Bulletin du Centre d'études médiévales d'Auxerre, 13, 2009, p. 355-367, en ligne sur http:// cem.revues.org/index 11137.html.

- BUChANAN, 2003 : Charles Buchanan, "Evidence of a scriptorium at the reformed canonry of S. Frediano in Lucca", dans Scriptorium, 57/1, 2003, p. 3-26.

- BUCHANAN, 2004 : Charles Buchanan, "Spiritual and spatial authority in medieval Lucca: illuminated manuscripts, stational liturgy and the gregorian reform ", dans Art history, 27/5, 2004, p. $723-744$.
- CADEI, 1982 : Antonio Cadei, «S. Maria immacolata di Ceri e i suoi affreschi medievali ", dans Storia dell'arte, 44, 1982, p. 13-29. - CAHN, (1969) 1982 : Walter Cahn, La Bible romane : chefs-d'auvre de l'enluminure, Fribourg, 1982 [éd. orig : Romanesque Bible Illumination, Oxford, 1969].

- CAMILLE, 1985 : Michael Camille, «Seeing and reading: some visual implications of medieval literacy and illiteracy ", dans Art History, 8/1, 1985, p. 26-49.

- CAMPANA, 1967 : Augusto Campana, «Paleografia oggi: rapporti, problemi e prospettivi di una 'coraggiosa disciplina' ", dans Studi Urbinati, 61, 1967, p. 1013-30. - CAMPANA, 1976 : Augusto Campana, "Le iscrizioni medievali di S. Gemini", dans Umberto Ciotti éd., S. Gemini e Carsulae, Milan, 1976, p. 81-132.

- CAMPANA, 1984 : Augusto Campana, "La testimonianza delle iscrizioni ", dans Wiligelmo e Lanfranco: il duomo di Modena, Modène, 1984, p. 363-373.

- Canossa 1077..., 2006 : Canossa 1077: Erschütterung der Welt; Geschichte, Kunst und Kultur am Aufgang der Romanik, Valentino Pace, Matthias Exner éd., (cat. expo., Padeborn, Museum der Kaiserpfalz, 2006), Munich, 2006.

- CANTARELla, 2005 : Glauco Maria Cantarella, Il sole e la luna: la rivoluzione di Gregorio VII papa, 1073-1085, Bari, 2005.

- CAPITANI, 1959-1961: Ovidio Capitani, «Per la storia dei rapporti tra Gregorio VII e Berengario di Tours", dans Studi gregoriani, 6, 1959-1961, p. 110-145.

- CAPITANI, 1986 : Ovidio Capitani, Storia dell'Italia medievale, 410-1216, Rome/Bari, 1986.

- CAPITANI, 1986-1988 : Ovidio Capitani, "L'età pregregoriana ", dans La storia, $i$ grandi problemi. Il medioevo, I, Turin, 19861988, p. 361-390.

- CAPITANI, 1990 : Ovidio Capitani, Traduzione ed interpretazione. Dialettiche ecclesiologiche del secolo XI, Rome, 1990

- CARMASSI, 2001 : Paola Carmassi, «Die Hochmittelalterlichen Fresken der Unterkirche von San Clemente in Rom als programmatische Selbstdarstellung des Reformpapsttums. Neue Einsichten zur Bestimmung des Entstehungskontexts ", dans Quellen und Forschungen aus italienischen Archiven und Bibliotheken, 81, 2001, p. 1-66. - CAROCCI, 1999 : Sandro Carocci, Il nepotismo nel medioevo: papi cardinali e famiglie nobili, Rome, 1999.

- CAROCCI, 2000 : Sandro Carocci, « Vassalli del papa: note per la storia della feudalità pontificia (secoli XI-XVI) ", dans Giulia Barone, Lidia Capo, Stefano Gasparri éd., Studi sul Medioevo per Girolamo Arnaldi, Rome, 2000, p. 55-90.

- CAROCCI, 2006 : Sandro Carocci éd., La nobiltà romana nel medioevo, (Collection de l'École française de Rome), Rome, 2006.

- CAROCCI, VenditTelli, 2001 : Sandro Carocci, Marco Vendittelli, "Società ed economia (1050-1420)", dans Storia di Roma dall'antichità ad oggi, Bari, 2001, p. 71-116.

- CERRINI, 2000 : Simonetta Cerrini, s.v. " Urbano II ", dans Enciclopedia dei papi, II, Rome, 2000, p. 222-228.

- CIARDI DUPRÉ, 2000 : Maria Grazia Ciardi Dupré, "Le Bibbie atlantiche toscane ", dans MANIACI, OROFINO, 2000, p. 73-79. - CiATti, Frosinini, BelluCCI, 2007 : Marco Ciatti, Cecilia Frosinini, Roberto Bellucci éd., La croce dipinta dell' Abbazia di Rosano: visibile e invisibile; studio e restauro per la comprensione, Florence, 2007.

- Cipollini, 2001 : Francesco Cipollini éd., Bruno di Segni (1048-1123) e la chiesa del suo tempo, (colloque, Segni, 1999), Venafro, 2001.

- Claussen, 2000 : Peter Cornelius Claussen, "Marmo e splendore. Architettura, arredi liturgici, spoliae ", dans ANDALORO, ROMANO, 2000, p. 151-174.

- Claussen, 2002 : Peter Cornelius Claussen, Corpus Cosmatorium, II, 1, Die Kirchen der Stadt Rom im Mittelalter 1050-1300 (A-F), Stuttgart, 2002

- Claussen, 2006 : Peter Cornelius Claussen, "Magistra Latinitatis - Opus romanum: Aspeckte kirchlicher Reform in der Sakralarchitektur und liturgischen Ausstattung in Rom ", dans Canossa 1077..., 2006, I, Essays, p. 297-308.

- Claussen, 2007 : Peter Cornelius Claussen, « Un nuovo campo della storia dell'arte: il secolo XI a Roma », dans ROMANO, ENCKELL JULLIARD, 2007, p. 61-84. - Claussen, 2008 : Peter Cornelius Claussen, "Scultura e splendori del marmo a Roma nell'età della riforma ecclesiastica nell'XI e XII secolo ", dans Matilde e il tesoro..., 2008, p. 202-215.

- Compostela e l'Europa..., 2010 : Compostela e l'Europa: la storia di Diego Gelmírez, Manuel Castiñeiras éd., (cat. expo., Paris, Musée national des monuments français/ Cité du Vatican, Braccio di Carlo Magno/ Compostelle, Mosteiro di San Martiño Pinario, 2010), Milan, 2010.

- Condello, 2005 : Emma Condello, «La Bibbia al tempo della riforma gregoriana: le Bibbie Atlantiche ", dans Paolo Cherubini éd., Forme e modelli della tradizione manoscritta della Bibbia, (Littera antiqua 13), Cité du Vatican, 2005, p. 347-372. 
- Constable, 2010 : Giles Constable, The Abbey of Cluny: A Collection of Essays to Mark the Eleven-Hundredth Anniversary of its Foundation, (Vita regularis, Abhandlungen, 43), Berlin, 2010.

- COWDREY, 1970 : Herbert E. J. Cowdrey, The Cluniacs and the gregorian reform, Oxford, 1970.

- COWDREY, 1972 : Herbert E. J. Cowdrey, The Epistolae vagantes of Pope Gregory VII, Oxford, 1972.

- COWDREY, 1983 : Herbert E. J. Cowdrey, The Age of the Abbot Desiderius: Montecassino the Papacy and the Normans in the Eleventh Twelfth Centuries, Oxford, 1983.

- COWDREY, 1998 : Herbert E. J. Cowdrey, Pope Gregory VII, 1073-1085, Oxford, 1998. - COWDREY, 2000 : Herbert E. J. Cowdrey, Popes and church reform in the $11^{\text {th }}$ century, Aldershot, 2000.

- CROISIER, 2006a : Jérôme Croisier, "La decorazione pittorica dell'Oratorio mariano di Santa Pudenziana ", dans Romano, 2006a, p. 199-206.

- Croisier, 2006b : Jérôme Croisier, " I mosaici dell'abside e dell'arco absidale della chiesa superiore di San Clemente ", dans ROMANO, 2006a, p. 209-218.

- CROISIER, 2006c : Jérôme Croisier, "La perduta decorazione dell'oratorio di $\mathrm{S}$. Nicola al Patriarchio lateranense ", dans ROMANO, 2006a, p. 290-293.

- Croisier, 2006d : Jérôme Croisier, " Il dipinto perduto con l'incoronazione di Lotario III al Patriarchio Lateranense ", dans ROMANO, 2006a, p. 296-297.

- Croisier, 2006e : Jérôme Croisier, " Il perduto dipinto con il prete Boninus in San Salvatore in Onda ", dans ROMANO, 2006a, p. 304.

- Croisier, $2006 f$ : Jérôme Croisier, " I mosaici dell'abside e dell'arco trionfale di Santa Maria in Trastevere ", dans RoMANO, 2006a, p. 305-311.

- DAlli Regoli, 1982 : Gigetta Dalli Regoli, " La miniatura lucchese tra la fine dell'XI e gli inizi del XII secolo: forme di decorazione 'umbro romana' e cultura grafica francese", dans Romanico padano, romanico europeo, (colloque, Parme, 1982), p. 237-288.

- De BlaAuw, 1994 : Sible De Blaauw, Cultus et decor: liturgia e architettura nella Roma tardoantica e medievale, Cité du Vatican, 1994 [éd. orig. : Cultus et decor: liturgie en architectur in laattantiek en middleeuws Rome, Delft, 1987].

- De BlaAuw, 2002 : Sible De Blaauw, "Contrasts in Processional Liturgy: a Typology of Outdoor Processions in
Twelfth-Century Rome ", dans Art, céremonial et liturgie au Moyen Âge, (colloque, Lausanne/Fribourg, 2000), (Études lausannoises d'histoire de l'art 1), Rome, 2002, p. 357-394.

- DE LUCA, 2006 : Maurizio De Luca, «Interventi conservativi e restauri ", dans ROMANO, DOS SANTOS, 2006, p. 53-54.

- Delogu, 1998 : Paolo Delogu éd., Roma medievale: aggiornamenti, Florence, 1998.

- Di CARPEgna FALCONIERI, 2002 : Tommaso Di Carpegna Falconieri, Il clero di Roma nel Medioevo: istituzioni e politica cittadina (secoli VIII-XIII), Rome, 2002.

- Dos SANTOS, 2006a : Felipe Dos Santos, "L'affresco staccato e il ciclo perduto con storie di santi già nel portico di Santa Cecilia in Trastevere ", dans RomAno, 2006a, p. 219-221.

- Dos SANTos, 2006b : Felipe Dos Santos, "La decorazione pittorica del cosidetto oratorio di San Giuliano in san Paolo fuori le mura ", dans RomAnO, 2006a, p. 282-289.

- Dos SAntos, 2007 : Felipe Dos Santos, «Entre la basilique et le cloitre. Les fresques du dit oratoire de S. Giuliano à S. Paolo fuori le mura ", dans ROMANO, ENCKELL JULLIARD, 2007, p. 331-355.

- DugGan, 1989 : Lawrence G. Duggan, "Was Art really the 'Book of the Illiterate'? ", dans Word and Image, 5, 1989, p. 227-251.

- ENCKell JUlLIARD, 2006a : Julie Enckell Julliard, "I perduti affreschi in San Salvatore in Thermis ", dans ROMANO, 2006a, p. 190.

- ENCKell JULliARD, 2006b : Julie Enckell Julliard, "La decorazione perduta della facciata di Santa Maria Nova ", dans ROMANO, 2006A, p. 344-345.

- ENCKELl JULLIARD, 2006c : Julie Enckell Julliard, "Il pannello con tre figure a mezzo busto mell'abside di Santa Maria in Pallara ", dans ROMANO, 2006a, p. 196-198.

- ENCKell JULLIARD, 2008 : Julie Enckell Julliard, Au seuil du salut : les décors peints de l'avant nef de Farfa en Sabine, Rome, 2008.

- FAVREAU, 1989: Robert Favreau, " Fonctions des inscriptions au Moyen Âge ", dans Cahiers de Civilisation médiévale, 32 , 1989, p. 203-232.

- FAVReAU, 1996 : Robert Favreau, Épigraphie et iconographie, (colloque, Poitiers, 1995), Poitiers, 1996.

- FAVREAU, 1997 : Robert Favreau, Épigraphie médiévale, (L'atelier du médiéviste, 5), Turnhout, 1997.
- FAVREAU, 1999a : Robert Favreau, "La mémoire du passé dans les inscriptions du haut Moyen Âge ", dans Ideologie e pratiche del reimpiego nell'alto medioevo, (colloque, Spolete, 1998), (Settimane di studio del Centro Italiano di Studi sull'Alto Medioevo, 46), 1999, vol. 2, p. 937-979.

-FAVREAU, 1999b : Robert Favreau, "Inscriptions de dédicace d'églises et de consécration d'autels à Rome, $\mathrm{XI}^{\mathrm{e}-}$ $\mathrm{XIII}^{\mathrm{e}}$ siècles ", dans Antonio Cadei éd., Arte d'Occidente: temi e metodi. Studi in onore di Angiola Maria Romanini, Rome, 1999, p. 947-956.

- Fichtenau, 1950 : Heinrich Fichtenau, "Neues zum Problem der italienischen 'Riesenibeln' ", dans Mitteilungen des Instituts für Österreichischen Geschichtsforschung, 48, 1950, p. 50-67.

- FILIPPINI, 1999 : Cristiana Filippini, The eleventh-century frescoes of Clement and other saints in the Basilica of San Clemente in Rome, thèse, Johns Hopkins University, 1999.

- FiLIPPINI, 2002 : Cristiana Filippini, " La chiesa e il suo santo: gli affreschi dell'undicesimo secolo nella chiesa di S. Clemente a Roma ", dans Art, Cérémonial et Liturgie au Moyen Âge, (colloque, Lausanne/ Fribourg, 2000), Rome, 2002, p. 107-123. - FILIPPINI, 2004 : Cristiana Filippini, "Functions of pictorial narratives and liturgical spaces: the eleventh-century frescoes of the titular saint in the basilica of San Clemente in Rome ", dans Thomas Dale, John Mitchell éd., Shaping sacred space and institutional identity in Romanesque mural painting. Essays in honour of Otto Demus, Londres, 2004, p. 122-138. - FILIPPINI, 2006 : Cristiana Filippini, "The image of the titular saint in the eleventh-century frescoes in San Clemente, Rome", dans Martina Bagnoli, Peter W. Parshall éd., The language of the object: essays in honour of Herbert L. Kessler, Londres, 2006, p. 245-250

- FILIPPINI, 2007 : Cristiana Filippini, « La leggenda di sant'Alessio nella chiesa di S. Clemente a Roma: genesi e funzione di una narrazione pittorica al momento della Riforma gregoriana ", dans ROMANO, ENCKELL JULLIARD, 2007, p. 289-303.

- Fliche, 1977 : Augustin Fliche, Storia della Chiesa, VIII, La riforma gregoriana e la riconquista cristiana (1057-1123), Turin, 1977 [éd. orig. : Histoire de l'Église depuis ses origines jusqu'a nos jours, VIII, La Réforme Grégorienne et la Reconquête chrétienne (1057-1123), Paris, 1940].

- FORNASARI, 1996 : Giuseppe Fornasari, Medioevo riformato del secolo XI. Pier Damiani e Gregorio VII, Naples, 1996. 
- FRANCOVICH, 1955 : Geza de Francovich, "I problemi della pittura e della scultura preromanica ", dans I problemi comuni dell'Europa post-carolingia, (colloque, Spolète, 1954), Spolète, 1955, p. 393-519. - FROSININI, MONCIATTI, WOLF, sous presse : Cecilia Frosinini, Alessio Monciatti, Gerhard Wolf éd., La pittura su tavola del XII secolo. Riconsiderazioni e nuove acquisizioni a seguito del restauro della croce di Rosano (colloque, Florence, 2009), Florence, sous presse.

- GANDOLFO, 1981 : Francesco Gandolfo, "Simbolismo antiquario e potere papale", dans Studi romani, 29, 1981, p. 9-28.

- GANDOLFO, 1984 : Francesco Gandolfo, "La cattedra 'gregoriana' di Salerno ", dans Bollettino storico di Salerno e Principato Citra, 2, 1984, p. 5-29.

- GANDOLFO, 1989 : Francesco Gandolfo, «La pittura romana tra XI e XII secolo e l'Antico ", dans Silvia Danesi Squarzina éd., Roma, centro ideale della cultura e dell'antico nei secoli XV e XVI, (colloque, Rome, 1985), Rome, 1989, p. 21-32.

- GANDOLFO, 2002 : Francesco Gandolfo, "Il ritratto di committenza ", dans ANDALORO, ROMANO, 2002, p. 139-149.

- GANDOLFO, 2004 : Francesco Gandolfo, Il ritratto di committenza nella Roma medievale, Rome, 2004.

- GANDOLFO, 2007 : Francesco Gandolfo, I puteali di S. Bartolomeo all'Isola e di Grottaferrata, dans ROMANO, ENCKELL JULLIARD, 2007, p. 165-184.

- GARRISON, 1953-1962 : Edward B. Garrison, Studies in the history of medieval Italian painting, Florence, 1953-1962, I, $1953-$ 1954 ; II, 1955-1956 ; III, 1957-1958 ; IV, 1960-1962 [réemprimé Londres, 1993]. - GHIRARDINI, 1970 : Lino Lionello Ghirardini, Saggio di una bibliografia dell'età matildico-gregoriana (1046-1122), (Deputazione di Storia Patria per le antiche provincie modenesi, Biblioteca, n.s. 14), Modène, 1970.

- GIOVÈ MARCHIOLI, 2006 : Nicoletta Giovè Marchioli, "L'epigrafia nobiliare romana: il caso delle iscrizioni funerarie ", dans CAROCCI, 2006, p. 345-365.

- GLASS, 2008 : Dorothy F. Glass, "Revisiting the 'Gregorian Reform' ", dans Colum Hourihane éd., Romanesque art and thought in the twelfth century: essays in honor of Walter Cahn, (Occasional papers/Index of Christian Art, Department of Art and Archaeology, Princeton University, 10), Princeton/ New York, 2008, p. 200-218.

- GoEz, 2000 : Werner Goez, Kirchenreform und Investiturstreit: 910-1122, (UrbanTaschenbücher, 462), Stuttgart, 2000.
- GOMBRICH, 1969 : Ernst H. Gombrich, "The evidence of image", dans Charles S. Singleton éd., Interpretation, Theory and Practice, Baltimore, 1969.

- GOMBRICH, 1982 : Ernst H. Gombrich, The image and the Eye. Further studies in the Psychology of Pictorial Representation, Ithaca, 1982.

-GORMAN, 2002 : Michael Gorman, "Manuscript Books at Monte Amiata in the Eleventh Century ", dans Scriptorium, 56, 2002, p. 225-293.

- GRAMIGNI, ZAMPONI, 2007 : Tommaso Gramigni, Stefano Zamponi, "Le iscrizioni della Croce di Rosano ", dans CiATTI, FROSININI, BELLUCCI, 2007, 2007, p. 7188.

- GRÉGOIRE, 1965 : Réginald Grégoire, Bruno de Segni. Exégète médiéval et théologien monastique, (Centro italiano di studi sull'alto medioevo, 3), Spolète, 1965.

- GREgOROVIUS, (1886) 1973 : Ferdinand Gregorovius, Storia della città di Roma nel medioevo, 3 vol., Turin, 1973 [éd. orig., Geschichte der Stadt Rom im Mittelalter vom V. bis XVI. Jahrhundert, 8 vol., Stuttgart, 1886].

- GuIDOBALDI, 1992 : Federico Guidobaldi, San Clemente. Gli edifici romani, la basilica paleocristiana e le fasi altomedievali, (San Clemente Miscellany, 4/1), Rome, 1992.

- GuidobALDI, 1997 : Federico Guidobaldi, " Gli scavi del 1993-5 nella basilica di S. Clemente a Roma e la scoperta del Battistero Paleocristiano. Nota preliminare ", dans Rivista di Archeologia Cristiana, 43, 1997, p. 459-449.

- HAmilton, 2003 : Louis I. Hamilton, "Memory, Symbol and Arson: Was Rome 'Sacked' in 1084? ", dans Speculum, 78/2, 2003, p. 378-399.

- HAMilton, 2005 : Louis I. Hamilton, " To consecrate the Church: Ecclesiastical Reform and the Dedication of Churches ", dans Christopher M. Bellitto, Louis I. Hamilton éd., Reforming the Church before Modernity. Patterns, Problems and Approaches, Aldershot, 2005, p. 105-137.

- HAMiLTON, 2010 : Louis I. Hamilton, A Sacred City: Consecrating Churches and Reforming Society in Eleventh-Century Italy, Manchester, 2010.

- HeRKLOTZ, 2000 : Ingo Herklotz, Gli eredi di Costantino. Il papato, il Laterano e la propaganda visiva nel XII secolo, Rome, 2000.

- HoegGer, 1975 : Peter Hoegger, Die Fresken in der ehemalige Abteikirche S. Elia bei Nepi, Stuttgart, 1975.

- HOFFMANN, 1972 : Hartmuth Hoffmann, s.v. "Bruno di Segni ", dans Di- zionario Biografico degli Italiani, XIV, Rome, 1972, p. 644-647.

- Homo, 1934 : Leon Homo, Rome médiévale (476-1420), Paris, 1934.

- HUBERT, 1990 : Étienne Hubert, Espace Urbain et habitat à Rome du Xe siècle à la fin du XVIII siècle, Rome, 1990.

- HUBERT, 2001 : Étienne Hubert, "L'organizzazione territoriale e l'urbanizzazione ", dans André Vauchez éd., Storia di Roma dall'antichità ad oggi. Roma medievale, Bari, 2001, p. 159-186.

- IACOBINI, 1991 : Antonio Iacobini, « La pittura e le arti suntuarie da Innocenzo III a Innocenzo IV (1198-1254)", dans Angela Maria Romanini éd., Roma nel duecento, l'arte nella città dei papi da Innocenzo III a Bonifacio VIII, Turin, 1991, p. 291-293. - IACOBINI, 2005 : Antonio Iacobini, "Immagini, ideologie, storiografia: il mosaico absidale del duomo di Salerno e l'arte della Riforma gregoriana ", dans Arturo Carlo Quintavalle éd., Medioevo: immagini e ideologie, (colloque, Parme, 2002), Milan, p. 288-301.

- IACOBInI, 2006 : Antonio Iacobini, " Il mosaico in Italia dall'XI all'inizio del XIII secolo: spazio, immagini, ideologia ", dans PIVA, 2006, p. 463-499.

- KeSSLER, 1985 : Herbert L. Kessler, "Picture as Scripture in Fifth-Century Churches ", dans Studia Artium Orientalis et Occidentalis, II, Tokyo, 1985, p. 17-31.

- Kessler, 1989a : Herbert L. Kessler, "L'antica basilica di S. Pietro come fonte e ispirazione per la decorazione delle chiese medievali", dans "Fragmenta Picta ": Affreschi e mosaici staccati del Medioevo Romano, (cat. expo., Rome, Castel Sant'Angelo, 1989-1990), Rome, 1989, p. 45-64.

- Kessler, 1989b : Herbert L. Kessler, "Caput et speculum omnium ecclesiarum: old St. Peter's and church decoration in medieval Latium ", dans Tronzo éd., Italian church decoration of the Middle Ages and Early Renaissance, Bologne/Baltimore, 1989, p. 119-146.

- KeSSLER, 1989c : Herbert L. Kessler, "Diction in the 'Bibles of the illiterate' ", dans Irving Lavin éd., World Art. Themes of Unity in Diversity, (colloque, Washington DC, 1986), Londres, 1989, II, p. 297-308. - Kessler, 2000 : Herbert L. Kessler, Spiritual seeing: picturing God's invisibility in Medieval art, Philadelphie, 2000.

- KeSSLER, 2002a : Herbert L. Kessler, Old St. Peter's and church decoration in medieval Italy, Spolète, 2002. 
- KesSLeR, 2002b : Herbert L. Kessler, "Corporeal texts, spiritual paintings and the mind's eye ", dans KesSler, 2002a, p. 159-178.

- KESSLER, 2003 : Herbert L. Kessler, «Il ciclo di S. Pietro in Valle: fonti e significato ", dans Giulia Tamanti éd., Gli affreschi di San Pietro in Valle a Ferentillo, Naples, 2003, p. 77-116.

- KESSLER, 2004 : Herbert L. Kessler, " Seroux's Decadent Column Capital and other Pieces in the Puzzle of S. Paolo fuori le mura in Rome ", dans Arte medievale, 3/1, 2004, p. 9-34.

- KeSSLER, 2005 : Herbert L. Kessler, "Image Theory in an Ecclesiastical Space ", dans Claude Arrignon, Marie-Hélène Debiès éd., Cinquante années d'études médiévales: à la confluence de nos disciplines, Turnhout, 2005, p. 295-308.

- Kessler, 2006a : Herbert L. Kessler, "Storie sacre e spazi consacrati: la pittura narrativa nelle chiese medievali fra IV e XII secolo ", dans PIVA, 2006, p. 435-462.

- KessLer, 2006b : Herbert L. Kessler, "Gregory the Great and Image Theory in Northern Europe During the Twelfth and Thirteenth Centuries ", dans Conrad Rudolph éd., A Companion to Medieval Art: Romanesque and Gothic in Northern Europe, Oxford, 2006, p. 151-171.

- KeSSLER, 2007a : Herbert L. Kessler, "A Gregorian Reform Theory of Art?", dans ROMANO, ENCKELl JULLIARD, 2007, p. 25-48.

- KESSLER, 2007b : Herbert L. Kessler, Neither God nor Man: Words Images and the Medieval Anxiety about Art, Fribourg-enBrisgau/Berlin/Vienne, 2007.

- KESSLER, sous presse : Herbert L. Kessler, "The French Connection: Word and Image on the Rosano Cross ", dans FrosININI, MONCIATTI, WOLF, sous presse.

- KINNEY, 1975 : Dale Kinney, S. Maria in Trastevere from its founding to 1215 , thèse, New York University, 1975.

- KINNEY, 2002 : Dale Kinney, " The Apse Mosaic of Santa Maria in Trastevere ", dans Elizabeth Sears, Thelma K. Thomas éd., Reading Medieval Images: The Art Historian and the Object, Michigan, 2002, p. 19-26.

- KITZINGER, 1972a : Ernst Kitzinger, " The Gregorian Reform and the Visual Arts: a problem of method", dans Transaction of Royal Historical Society, 5/22, 1972, p. 87102 [réédité dans, Studies in late antique: Byzantine and medieval Western art, Londres, 2003, p. 889-909].

- KITZINGER, 1972b : Ernst Kitzinger, " The first Mosaic Decoration of Salerno
Cathedral ", dans Jahrbuch der Osterreichischen Byzantinistk, 21, 1972, p. 149-162. - KITZINGER, 1980 : Ernst Kitzinger, "A Virgin Face: Antiquarism in TwelfthCentury Art ", dans Art Bulletin, 62, 1980, p. 6-19.

- KLEIN, 1992 : Peter K. Klein, «Introduction: the apocalypse in Medieval art", dans Richard K. Emmerson, Bernard McGinn éd., The Apocalypse in the Middle Ages, Ithaca, 1992, p. 159-199.

- KLein, LAufner, Franz, 2001 : Peter K. Klein, Richard Laufner, Gunther Franz, Die Trierer Apokalypse: Codex 31 der Stadtbibliothek Trier, (Glanzlichter der Buchkunst, 10), Graz, 2001.

- KOCH, 1990 : Walter Koch, «Zur stadtrömischen Epigraphik des 13. Jahrhunderts - mit Rückblick auf das Hochmittelalter ", dans Walter Koch éd, Epigraphik 1988: Fachtagung für mittelalterliche und neuzeitliche Epigraphik, (colloque, Graz, 1988), Vienne, 1990, p. 271-280.

- KOCH, 1995 : Walter Koch, "Spezialfragen der Inschriftenpaläeographie », dans Guglielmo Cavallo, Cyril Mango éd., Epigrafia medievale greca e latina. Ideologia e funzione, (colloque, Erice (TP), 1991), Spolète, 1995, p. 267-291.

- KotTMAnN, 2007 : Delia Kottmann, «Le cycle apocalyptique de Castel Sant'Elia ", dans ROMANO, ENCKELL JULLIARD, 2007, p. 411-431.

- KRAUtheIMER, 1980 : Richard Krautheimer, Rome, profile of a City, 312-1308, Princeton, 1980.

- KRAUTHEIMER et al., 1937 : Richard Krautheimer et al., Corpus basilicarum Christianarum Romae, I, Rome/New York, 1937.

- LADNER, 1931 : Gerhart B. Ladner, «Die italienische Malerei im 11. Jahrhundert", dans Jahrbuch der Wiener Sammlungen, 5 , 1931, p. 33-160.

- LIVERANI, 2006 : Paolo Liverani, " Costantino offre il modello della basilica sull'arco trionfale ", dans ANDALORO, 2006, p. 90-91.

- LOBRICHON, 2000 : Guy Lobrichon, « Riforma ecclesiastica e testo della Bibbia ", dans MANIACI, OROFINO, 2000, p. 15-23.

- LoCKE-PERCHUK, 2009 : Alison LockePerchuk, In the Image of Elijah: The Artistic Foundations of the Community in a Medieval Italian Monastery, thèse, Yale University, 2009.

-Lucca e l'Europa..., 2010 : Lucca e l'Europa: un'idea di Medioevo (V-XI secolo), Clara Baracchini et al. éd., (cat. expo., Lucca, Fondazione Ragghianti, 2010-2011), Lucca, 2010.
- MÂLE, 1953 : Émile Mâle, La cathédrale de Reims, Paris, 1953.

- MAGIONAMI, 2006 : Leonardo Magionami, I manoscritti del capitolo di San Lorenzo di Perugia, Rome, 2006.

- MANIACI, 2000 : Marilena Maniaci, « La struttura delle Bibbie Atlantiche ", dans MANIACI, OROFINO, 2000, p. 47-60.

- MARUCCHI, 1956-1957 : Adriana Marucchi éd., Giulio Mancini (1558-1630): considerazioni sulla pittura, Rome, 19561957

- Matilde di Canossa..., 2008 : Matilde di Canossa: il papato e l'impero. Storia, arte, cultura alle origini del romanico, Renata Salvarani, Liana Castelfranchi éd., (cat. expo., Mantoue, 2009), Cinisello Balsamo (MI), 2008.

- Matilde e il tesoro..., 2008 : Matilde e il tesoro dei Canossa: tra castelli, monasteri e città, Arturo Calzona éd., (cat. expo., Reggio Emilia, Plazzo Magnani/Canossa, Museo Naborre Campanini, 2008-2009), Cinisello Balsamo (MI), 2008.

- Matthiae, 1965-1966 : Guglielmo Matthiae, Pittura romana del medioevo, 2 vol., Rome, 1965-1966.

- MAtThiae, GANdolfo, 1988 : Guglielmo Matthiae, Francesco Gandolfo éd., Pittura romana del Medioevo, II, Secoli XIXIV, Rome, 1988.

- MAzzocchI, 2001 : Eleonora Mazzocchi, "Una parete dai molti misteri: alcune precisazioni sugli affreschi della basilica inferiore di San Crisogono a Roma ", dans Annali della Scuola Normale Superiore di Pisa. Classe di Lettere e Filosofia, IV/6/1, 2001, p. 39-60.

- MAzzocchi, 2007 : Eleonora Mazzocchi, "Il cuore antico della Riforma ", dans ROMANO, ENCKELL JULLIARD, 2007, p. 247-273.

- Miglio, 2002 : Luisa Miglio, "Castel Sant'Elia ", dans Luigi Cimarra et al. éd., Inscriptiones Medii Aevi Italiae (saec. VI-XII), I, Lazio - Viterbo, Spolète, 2002, p. 1-36.

- MonciatTI, 2007 : Alessio Monciatti, « La croce dipinta dell'abbazia di Santa Maria Assunta a Rosano ritrovata ", dans CIATTI, FROSININI, BELLUCCI, 2007, p. 49-70.

- MoretTI, 2003-2004 : Simona Moretti, " Alle porte di Roma: un esempio pittorico e il suo contesto da ricostruire. La 'Grotta degli angeli' a Magliano Romano ", dans Atti della Pontificia Accademia romana di archeologia. Rendiconti, 76, 20032004, p. 105-133.

- Morghen, 1974 : Raffaello Morghen, Gregorio VII e la riforma della Chiesa nel secolo XI. Nuova edizione corretta, integrata e aggiornata, Palerme, 1974. 
- Mullooly, 1866 : Joseph Mullooly, Brevi notizie delle antiche pitture discoperte nella basilica sotterranea di S. Clemente in Roma le cui date vanno dalla fine del terzo al decimo secolo, Rome, 1866.

- NAVARRA, 1980 : Bruno Navarra, S. Bruno Astense, vescovo di Segni e abate di Montecassino, Rome, 1980.

- NiE, MORRISON, MOSTERT, 2005 : Giselle de Nie, Karl F. Morrison, Marco Mostert éd., Seeing the invisible in late antiquity and the early middle ages: papers from "Verbal and pictorial imaging: representing and accessing experience of the invisible, 400-1000", (colloque, Utrecht, 2003), Turhout, 2005.

- NiLGEN, 1981 : Ursula Nilgen, "Maria Regina - ein politischer Kultbildtypus? ", dans Römisches Jahrbuch für Kunstgeschichte, 19, 1981, p. 1-33.

- NORDENFALK, 1958 : Carl Nordenfalk, "Romanesque Book illumination", dans André Grabar, Carl Nordenfalk éd., Romanesque Painting from the Eleventh to the Thirteenth Century, Genève, 1958, p. 133-206.

- NoREen, 2001 : Kirstin Noreen, "Lay Patronage and the Creation of Papal sanctity during the Gregorian Reform: The Case of Sant'Urbano alla Caffarella, Rome ", dans Gesta, 40/1, 2001, p. 39-60. - NOREEN, 2002 : Kirstin Noreen, «Sant'Urbano alla Caffarella, Rome: the reconstruction of an ancient memorial ", dans Memoirs of the American Academy in Rome, 2002, 47, p. 57-82.

- Orofino, 2001-2002 : Giulia Orofino, "Per un'iconografia comparata delle Bibbie atlantiche ", dans Rivista di storia della miniatura, (colloque, Parme, 2000), 6-7, 2001-2002, p. 29-40.

- OROFINO, 2003 : Giulia Orofino, «Bibbie atlantiche. Struttura del testo e racconto del Libro 'riformato': spunti da una mostra ", dans Arturo Carlo Quintavalle éd., Medioevo: immagine e racconto, (colloque, Parme, 2000), Milan, 2003, p. 253-264.

- OROFINO, 2008 : Giulia Orofino, " Pittura e miniatura nell'Italia centro-meridionale al tempo della Riforma gregoriana ", dans Milagros Guardia, Carles Mancho éd., Les fonts de la pintura romanica, Barcelone, 2008, p. 7-175.

- OSBORNE, 1997 : John Osborne, «Proclamations of Power and Presence: the Setting and Function of Two EleventhCentury Murals in the Lower Church of San Clemente, Rome", dans Medieval Studies, 59, 1997, p. 155-172.
- OSBORNE, 2004 : John Osborne, "Framing sacred space: eleventh-century mural painting in the churches of Rome", dans Analecta Romana Instituti Danici, 30, 2004, p. 137-151.

- PACE, 1993-1994 : Valentino Pace, «Riforma della chiesa e visualizzazione della santità nella pittura romana: i casi di sant'Alessio e di santa Cecilia ", dans Wiener Jahrbuch für Kunstgeschichte, 46-47, 1993-1994, p. 541-548.

- PACE, 1997 : Valentino Pace, « La cattedrale di Salerno. Committenza programma e valenze ideologiche di un monumento di fine XI secolo nell'Italia meridionale ", dans Faustino Avagliano éd., Desiderio di Montecassino e l'arte della Riforma gregoriana, Cassino, 1997, p. 188-230.

- PACE, 2007 : « La Riforma e i suoi programmi figurativi: il caso romano, fra realtà storica e mito storiografico ", dans ROMANO, ENKELL JULLIARD, 2007, p. 49-59. - PAESELer, 1938 : Wilhelm Paeseler, « Die römische Weltgerichtstafel im Vatikan: ihre Stellung in der Geschichte des Weltgerichtsbildes und in der römischen Malerei des 13. Jahrhunderts ", dans Kunstgeschichtliches Jahrbuch der Bibliotheca Hertziana, 2, 1938, p. 313-393.

- PALAzzo, 1988 : Éric Palazzo, "L'iconographie des fresques de Berzé-la-Ville dans le contexte de la réforme grégorienne et de la liturgie clunisienne", dans Les Cahiers de Saint-Michel de Cuxa, 19, 1988, p. 169-182.

- PALAzzo, 1998 : Éric Palazzo, «Iconographie et liturgie dans les études médiévales aujourd'hui : un éclairage méthodologique ", dans Cahiers de civilisation médiévale, 41, 1998, p. 65-69.

- PALAzzo, 2006 : Éric Palazzo, « Rom, die Gregorianische Reform und die Liturgie ", dans Canossa 1077..., 2006, p. 277-282.

- PALAzzo, 2007 : Éric Palazzo, « Rome, la Réforme grégorienne et la liturgie : état de la question et perspective de recherches ", dans ROMANO, ENCKELL JULLIARD, 2007, p. 13-23.

- PARlato, 2000 : Enrico Parlato, "La processione di Ferragosto e l'acheropita del Sancta Sanctorum ", dans Giovanni Morello, Gerhard Wolf éd., Il volto di Cristo (cat. expo., Rome, Palazzo delle Esposizioni, 2000-2001), Milan, 2000, p. 51-52. - PARlato, 2002 : Enrico Parlato, «Le icone in processione ", dans ANDALORO, ROMANO, (2000) 2002a, p. 55-72.

- PARLATO, ROMANO, (1992) 2001 : Enrico Parlato, Serena Romano, Roma e il Lazio. Il romanico, Milan, (1992) 2001.
- PenNesi, 2006 : Stefania Pennesi, "Sant'Urbano alla Caffarella ", dans ANDALORO, 2006, p. 139-150.

- PenNESI, 2007 : Stefania Pennesi, « I cicli dei martiri Cecilia e Sebastiano ai SS. Nereo e Achilleo: continuità dei programmi narrativi agiografici nella pittura romana fra X e XI secolo ", dans ROMANO, ENCKELL JULLIARD, 2007, p. 113-140.

- PERoni, Riccioni, 2000 : Adriano Peroni, Stefano Riccioni, " The reliquary altar of S. Maria del Priorato in Rome ", dans Julia M. H. Smith éd., Early Medieval Rome and the Christian West: Essays in honour of Donald A. Bullogh, Leyde, 2000, p. 135-50. - Petrucci, 1986 : Armando Petrucci, La scrittura. Ideologia e rappresentazione, Turin, 1986 [trad. fr. : Jeux de lettres. Formes et usages de l'inscription en Italie, $X I^{e}-X X^{e}$ siècles, Paris, 1993].

- PetruCCI, 2002 : Armando Petrucci, «Divagazioni paleografiche sulla Roma Gregoriana ", dans Ludovico Gatto, Paola Supino Martini éd., Studi sulle società e le culture del Medioevo per Girolamo Arnaldi, II, Rome, 2002, p. 471-478.

- PIAzZA, 2006 : Simone Piazza, Pittura rupestre medievale: Lazio e Campania settentrionale (secoli VI-XIII), (Collection de l'École française de Rome, 370), Rome, 2007.

- PIAZZA, 2007 : Simone Piazza, «Peintures rupestres dans le Latium à l'époque de la Réforme grégorienne : la 'Grotta di S. Cristina' à Bolsena et autres lieux plus ou moins connus ", dans ROMANO, ENCKELL JUILLARD, 2007, p. 381-410.

- PIVA, 2006 : Paolo Piva éd., L'arte medievale nel contesto (300-1300): funzioni, iconografia, tecniche, Milan, 2006.

- PRANDI, 1978 : Adriano Prandi, Aggiornamento dell'opera di Émile Bertaux sotto la direzione di Adriano Prandi, IV-VII, Rome, 1978. - PREMOLI, 1975-1976 : Beatrice Premoli, " Affreschi medievali nella chiesa dell'Assunta di Ceri ", dans Colloqui del Sodalizio, 1975-1976, 5, p. 24-33.

- QUentin, 1922 : Henri Quentin, Memoire sur l'établissement du texte de la Vulgate, I, Octateuque, Rome/Paris, 1922.

- QuintaVAlLE, 2002 : Arturo Carlo Quintavalle éd., Il Medioevo: i modelli, (colloque, Parme, 1999), (I convegni di Parma, 2), Milan, 2002

- Quintavalle, 2003a ： Arturo Carlo Quintavalle, "Riforma gregoriana, scultura e arredi liturgici fra XI e XII secolo", dans Enrico Castelnuovo, Giuseppe Sergi éd., Arti e storia nel Medioevo, II, Del costruire: tecniche, artisti, artigiani, committenti, Turin, 2003, p. 235-266. 
- Quintavalle, 2003b : Arturo Carlo Quintavalle, "Le origini di Nicholaus e l'immagine della riforma fra secolo XI e secolo XII nella 'Lombardia' ", dans Arturo Carlo Quintavalle éd., Medioevo: immagine e racconto, (colloque, Parme, 2000), Milan, 2003, p. 213-236.

- Quintavalle, 2008 : Arturo Carlo Quintavalle, " Rosano e i crocifissi viventi della riforma: dal 'Volto Santo' di Lucca a Batlló ", dans OPD restauro, 20, 2008, p. 139-170.

- QuinTAVAlLE, 2009 : Arturo Carlo Quintavalle éd., Medioevo: Immagine e memoria, (I convegni di Parma, 11), Milan, 2009.

- QuintaVAlle, 2010 : Arturo Carlo Quintavalle, "Riforma Gregoriana e origini del 'romanico' ", dans Compostela e l'Europa..., 2010, p. 204-231.

- Redig De CAMPos, 1935 : Deoclecio Redig De Campos, "Sopra una tavola sconosciuta del secolo XI rappresentante il Giudizio Universale ", dans Atti della Pontificia Accademia romana di archeologia. Rendiconti, 3a/9, 1935, p. 149-151.

- REYNOLDS, sous presse : Roger E. Reynolds, "The Liturgy of Rome in the Eleventh Century: past research and future opportunities", dans Scientiae veritatis Festschrift für Hubert Mordek zum 65 Geburstag, sous presse.

- RICCIONI, 2000 : Stefano Riccioni, « Epigrafia, spazio liturgico e Riforma gregoriana, un paradigma: il programma di esposizione grafica di S. Maria in Cosmedin a Roma ", dans Hortus Artium Medievalium, 6, 2000, p. 143-156.

- RICCIONI, 2002 : Stefano Riccioni, " L'autel-reliquaire de Sainte-Marie de l'Aventin à Rome, exemple de la 'renovatio' clunisienne ", dans Odilon de Merceur, L'Auvergne et Cluny : la "Paix de Dieux" et l'Europe de l'an mil, (colloque, Lavoûte-Chilhac, 2000), Nonnette, 2002, p. 205-219.

- RicCIONI, 2006 : Stefano Riccioni, Il mosaico di S. Clemente a Roma: "Exemplum" della Chiesa riformata, Spolète, 2006 [CR par Dale Kinney, dans Speculum, 85/1, 2010, p. 189-192, et par Alessia Trivellone, dans Cahiers de Civilisation Médiévale, 2009, 52, p. 187-188].

- RICCIONI, 2007a : Stefano Riccioni, "Segni epigrafici e sistemi illustrativi 'alla greca' nel mosaico di S. Clemente a Roma ", dans Medioevo Mediterraneo: l'Occidente, Bisanzio e l'Islam dal tardoantico al secolo XII, (colloque, Parme, 2004), Milan, 2007, p. 371-380.

- RICCIONI, 2007b : Stefano Riccioni, "'Litterae' et 'Figurae' : pour un art 'rhétorique' dans la Rome de la Réforme grégorienne ", dans ROMANO, ENCKELL JULLIARD, 2007, p. 141-163.

- RiCcioni, 2008 : Stefano Riccioni, "'Epiconographie' de l'art roman en France et en Italie (Bourgogne/Latium) : l'art médiéval en tant que discours visuel et la naissance d'un nouveau langage ", dans Bulletin du Centre d'études médiévales d'Auxerre, 12, 2008, p. 267282, en ligne sur http://cem.revues.org/ document7132.html.

- RICCIONI, 2009 : Stefano Riccioni, The Rhetoric of Visuality in the Mosaic of S. Maria in Trastevere in Rome, LMS dissertation, Pontifical Institute of Medieaval Studies, Toronto, 2009.

- RiCCIONI, sous presse a : Stefano Riccioni, " Colores rethorici. Réflexions sur la rhétorique de la couleur dans les mosaïques de Rome du XII ${ }^{e}$ siècle ", dans Couleurs et lumière à l'époque romane, numéro spécial de Revue d'Auvergne, sous presse.

- RICCIONI, sous presse $b$ : Stefano Riccioni, « The Word in the Image: an Epiconographic Analysis of Reformed Mosaics in Rome (Twelfth-century)", dans Acta ad archaeologiam et artium historiam pertinentia, 25 , sous presse.

- RICCIONI, sous presse c : Stefano Riccioni, " La croce di Rosano oltre il Lazio e la Toscana. Riflessi 'europei' della Riforma gregoriana", dans Pittura su tavola nel XIII secolo: riconsiderazioni e nuove acquisizioni a seguito del restauro della Croce di Rosano, (colloque, Florence, 2009), Florence, sous presse.

- ROMANO, 1992 : Serena Romano, Eclissi di Roma. Pittura murale a Roma e nel Lazio da Bonifacio VIII a Martino V (1295-1431), Rome, 1992.

- Romano, 2002a : Serena Romano, "I pittori romani e la tradizione ", dans ANDALORO, ROMANO, (2000) 2002a, p. 103138.

- Romano, 2002b : Serena Romano, "Il cantiere di San Paolo fuori le mura: il contatto con i prototipi ", dans QUINTAVALLE, 2002, p. 615-630.

- RomANo, 2006a : Serena Romano éd., La pittura medievale a Roma, 312-1431: Corpus e Atlante, IV, Riforma e traditione: 10501198, Milan, 2006.

- ROMANo, 2006b : Serena Romano, " Roma XI secolo: Da Leone IX a Ranieri di Bieda ", dans ROMANO, 2006a, p. 15-35.

- ROMANo, 2006c : Serena Romano, "I resti della decorazione affrescata nel sottotetto delle navate laterali della chiesa di S. Clemente ", dans Romano, 2006a, p. 247-249.
- RoMANo, 2006d : Serena Romano, "La Madonna con bambino e donatrice nel battistero della chiesa inferiore di San Clemente ", dans ROMANO, 2006a, p. 66-67. - ROMANo, 2006e : Serena Romano, "La chiesa trionfante (1100-1143 ca.) ", dans ROMANO, 2006a, p. 163-182.

-ROMANo, 2006f : Serena Romano, «Il perduto ciclo con storie dei santi Lorenzo, Cirilla, Ireneo, Abbondio e altri santi nel portico meridionale di San Lorenzo fuori le mura ", dans ROMANO, 2006a, p. 156-159. -ROMANO, 2006g : Serena Romano, "Storie di San Benedetto e altri santi sulla parete destra della navata ", dans RoMANO, 2006a, p. 79-88.

- ROMANO, 2006h : Serena Romano, «La perduta decorazione del catino absidale di San Lorenzo in Lucina ", dans ROMANO, 2006a, p. 294-295.

-ROMANO, 2007 : Serena Romano, "La lotta per il primato. Frammenti e fatti sparsi tra Italia e Francia nell'età della Riforma ", dans Arturo Calzona, Roberto Campari, Massimo Mussini éd., Immagine e ideologia: studi in onore di Arturo Carlo Quintavalle, Milan, 2007, p. 167-172.

-ROMANO, 2008a : Serena Romano, "Rome et l'Antique : $\mathrm{XI}^{\mathrm{e}}$-XII ${ }^{\mathrm{e}}$ siècles ; remarques, souvenirs, considérations éparses", dans Actualité de l'art antique dans l'art roman, (colloque, Cuxa, 2007), (Les Cahiers de Saint-Michel de Cuxa, 39), Codalet, 2008, p. 23-30.

-ROMANO, 2008b : Serena Romano, "Femmine, sante e nobildonne abbigliate: uno sguardo femminile sulla pittura a Roma nell'XI secolo ", dans Matilde e il tesoro..., 2008, p. 188-201.

-ROMANO, 2009 : Serena Romano, "Commedia antica e sacra rappresentazione. Gli affreschi con 'Storie di san Clemente' nella basilica inferiore di San Clemente a Roma ", dans Marco Praloran, Serena Romano dir., Gabriele Bucchi, Ivan Foletti éd., Figura e racconto: narrazione letteraria e narrazione figurativa in Italia dall' Antichità al primo Rinascimento - Figure et récit: narration littéraire et narration figurative en Italie de l'antiquité à la première Renaissance, (colloque, Lausanne, 2005), (Études lausannoises d'histoire de l'art, 9), Florence, 2009, p. 53-88.

- ROMANO, 2010 : Serena Romano, « Rom und die Ikonen: Überlegungen zu Monument und Dokument in Mittelalter ", dans Martin Büchsel, Rebecca Müller éd., Intellektualisierung und Mystifizierung mittelalterischer Kunst: 'Kultbild': Revision eines Begriffs (Neue Frankfurter Forschungen zur Kunst, 10), Berlin, 2010, p. 133-153. 
- ROMANO, sous presse : Serena Romano, " Un'aggiunta al Corpus della pittura medievale a Roma: i Santi Bonifacio e Alessio all'Aventino ", dans Walter Angelelli, Francesca Pomarici éd., Atti in onore di Francesco Gandolfo, sous presse.

- Romano, Dos SANTOS, 2006 : Serena Romano, Felipe dos Santos, « La tavola del Giudizio universale già in San Gregorio Nazianzeno (Pinacoteca Vaticana) ", dans ROMANO, 2006a, p. 45-55.

- ROMANO, ENCKELL JULLIARD, 2007 : Serena Romano, Julie Enkell Julliard éd., Roma e la Riforma gregoriana: tradizioni e innovazioni artistiche (XI-XII secolo), (colloque, Lausanne, 2004), (Études lausannoises d'histoire de l'art, 5), Rome, 2007.

-Russo, 2000 : Daniel Russo, «Espace peint, espace symbolique, construction ecclésiologique : les peintures de Berzé-laVille (Chapelle-des-moines) ", dans Revue Mabillon, revue internationale d'histoire et de littérature religieuses, 11/72, 2000, p. 57-87. -Russo, 2005 : " D'une réforme à l'autre : l'étude des peintures religieuses en Bourgogne, $\mathrm{XII}^{\mathrm{e}}-\mathrm{XVI}^{\mathrm{e}}$ siècles ", dans Daniel Russo éd., Peintures murales $X I I^{e}-X V I^{e}$ : regards comparés, Dijon, 2005, p. 103-112. -Russo, 2007 : Daniel Russo, « Byzance et l'art médiéval : la question de l'intermédiaire italien ", dans Revue de l'art, 158, 2007, p. 5-12.

- RUSSO et al., 2008 : Daniel Russo et al. éd., "Autour de Herbert Leon Kessler ", dans Bulletin du centre d'études médiévales d'Auxerre, 11, 2007, en ligne sur http:// cem.revues.org/index1381.html.

- SCHAPIRO, 1973 : Meyer Schapiro, Words and Pictures: On the Literal and Symbolic in the Illustration of a Text, La Haie/Paris, 1973. - SCHIEFFER, 2008 : Rudolf Schieffer, "Il contesto generale: Il papato riformatore dal 1046 ", dans Matilde di Canossa..., 2008, p. 65-75.

- SPeciale, 1991 : Lucinia Speciale, Montecassino e la Riforma Gregoriana: L'exultet Vat. lat. 592, (Studi di Arte medievale, 3), Rome, 1991.

- SPeCiAle, 2002 : Lucinia Speciale, Il ciclo benedettino del Lezionario Vat. Lat. 1202 e i suoi modelli, dans QuiNTAVALLE, 2002, p. 673-681.

-SPeCIALE, 2003 : Lucinia Speciale, "Sant'Angelo in Formis: i primi restauri (1869-1902) ", dans Maria Ida Catalano, Gabriella Prisco éd., Storia del restauro dei dipinti a Napoli e nel Regno nel XIX secolo: Atti del convegno internazionale di studi, (colloque, Naples, 1999), (Bollettino d'arte: Volume speciale, 2003), Rome, 2003, p. 287-300.
- Speciale, 2006 : Lucinia Speciale, " 'Dall'alto dei ponti': Toesca a Sant'Angelo in Formis ", dans Francesco Abbate éd., Ottant'anni di un Maestro: omaggio a Ferdinando Bologna, I, Naples, 2006, p. 49-57. - SPeciale, 2007a : Lucinia Speciale, "Riforma Gregoriana e tradizione figurativa ", dans Roberto Cassanelli, Eduardo López-Tello García éd., Benedetto: l'eredità artistica, Milan, 2007, p. 185-190.

- Speciale, 2007b : Lucinia Speciale, "Iohannes presbyter e la data d'esecuzione della Bibbia di Santa Cecilia: note storiografiche ", dans Arturo Calzona, Roberto Campari, Massimo Mussini éd., Immagine e ideologia. Studi in onore di Arturo Carlo Quintavalle, Milan, 2007, p. 132-13.

- Speciale, 2009a : Lucinia Speciale, « Memoria e scrittura : 'Tituli', programma, scelte d'immagine da Montecassino a Sant'Angelo in Formis ", dans Quintavalle, 2009, p. 144-153.

- SPeciale, 2009b : Lucinia Speciale, "Scrivere per immagini: i rotoli dell'Exultet ", dans Benedetto Vetere, Daniela Caracciolo éd., Metodo della ricerca e ricerca del metodo. Storia, arte, musica a confronto, (colloque, Lecce, 2007), Galatina, 2009, p. 107-128.

- STICKLER, 1970-1995 : Alfonso M. Stickler éd., Studi gregoriani per la storia della Libertas Ecclesiae, Rome, 1970-1995.

- STROLL, 1987 : Mary Stroll, The Jewish Pope: Ideology and Politics in the Papal Schism of 1130, Leyde, 1987.

- STROLL, 1991 : Mary Stroll, Symbols as Power. The Papacy following the Investiture Contest, Leyde/New York/Copenhague/ Cologne, 1991.

- STROLL, 1997 : Mary Stroll, The medieval abbey of Farfa. Target of Papal and Imperial Ambitions, Leyde/New York/Cologne, 1997.

- STROLL, 2004 : Mary Stroll, Calixtus II (1119-1124): a Pope born to rule, Leyde/ Boston, 2004.

-SUCKALE, 2002 : Robert Suckale, Das mittelalterliche Bild als Zeitzeuge: sechs Studien, Berlin, 2002.

- SUPINO MARTINI, 1988 : Paola Supino Martini, "La scrittura delle Scritture (sec. XI-XII) ", dans Scrittura e Civiltà, 12, 1988, p. 101-118.

- SUPINO MARTINI, 2001a : Paola Supino Martini, "Aspetti della cultura grafica a Roma fra Gregorio Magno e Gregorio VII ", dans Roma nell'alto Medioevo, (colloque, Spolète, 2000), (Settimane di studio del Centro Italiano di Studi sull'Alto Medioevo, 48), Spolète, 2001, p. 921-968.
- SUPINO MARTINI, 2001b : Paola Supino Martini, "Società e cultura scritta ", dans André Vauchez éd., Storia di Roma dall'antichità ad oggi. Roma medievale, Bari, 2001, p. 241-265.

- TABACCO, 2004 : Giovanni Tabacco, " Northern and Central Italy in the Eleventh Century ", dans David Luscombe, Jonathan Riley-Smith éd., The New Cambridge Medieval History, IV, c. 1024-c. 1198, Cambridge, 2004, p. 72-93.

- TAGLIAFERRI, 2003 : Elisa Tagliaferri, "Gli affreschi della basilica inferiore di San Clemente. Rivisitazione iconografica e revisione cronologica ", dans Arte, musica e spettacolo, 4, 2003, p. 153-179.

- TAGLIAFERRI, 2004-2005 : Elisa Tagliaferri, I rapporti tra la pittura laziale romanica e la committenza nell'età della riforma gregoriana: San Pietro a Tuscania ed i cicli pittorici minori dell'alto Lazio, thèse, Università degli Studi di Firenze, 2005.

- TAGLIAFERRI, 2008 : Elisa Tagliaferri, « Il donatore nell'iconografia e nelle iscrizioni degli affreschi laziali tra XI e XIII secolo: una spia della rinascita della società laica ", dans Iconographica, 7, 2008, p. 44-57. - TAGLIAFERRI, 2009 : Elisa Tagliaferri, « La pittura su tavola nel XII secolo. Riconsiderazioni e nuove acquisizioni a seguito del restauro della Croce di Rosano. Convegno internazionale, Firenze, Kunsthistorisches Institut, 8-9 gennaio 2009 ", dans Kunstchronik, 62/11, 2009, p. 553-561.

- TARTUFERI, 2009 : Angelo Tartuferi, "Qualche osservazione sulla Croce dipinta di Rosano restaurata ", dans QUINTAVALLE, 2009, p. 252-258.

- Telesko, 1994: Wiener Telesko, «Ein Kreuzreliquiar in der Apsis? Überlegungen zum Konzept der mittelalterlichen Apsisdekoration von San Clemente in Rom ", dans Römischen Historische Mitteilungen, 36, 1994, p. 53-79.

- TELLENBACH, 1936 : Gerd Tellenbach, $L i$ bertas, Kirche und Weltordunung im Zeitalter des Investiturstreites, Stuttgart, 1936.

-THÜMMEL, 2002 : Hans G. Thümmel, «Das Apsismosaik von San Clemente in Rom », dans Federico Guidobaldi, Alessandra Guiglia Guidobaldi éd., Ecclesiae Urbis, (colloque, Rome, 2000), Cité du Vatican, 2002, vol. 3, p. 1725-1738.

- TIBERIA, 1999 : Vitaliano Tiberia, I mosaici del XII secolo e di Pietro Cavallini in Santa Maria in Trastevere: restauri e nuove ipotesi, Todi, 1996. - Toesca, 1929 : Pietro Toesca, "Miniature romane dei secoli X e XII", dans Rivista dell'Ist. di Archeologia e Storia dell'Arte, 1/7, 1929, p. 69-96. 


\section{MOYEN ÂGE}

- TOGNI, 2003 : Nadia Togni, « Les 'Bibles atlantiques' et la réforme ecclésiastique du $\mathrm{XI}^{\mathrm{e}}$ siècle : les enjeux d'une recherche sur les Bibles de Genève et de Sion ", dans Gazette du livre médiéval, 42, printemps 2003 , p. 1-6.

- ToGNI, 2007 : Nadia Togni, «Un esemplare di bibbia gigante italiana dell'XI secolo conservato in Croazia: la Bibbia atlantica di Dubrovnik ", dans Segno e testo, 4 , 2007, p. 341-393.

- TOGNI, sous presse : Nadia Togni éd., Les Bibles atlantiques : le manuscrit biblique à l'époque de la réforme ecclésiastique du $X I^{e}$ siècle, (colloque, Genève, 2010), Florence, sous presse.

- TOUBERT, 1970 : Hélène Toubert, « Le renouveau paléochrétien à Rome au début du XII siècle ", dans Cahiers Archéologiques, 20, 1970, p. 99-154 [republié dans TouBERT, 1990, p. 239-310].

- TOUBERT, 1976 : Hélène Toubert, « Rome et le Mont-Cassin : nouvelles remarques sur les fresques de l'église inférieure de Saint-Clément de Rome ", dans Dumbarton Oaks Papers, 30, 1976, p. 1-33 [republié dans TOUBERT, 1990, p. 193-238].

- TOUBERT, 1990 : Hélène Toubert, Un Art dirgé. Réforme grégorienne et Iconographie, Paris, 1990.

- TOUBert, SPeCiale, 2001 : Hélène Toubert, Lucina Speciale, Un'arte orientata: Riforma gregoriana e iconografia, Milan, 2001. - TRIVELlone, 2007 : Alessia Trivellone, " Il cosidetto oratorio mariano della chiesa di S. Pudenziana e i suoi affreschi: nuove considerazioni ", dans ROMANO, ENCKELL JULLIARD, 2007, p. 305-330.

- TRONZO, 1989 : William Tronzo, « Apse decoration, the Liturgy and the Perception of Art in Medieval Rome: S. Maria in Trastevere and S. Maria Maggiore ", dans William Tronzo éd., Italian Church Decoration of the Middle Ages and Early Renaissance, Bologne/Baltimore, 1989, p. 167-193.

- VAUCHEZ, 2001 : André Vauchez éd. Storia di Roma dall'antichità ad oggi. Roma medievale, Rome/Bari, 2001.

- VeRCELlONE, 1860-1864 : Carlo Vercellone, Variae lectiones Vulgatae, Rome, 18601864.

- VERDIER, 1976 : Philippe Verdier, « Suger a-t-il été en France le créateur du thème iconographique du couronnement de la Vierge ?", dans Gesta, 15/1-2, 1976, p. 227-236.

- VeRDIER, 1980 : Philippe Verdier, Le couronnement de la Vierge : les origines et le premiers développements d'un thème iconographique, Montréal, 1980.

- Verità, 2000 : Marco Verità, « Tecniche di fabbricazione dei materiali musivi vitrei: Indagini chimiche e mineralogiche ", dans BORSOOK, GIOFFREDI SUPERBI, PAGLIARULO, 2000, p. 47-64.

- VIGGianI, 2006 : Claudia Viggiani, «Basilica dei Santi Bonifacio e Alessio all'Aventino: nuove scoperte e ipotesi ", dans Arte medievale, 5, 1, 2006, p. 131-140.
- WILPERT, 1906 : Joseph Wilpert, Le pitture della basilica primitiva di S. Clemente, Rome, 1906.

- WILPERT, 1916 : Joseph Wilpert, Die römischen Mosaiken und Malereien der christlichen Bauten vom IV. bis XIII. Jahrhundert, Fribourg-en-Brisgau, 1916.

- WIRTH, 1999 : Jean Wirth, L'image à

l'époque romane, Paris, 1999.

- WOLF, 1990 : Gerhard Wolf, "Salus Populi Romani »: die Geschichte römischer Kultbilder im Mittelalter, Weinheim, 1990. - YAWn, sous presse : Liala Yawn, "The Italian giant Bible ", dans Susan Boynton, Diane Reilly éd., The Practice of the Bible in the Western Middle Ages, New York, sous presse.

- ZCHOMELIDSE, 1996 : Nino M.E. Zchomelidse, Santa Maria Immacolata in Ceri: Pittura sacra al tempo della Riforma Gregoriana, Sakrale Malerei im Zeitalter der Gregorianischen Reform, Rome, 1996.

- ZCHOMELIDSE, 2003 : Nino M.E. Zchomelidse, " Das Bild im Busch: zur Theorie und Ikonographie der alttestamentlichen Gottesvision im Mittelatler ", dans Bernd Janowski, Nino Zchomelidse éd., Die Sichtbarkeit des Unsichtbaren. Zur Korrelation von Text und Bild im Wirkungskeis der Bibel, Stuttgart, 2003, p. 165-189. 